\title{
High Temperature Test Facility Preliminary RELAP5-3D Input Model Description
}

\author{
Paul D. Bayless
}

December 2015

The INL is a

U.S. Department of Energy

National Laboratory

operated by

Battelle Energy Alliance
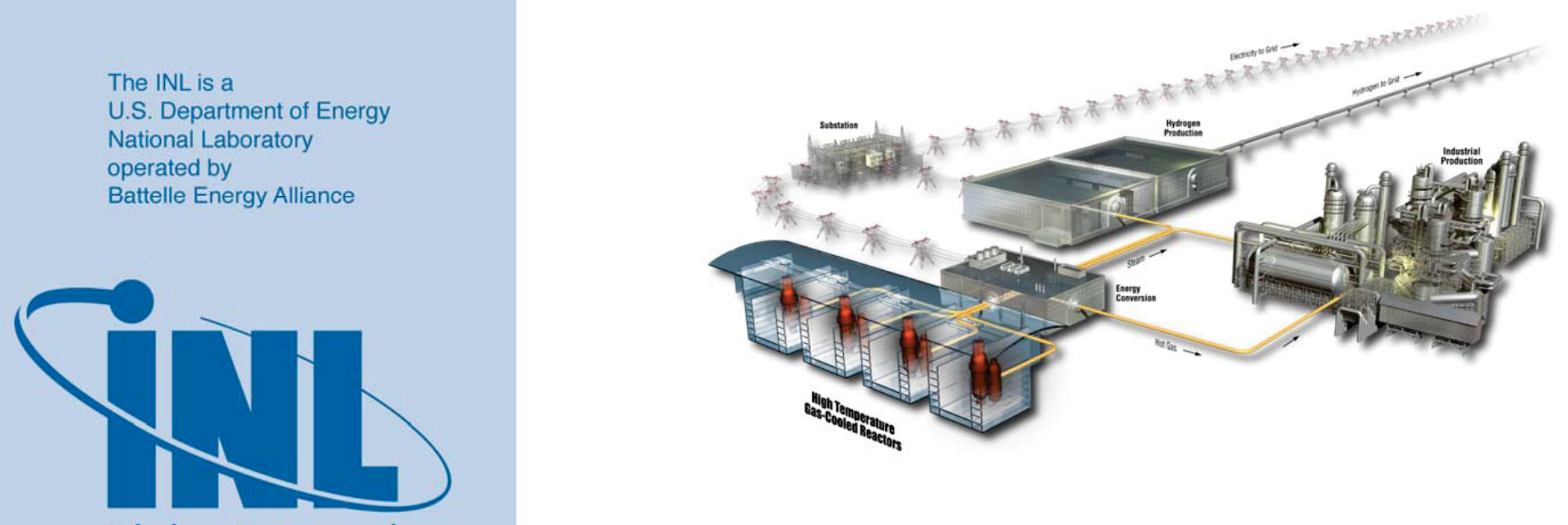

Idaho National Laboratory 


\section{DISCLAIMER}

This information was prepared as an account of work sponsored by an agency of the U.S. Government. Neither the U.S. Government nor any agency thereof, nor any of their employees, makes any warranty, expressed or implied, or assumes any legal liability or responsibility for the accuracy, completeness, or usefulness, of any information, apparatus, product, or process disclosed, or represents that its use would not infringe privately owned rights. References herein to any specific commercial product, process, or service by trade name, trade mark, manufacturer, or otherwise, does not necessarily constitute or imply its endorsement, recommendation, or favoring by the U.S. Government or any agency thereof. The views and opinions of authors expressed herein do not necessarily state or reflect those of the U.S. Government or any agency thereof. 


\title{
High Temperature Test Facility Preliminary RELAP5-3D Input Model Description
}

\author{
Paul D. Bayless
}

December 2015

\begin{abstract}
Idaho National Laboratory
INL ART TDO Program

Idaho Falls, Idaho 83415
\end{abstract}

http://www.inl.gov

Prepared for the

U.S. Department of Energy

Office of Nuclear Energy

Under DOE Idaho Operations Office

Contract DE-AC07-05ID14517 


\title{
ART Program
}

\section{High Temperature Test Facility Preliminary RELAP5-3D Input Model Description}

\author{
INL/EXT-15-37400
}

December 2015

Author:
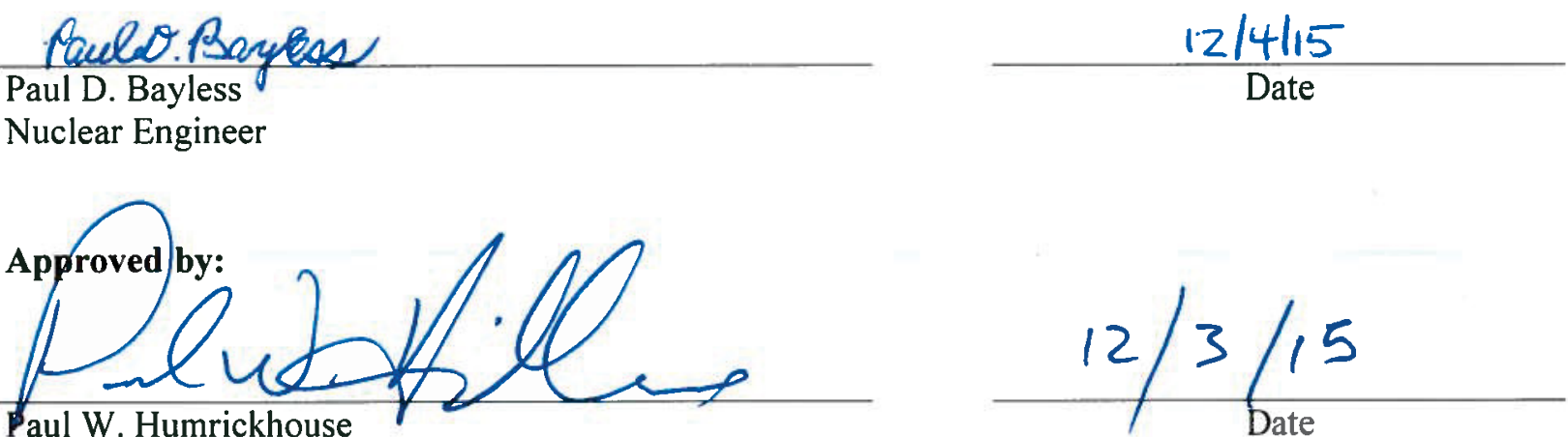

Paul W. Humrickhouse

Nuclear Engineer

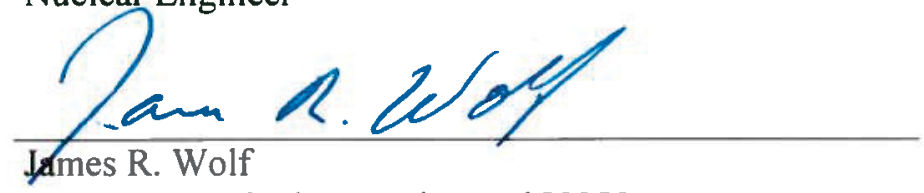

INL ART Methods Experimental V\&V

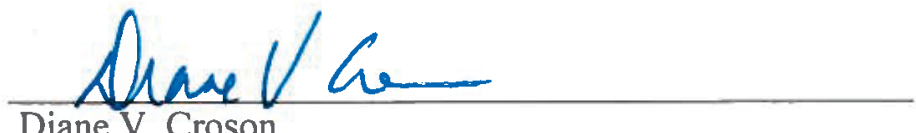

INL ART TDO Deputy Director

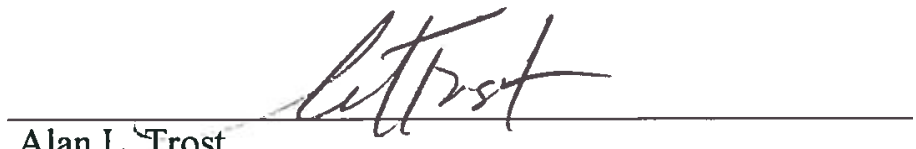

Alan L.'Trost

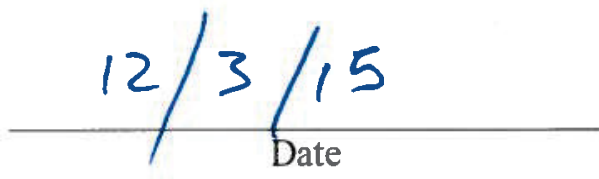

INL ART TDO Quality Assurance
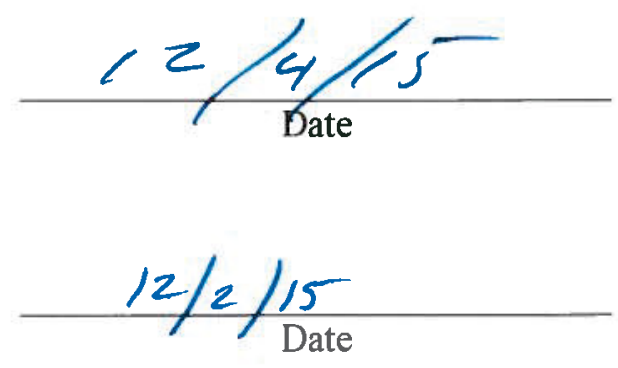


\begin{abstract}
A RELAP5-3D input model is being developed for the High Temperature Test Facility at Oregon State University. The current model is described in detail. Further refinements will be made to the model as final as-built drawings are released and when system characterization data are available for benchmarking the input model.
\end{abstract}




\section{CONTENTS}

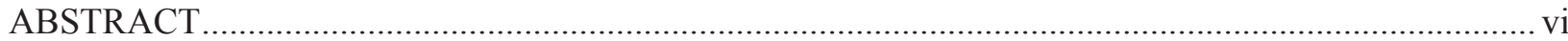

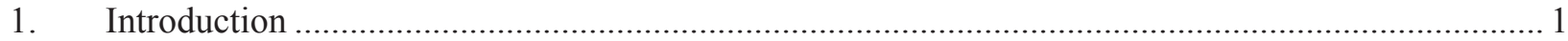

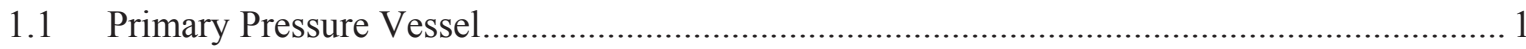

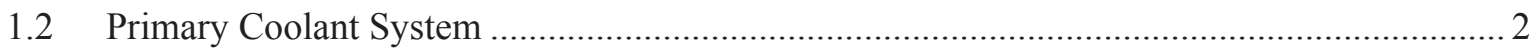

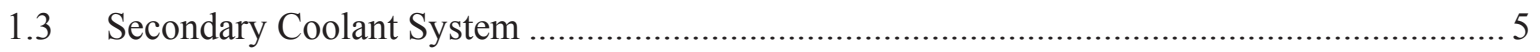

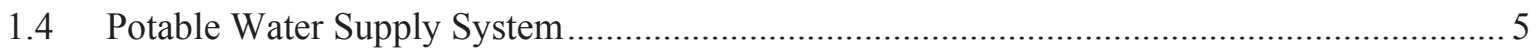

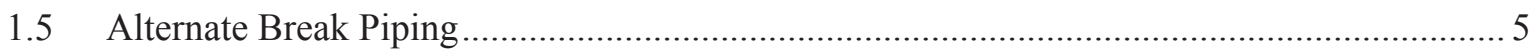

1.6 Reactor Cavity and Reactor Cavity Cooling System ......................................................... 5

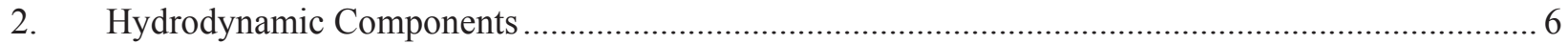

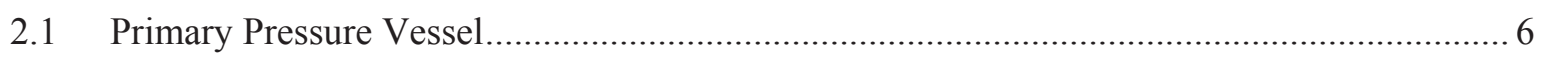

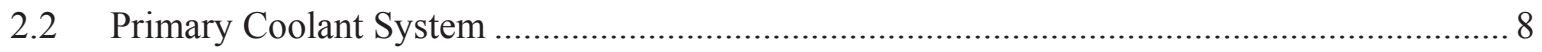

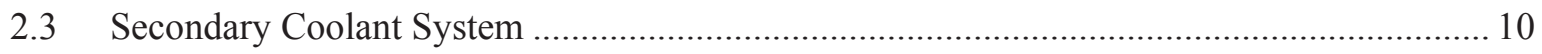

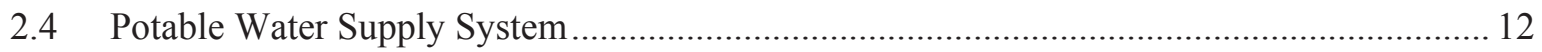

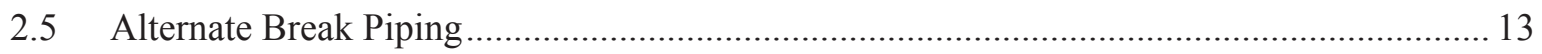

2.6 Reactor Cavity and Reactor Cavity Cooling System ......................................................... 14

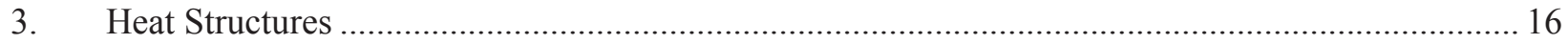

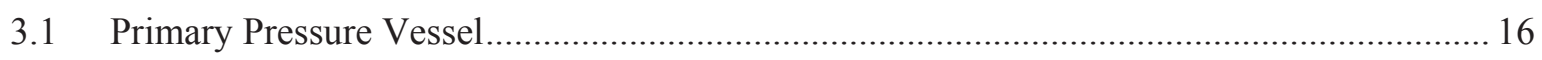

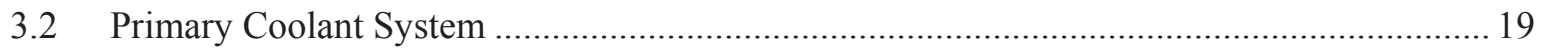

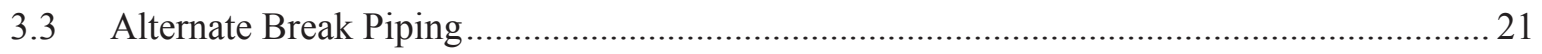

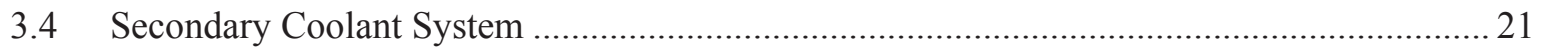

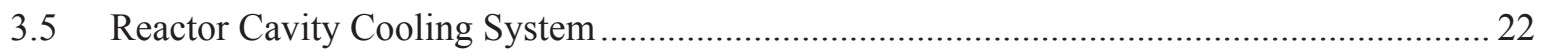

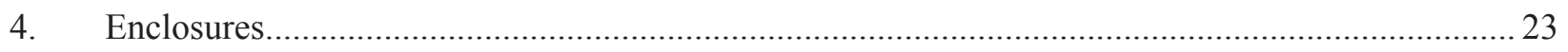

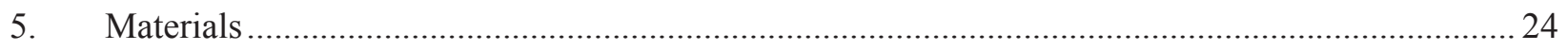

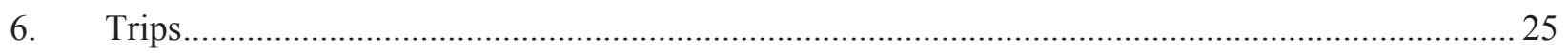

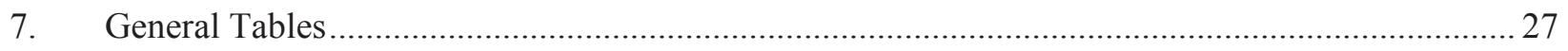

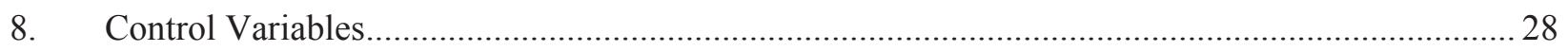

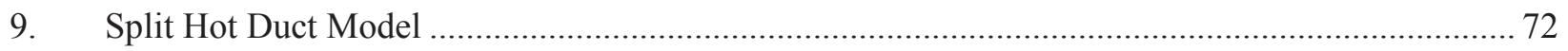

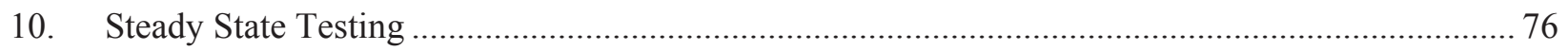

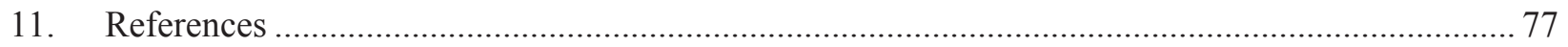




\section{FIGURES}

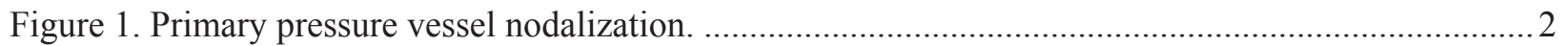

Figure 2. Primary pressure vessel radial nodalization. ........................................................................... 3

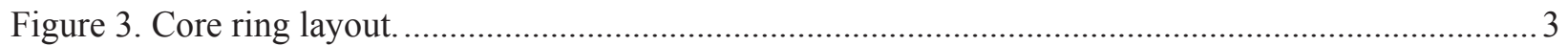

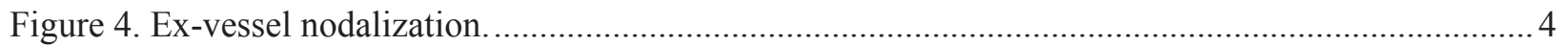

Figure 5. Revised nodalization for the split hot duct input model. ..................................................... 73

\section{TABLES}

Table 1. HTTF Drawings used in developing the input model. 


\section{High Temperature Test Facility Preliminary RELAP5-3D Input Model Description}

\section{Introduction}

A RELAP5-3D input model is being developed for the High Temperature Test Facility (HTTF) at Oregon State University. The model will be used for code assessment using experiment data from the HTTF. The model includes hydrodynamic components, heat structures, trips, and control systems. Systems modeled are the primary coolant system (PCS), secondary coolant system (SCS), reactor cavity cooling system (RCCS), the potable water system that supplies both the secondary coolant system and the RCCS, and the reactor cavity. The reactor cavity simulation tank (RCST) is considered part of the PCS.

The input model is still under development. While some as-built drawings have been received and used, a complete set is not yet available. Also, adjustments to the model will likely need to be made during the benchmarking process once data from the facility are available.

The general component numbering scheme is:

100-199: primary pressure vessel

200-299: PCS piping

300-399: secondary coolant system

400-499: potable water system

600-699: alternate break piping

900-999: reactor cavity and RCCS

More details on all of the components are provided below.

\subsection{Primary Pressure Vessel}

The hydrodynamic component numbers in the primary pressure vessel are from 100 to 199 . Heat structures are generally numbered the same as the boundary volumes.

The primary pressure vessel nodalization is shown in Figure 1. Flow enters from the cold duct, passes through the core support structure under the outlet plenum bottom plate, then flows up between the primary pressure vessel and core barrel to the inlet plenum. Flow then passes down through various flow channels in the core and reflectors, recombines in the outlet plenum, then flows out into the hot duct.

The heated region of the core is divided into ten equal length axial segments, one for each block. The upper and lower reflectors each have two axial regions. This axial nodalization extends through each of the radial components in the vessel and in the RCCS.

The primary pressure vessel is divided into a number of different radial regions, as illustrated in Figure 2. The central reflector is divided into three regions: a central solid cylinder, a middle ring that contains the six 0.75 -in.-diameter gap simulation channels and the ceramic that is directly influenced by the holes, and a solid outer ring that is adjacent to the core. The core is also divided into three rings, as it is designed on the hexagonal block pattern of the Modular High-temperature Gas-cooled Reactor, which has three fueled rings. Figure 3 shows which blocks are included in each of the rings in a 60-degree sector; the boundaries of the inner and outer rings were extended beyond the full hexagonal block geometry to include all of the coolant channels. The inner ring includes 23 hexagonal blocks with 56 heater rods and 138 coolant channels, the middle ring models 24 blocks with 72 heater rods and 144 coolant channels, and the outer ring includes 39 blocks with 82 heater rods and 234 coolant channels. The side reflector is divided into three regions: an inner solid ring next to the outer core ring, a middle ring 
that contains the 36 0.625-in. diameter gap simulation channels and associated ceramic, and a solid outer ring. The next radial structure is the permanent side reflector (PSR), which has a coolant gap on either side. Continuing outward, the core barrel is next, followed by the coolant riser region, and finally the primary pressure vessel itself.

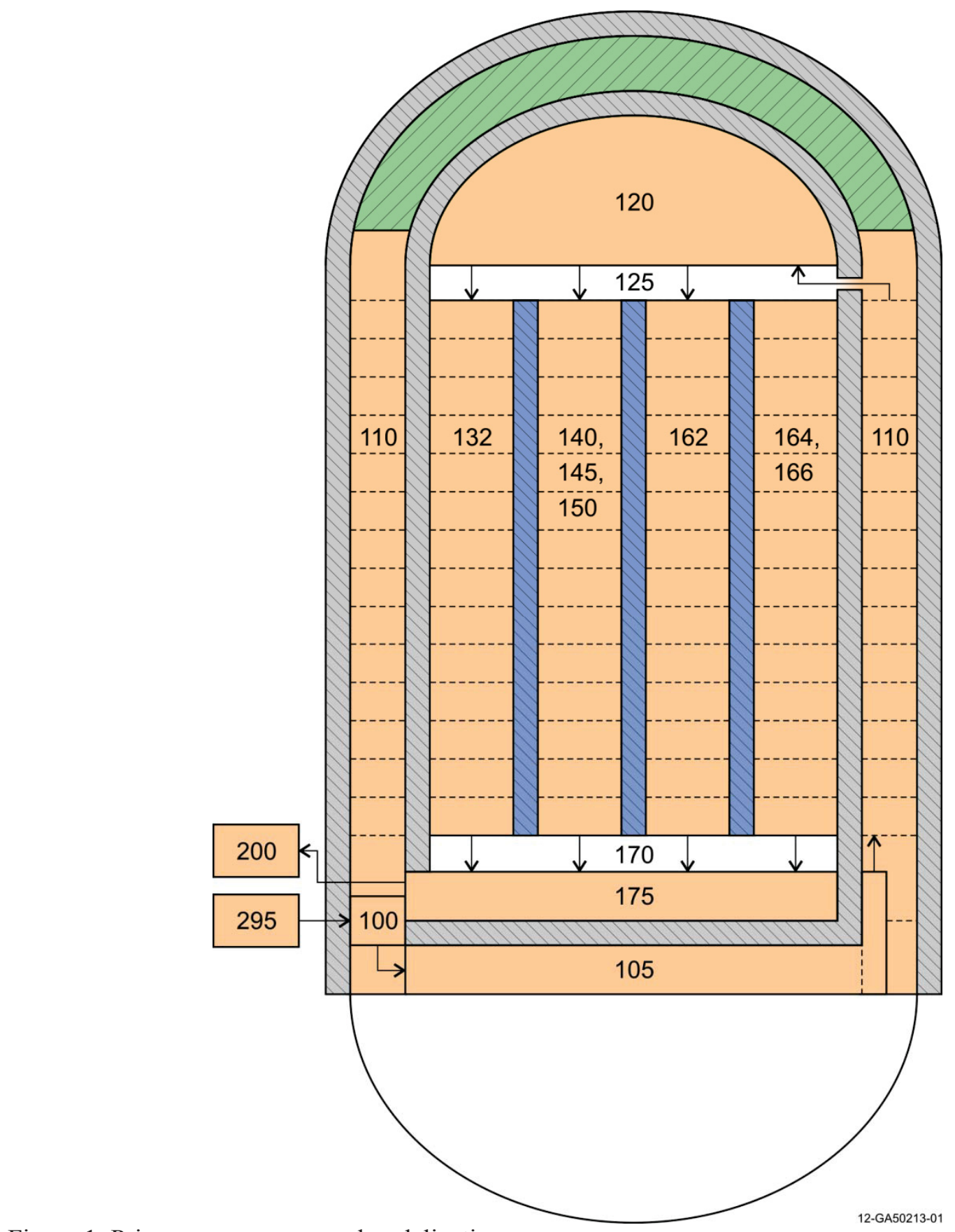

Figure 1. Primary pressure vessel nodalization.

\subsection{Primary Coolant System}

The hydrodynamic component numbers in the PCS are from 200 to 299. Heat structures are generally numbered the same as the boundary volumes. 


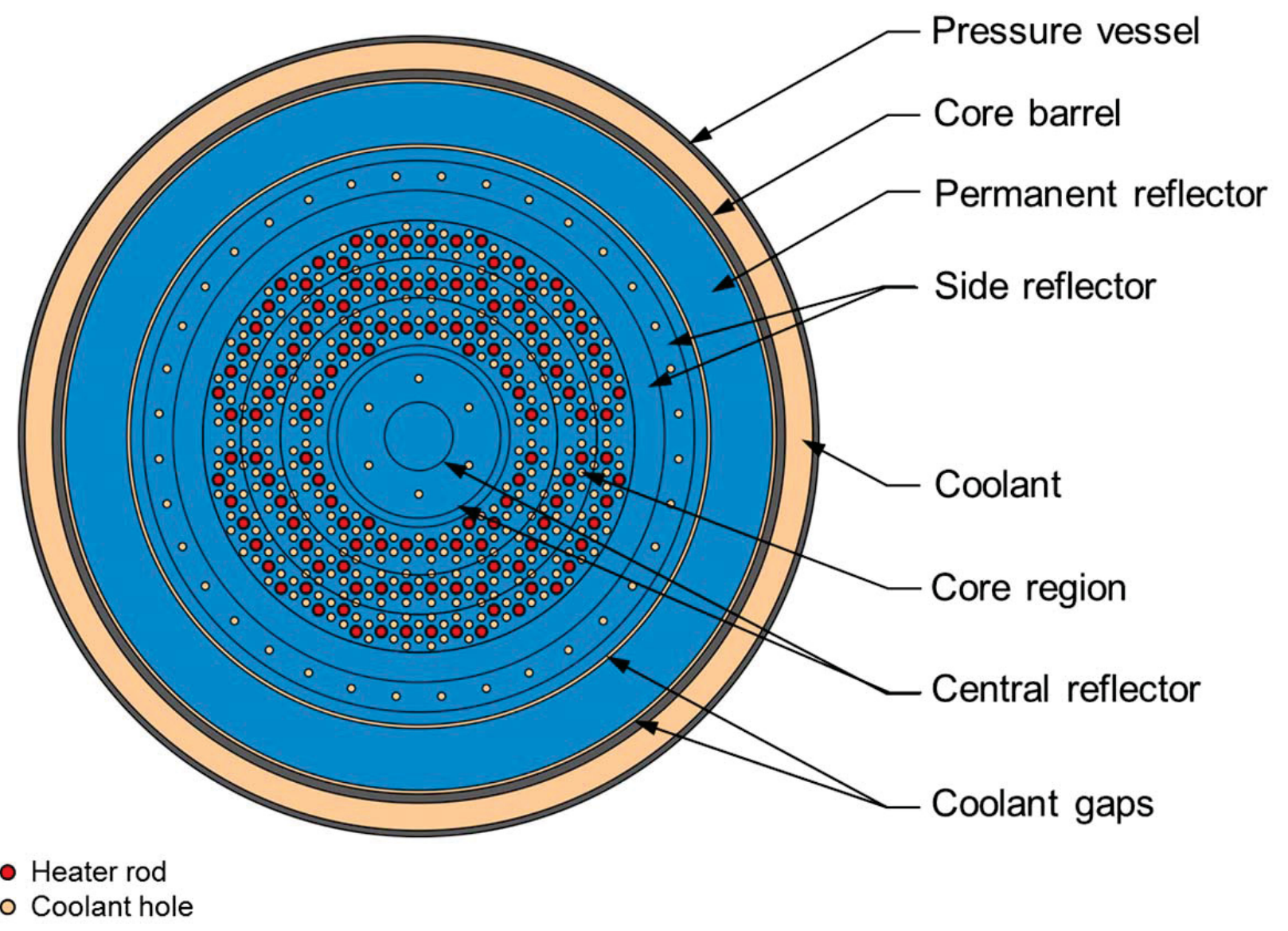

Figure 2. Primary pressure vessel radial nodalization.

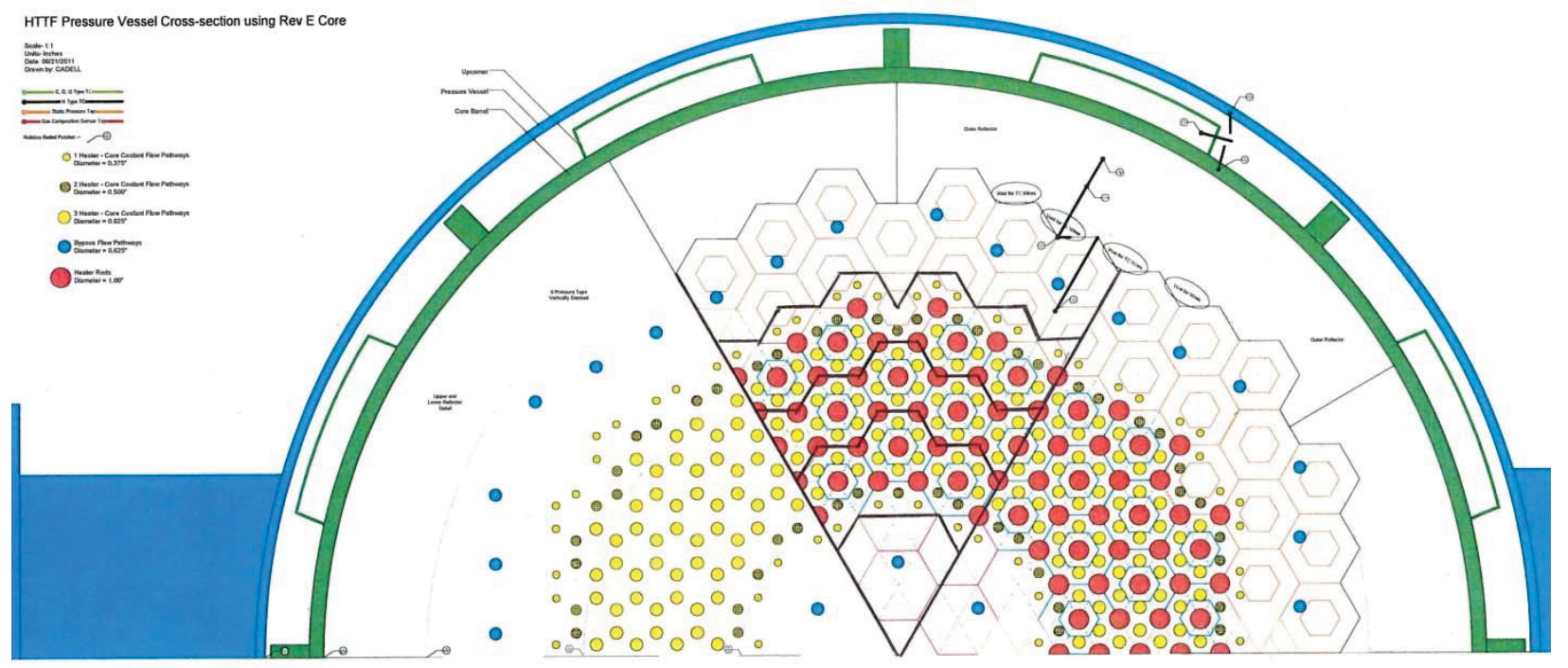

Figure 3. Core ring layout. 
The nodalization of the PCS is shown in Figure 4. Hot gas exits the primary pressure vessel into the hot duct, then flows up through a check valve and into the steam generator inlet plenum and tubes. The cooled gas flows out of the steam generator into piping that leads to the compressor. From the compressor, flow proceeds through an isolation valve, into a crossover pipe, into an annulus around the hot duct, and then back into the primary pressure vessel.

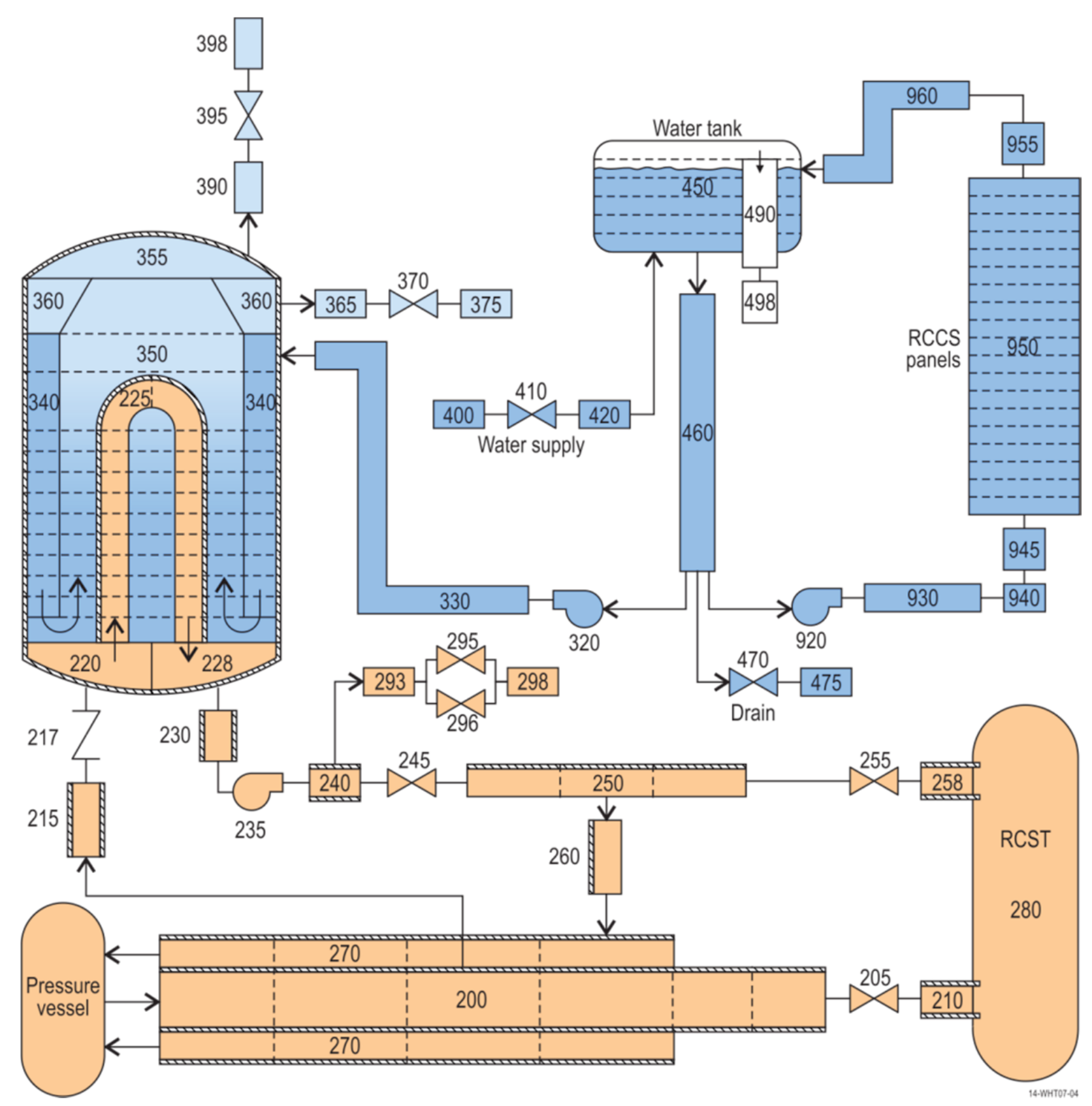

Figure 4. Ex-vessel nodalization.

Break valves are located on the ends of the hot duct and compressor discharge pipes, connecting them to the (RCST. These valves are closed during steady state operation. Safety relief valves and a depressurization line are connected to the cold leg piping between the compressor and the loop isolation valve. These are modeled as a single line in the RELAP5-3D input model. 


\subsection{Secondary Coolant System}

The hydrodynamic component numbers in the SCS are from 300 to 399. Heat structures are generally numbered the same as the boundary volumes.

The nodalization of the SCS is also provided in Figure 4. The feedwater pump draws suction from a water storage day tank and pumps it into the steam generator downcomer. The downcomer extends to near the tube sheet. The water is then boiled on the outside of the tubes as it flows upward to the steam dome at the top of the steam generator. The steam then turns back downward before exiting out the side of the steam generator. The steam then flows through a pressure control valve in the steam line before flowing through more piping and being vented to the atmosphere. This downstream piping is not included in the RELAP5-3D input model.

A safety relief valve is connected to a nozzle on the top of the steam generator. The piping downstream of the relief valve is not included in the input model.

\subsection{Potable Water Supply System}

Hydrodynamic components in the potable water supply system are numbered from 400 to 499 . There are no heat structures associated with this system.

The principal component in the system is the water storage day tank. This tank is the water source for both the secondary coolant system and the reactor cavity cooling system. The tank water level is maintained within a specified range. When the level gets too low, a valve opens in the supply line, allowing water from the public water system to flow into the tank. When the level rises to a certain level, the supply line valve is closed. The tank also has an interior drain/vent line that extends from the bottom of the tank to near the top; it is modeled as being open to the atmosphere below the tank.

Other components in the system are the makeup water supply to the tank and an outlet line connected to the bottom of the tank. Both the feedwater and RCCS pumps take suction from this outlet line, and a tank drain valve is also connected to the outlet line.

\subsection{Alternate Break Piping}

Piping and valves associated with breaks located at the top and bottom of the pressure vessel are numbered from 600 to 699 . Heat structures are generally numbered the same as the boundary volumes. These components are currently inactive in the input model (commented out) since they would only be active during an appropriate break simulation and would otherwise slow the system calculations down without providing any beneficial information.

\subsection{Reactor Cavity and Reactor Cavity Cooling System}

Hydrodynamic components in the reactor cavity and RCCS are numbered from 900 to 999 . Heat structures are generally numbered the same as the boundary volumes.

The reactor cavity is modeled as a large air-filled volume at atmospheric pressure, and is located between the primary pressure vessel and the RCCS panels. The RCCS draws flow from the water storage tank and pumps it through a series of pipes into the cooling panels surrounding the primary pressure vessel. Water exiting the top of the panels is collected and returned to the water storage tank.

Subsequent sections provide details on each of the components in the input model, grouped by component type. These are followed by a brief description of changes made to the model during initial steady state testing, and then by references used in developing the input model. 


\section{Hydrodynamic Components}

Unless otherwise noted, default values for the volume and junction flags are used.

Approximate initial conditions are entered, as it is expected that a steady state calculation will be run to establish the desired conditions prior to a transient calculation. The initial values entered will be for normal steady state operation at full power $(2200 \mathrm{~kW})$.

\subsection{Primary Pressure Vessel}

Component 100 is a two-junction branch representing the primary pressure vessel coolant inlet region. It is a vertical volume, with the top at the midpoint of the outlet plenum and the bottom at the midpoint of the coolant region between the lower support plate and the middle distributor plate. Junction 1 connects to the outlet of the cold duct (Component 270) and junction 2 connects to the inlet of Component 105.

Component 105 is a two-volume pipe representing the coolant region below the core support plate. The first volume includes the volume between the lower support plate and the middle distributor plate; the second volume includes the volume between the middle distributor plate and the upper bulkhead plate. The coolant volume in the gaps around the power supply cylinders where they pass through the middle distributor plate is neglected. The length of each volume is assumed to be equal to the radius of the middle plate, as the flow comes from the periphery to the center, then back out to the periphery. The elevation change between the two volumes is included in the first volume. It is assumed that there are 30 1.75-in.-diameter cylinders extending through both flow regions, providing the power supply to the heater rods.

Component 108 is a single junction that connects the outlet of Component 105 to the inlet of Component 110. It is modeled as a smooth area change with no user-input loss coefficients.

Component 110 is a two-volume pipe representing the coolant in the region between the core barrel and the upcomer shell (referred to as the "jacket shell" on Drawing 25835-1). It is connected to the outlet of Component 105 and to the inlet of the fourth cell in Component 115, the junction in the middle of the bottom reflector region. The first cell extends from the outlet of Component 105 to the top of the outlet plenum. The second cell extends the length of the lower cell in the bottom reflector.

Component 112 is a single junction that connects the outlet of Component 110 to the inlet of the fourth cell in Component 115. It is modeled as an abrupt area change with code-calculated loss coefficients.

Component 115 is a 17 -volume pipe representing the gap between the core barrel and the primary pressure vessel. It spans the elevation from the lower core support plate to above the flow slots in the upper plenum. The axial nodalization is the same as that inside the core barrel. Four of the volumes are stagnant, as normal coolant flow enters the fourth volume and exits the sixteenth.

Component 120 is a branch component representing the inlet (upper) plenum. It has one junction connecting to the coolant gap between the core barrel and the primary pressure vessel (Component 115). This volume extends from the top of the core barrel to the top of the upper plenum shroud.

Component 125 is a multiple junction component that connects the inlet plenum to the inlets of each of the core and reflector cooling channels. It has five junctions. Junction 1 connects to the central reflector, junction 2 to the inner core ring, junction 3 to the middle core ring, junction 4 to the outer core ring, and junction 5 to the side reflector. All junctions are modeled as abrupt area changes with user-input loss coefficients (flag $\mathrm{a}=2$ ) of 0.5 for forward flow and 1.0 for reverse flow, standard for sudden sharpedged contractions/expansions with a large area change. 
Component 132 is a 14 -volume pipe component representing the six 0.75 -in. diameter holes in the central reflector. It extends from the inlet plenum to the outlet plenum.

Component 140 is a 14-volume pipe component that represents the coolant channels in the inner core ring, extending from the inlet plenum to the outlet plenum. This includes the area of 840.625 -in. diameter holes, 30 0.5-in. diameter holes, and 24 0.375-in. diameter holes. The hydraulic diameter of the channel was adjusted to provide the same pressure drop as if the holes were modeled individually; this diameter was determined by running a standalone model of this core ring with the three different holes sizes modeled and iterating on the combined channel hydraulic diameter.

Component 141 is a 10 -volume pipe component representing the helium gap around the inner core ring heater rods. It extends over the heated length.

Component 142 is a single junction component connecting Component 141 to Component 143.

Component 143 is a time-dependent volume that maintains a constant pressure in the helium gap around the inner core ring heater rods.

Component 145 is a 14 -volume pipe component that represents the 1440.625 -in. diameter cooling holes in the middle core ring. It extends from the inlet plenum to the outlet plenum.

Component 146 is a 10-volume pipe component representing the helium gap around the middle core ring heater rods. It extends over the heated length.

Component 147 is a single junction component connecting Component 146 to Component 148.

Component 148 is a time-dependent volume that maintains a constant pressure in the helium gap around the middle core ring heater rods.

Component 150 is a 14-volume pipe component representing the coolant channels in the outer core ring, extending from the inlet plenum to the outlet plenum. This includes the area of 960.625 -in. diameter holes, 66 0.5-in. diameter holes, and 72 0.375-in. diameter holes. As with Component 140, the channel hydraulic diameter was adjusted to provide the appropriate pressure drop.

Component 151 is a 10 -volume pipe component representing the helium gap around the outer core ring heater rods. It extends over the heated length.

Component 152 is a single junction component connecting Component 151 to Component 153.

Component 153 is a time-dependent volume that maintains a constant pressure in the helium gap around the outer core ring heater rods.

Component 162 is a 14 -volume pipe component that represents the 360.625 -in. diameter holes in the side reflector. It extends from the inlet plenum to the outlet plenum.

Component 164 is a 14-volume pipe component that represents the gap between the side reflector and the permanent side reflector (PSR). It extends from the top of the upper reflector to the outlet plenum. It is connected to the outlet plenum, but not to the inlet plenum, as this gap is covered by the upper reflector top plate.

Component 166 is a 14-volume pipe component that represents the gap between the PSR and the core barrel. It extends from the top of the upper reflector to the outlet plenum. It is connected to the outlet plenum, but not to the inlet plenum, as this gap is also covered by the upper reflector top plate.

Component 170 is a multiple junction component connecting the core and reflector coolant channels and gaps to the outlet plenum. It has seven junctions. Junction 1 connects to the central reflector, junction 2 to the inner core ring, junction 3 to the middle core ring, junction 4 to the outer core ring, junction 5 to the side reflector, junction 6 to the gap between the side and permanent side reflectors, and junction 7 to the gap between the permanent side reflector and the core barrel These junctions are all modeled as abrupt 
area changes with user-input loss coefficients (junction flag $\mathrm{a}=2$ ). The three core channels have forward and reverse loss coefficients of 2.5 to account for the channeling of the individual flow paths in the bottom reflector region. The reflector channels have forward loss coefficients of 1.0 and reverse loss coefficients of 0.5 , as they are straight flow paths with a sudden expansion into the outlet plenum.

Component 175 is a branch component representing the outlet plenum. It has one junction connecting to the hot duct (Component 200).

\subsection{Primary Coolant System}

Component 200 is the hot duct. It is modeled as a six-volume pipe. Cell lengths are selected such that the first instrument rake, the pipe to the steam generator, and the return pipe from the compressor to the cold duct are at cell centers. The segment from the end of the fourth cell to the modeled break valve (Component 205) includes the physical valve in the facility; this segment is divided into two cells to have comparable cell lengths through the hot leg. The loss coefficient for flow through the valve is located at internal junction 5 in the pipe, rather than in the valve junction. It is assumed that the valve flow area is equal to that of the hot duct. The forward loss coefficient is based on the nominal hot leg Reynolds number, assuming the break valve is a gate valve. The reverse loss coefficient is set to 0.0 , as any flow back into the system from the RCST will not be turbulent.

Component 205 is a valve representing valve V-313, which is the hot duct break valve leading to the RCST. It is modeled as a motor valve with a stroke time of $5 \mathrm{~s}$ (assumed value pending receipt of actual data). The valve area is modeled as changing linearly with the stem position. Trip 205 opens the valve, and trip 206 closes it.

Component 210 is the pipe between valve V-313 and the RCST. It is modeled as a branch with one junction, connecting the outlet of this component to the RCST, Component 280. The junction is modeled as an abrupt area change with user-input loss coefficients; the forward and reverse loss coefficients are for a sudden expansion/contraction with a large area ratio. If a hot duct break is being simulated, with the spool piece installed, the junction connects the outlet of Component 282 to the outlet of this component; in this case, the area change is modeled as abrupt with code-calculated loss coefficients.

Component 215 is the pipe between the hot duct and the steam generator inlet. It consists of the steam generator nozzle and check valve body shown on Drawing PCS-100. The pipe is modeled as a branch with one junction, connecting the hot duct to the inlet of the branch. Drawing PCS-100 appears to indicate that the steam generator inlet flange is connected directly to the outlet of the check valve, $27.5 \mathrm{in}$. above the hot duct centerline. However, that results in a gap of about 7.5 in. around the loop, so the extra length is included in this volume.

Component 217 is the check valve (V-101) in the pipe between the hot duct and the steam generator inlet. It is modeled as being connected to the steam generator inlet plenum.

Component 220 is the steam generator inlet plenum. It includes both the plenum and the 45 -degree elbow between the plenum and the flange. It is modeled as a branch with one junction, that connecting to the steam generator tubes. This junction is modeled as an abrupt area change with user-input loss

coefficients. The loss coefficients are based on a sudden contraction/expansion from the plenum flow area at the tube sheet to the tube flow area. The loss from the elbow and the entrance to the plenum are included in the Component 217 loss coefficient.

Component 225 is the steam generator tubes. The 188 tubes are modeled as a 22 -volume pipe. Cells 1-10 carry the gas flow up, cells 11 and 12 are the U-bend, and cells 13-22 are the downflow side. The tube bends are assumed to start at the top baffle plate. They are also assumed to be smooth 180-degree bends, so that the radius of the bend is equal to the distance from the center of the bundle (90-270 degree line on Drawing 25838, sheet 3) to the center of each tube. The loss from the bend is located at the 
junction at the top of the tubes, junction 11. The first and last cells include the flow through the tube sheet.

Component 228 is the steam generator outlet plenum. It includes both the plenum and the 45-degree elbow between the plenum and the flange. It is modeled as a branch with two junctions. The inlet junction is modeled as an abrupt area change at the tube sheet with user-input loss coefficients. The outlet junction is modeled as a smooth area change with a loss coefficient equal to that of a sudden contraction from the largest plenum area to the pipe area; this should over estimate the loss exiting the plenum, but will be compensated for by neglecting the bend loss from the elbow.

Component 230 is the pipe between the steam generator outlet and the compressor inlet. It is modeled using a single volume component. There are two bends in this section of piping. The losses associated with these bends are included in the compressor inlet junction; the estimated friction loss in the bends is subtracted from the published loss coefficient values, as the code will calculate the friction loss.

Component 233 is a single junction connecting the outlet of Component 230 to the inlet of Component 234; it is used only during steady state calculations.

Component 234 is a time-dependent volume that provides pressure control during steady state calculations; it is deleted for transient calculations.

Component 235 is the circulator volume. It is modeled as a branch with one junction, connecting the piping from the steam generator outlet to the inlet of the circulator.

Component 237 provides the circulator forced flow. It is modeled as a time-dependent junction, with the flow rate determined by control variable 237 during steady state. The time-dependent junction component is expected to provide sufficient modeling of the circulator function, as transients should result in isolation of the portion of the loop piping containing the circulator.

Component 240 is the pipe between the compressor outlet and valve V-203. It is modeled as a single volume, and includes the volume of the pipe and half of the valve. The flow area of the valve is assumed to be the same as that of the pipe.

Component 245 is a valve representing valve V-203. It is modeled as a motor valve with a stroke time of $5 \mathrm{~s}$ (assumed value pending receipt of actual data). The valve area is modeled as changing linearly with the stem position. Trip 245 opens the valve, and trip 246 closes it. The junction is modeled as an abrupt area change with user-input loss coefficients; the loss coefficients are based on flow through a ball valve and through one 90-degree bend (between the compressor and the valve).

Component 250 is the pipe between valve V-203 and the cold leg break valve (V-313). It is modeled as a pipe with three volumes. The first volume extends from the middle of valve V-203 to the tee upstream of the break valve. The second volume is the straight passage of the tee. The third volume is the volume in valve V-313, which is assumed to have the same flow area as the upstream piping. The first junction includes the loss coefficient from the 90-degree elbow in the piping.

Component 255 is valve V-311, which is the cold leg break valve leading to the RCST. It is modeled as a motor valve with a stroke time of $5 \mathrm{~s}$ (assumed value pending receipt of actual data). The valve area is modeled as changing linearly with the stem position. Trip 255 opens the valve, and trip 256 closes it. The forward loss coefficient is based on the nominal hot (cold?) leg Reynolds number, assuming the break valve is a gate valve. The reverse loss coefficient is set to 0.0 , as any flow back into the system from the RCST will not be turbulent.

Component 258 is the pipe between valve V-311 and the RCST. It is modeled as a branch with one junction, connecting the outlet of this component to the RCST, Component 280. The junction is modeled as an abrupt area change with user-input loss coefficients; the forward and reverse loss coefficients are for a sudden expansion/contraction with a large area ratio. If a hot duct break is being simulated, with the 
spool piece installed, the junction connects the outlet of this component to the inlet of Component 282; in this case, the area change is modeled as smooth with loss coefficients of 0.0.

Component 260 is the crossover pipe from the cold leg tee to the cold duct. It is modeled as a branch with two junctions. The first junction is the tee off of the cold leg pipe upstream of the break valve. The forward loss coefficient is that of flow for a diverging wye, and the reverse loss coefficient is that for a converging wye; in both cases, all of the flow is through the branch. The second junction is the connection to the cold duct. The forward loss coefficient at the junction is approximated as that of flow from the side branch of a converging wye. The reverse loss coefficient is for a diverging wye. The geometry of the connection does not match either of the formulas associated with Diagram 7-18 in Idelchik; the second formula is used, and uncertainties in this loss coefficient should not be significant as reverse flow is only expected during some transient tests with natural circulation flow.

Component 270 is the cold duct. It is modeled as a four-volume pipe. The junctions are at the same locations as those in the common portion of the hot duct.

Component 280 is the RCST. It is normally modeled as a two-volume vertical pipe. The lower volume represents the region below the break nozzles, which is assumed to not participate in any gas mixing in the tank. The upper volume represents the portion of the tank that will participate in mixing with gas entering from the PCS. With this being modeled as a single cell, all of the fluid will be perfectly mixed. This will over estimate the temperature of gas re-entering the PCS from the tank, as no thermal stratification will occur in the tank; this is a limitation of the one-dimensional modeling of the tank. However, there is no basis for a two- or three-dimensional model, and unphysically large recirculating flows have been observed in the past when such a modeling approach was attempted. The lengths of the two volumes are distorted to maintain the top and bottom of the tank at the appropriate elevations; the total volume is preserved, and the hydraulic diameter used is that of the tank cylinder. A single-volume model is also available; this model is intended to be used for the hot duct break, where there is no connection between the break lines and the RCST (a spool piece connects the two break lines inside the tank - see Component 282).

Component 282 is the spool piece that is installed for hot duct breaks, connecting the hot and cold leg break nozzles inside the RCST. It is modeled as a single volume. Without a full set of dimensional information, the pipe is assumed to be a 180-degree bend with a bend diameter equal to the distance between the hot and cold break nozzle centerlines. From Drawing 25836, sheet 3, it appears that the pipe is the same size as the cold leg nozzle piping, and that is therefore assumed to be the case.

Component 293 is the piping leading to the inlet of the pressure relief valve (PSV-100). It is modeled as a branch with one junction. The forward loss coefficient at the junction is that of flow into the side branch of a diverging wye. The reverse loss coefficient is for flow from the side branch of a converging wye; this loss coefficient should not matter, as reverse flow through the pressure relief line should not occur, except for a very small expansion outflow as the system depressurizes.

Component 295 is the pressure relief valve (PSV-100). It is modeled as a trip valve that is open when trip 1295 is true.

Component 296 is the depressurization valve (V-400). It is modeled as a trip valve that is open when trip 1296 is true.

Component 298 is the pressure boundary volume downstream of the pressure relief and depressurization valves.

\subsection{Secondary Coolant System}

Component 320 is the feedwater pump (P-010). It is modeled as a time-dependent junction. The flow through the pump is determined by control variable 320. The pump suction is taken from the water storage tank outlet line, Component 460. 
Component 330 is the piping between the feedwater pump and the steam generator. The valves in this piping, V-011, V-012, and LCV-013, are not modeled explicitly. The logic controlling LCV-013 will be included in the controls for Component 320. The piping is modeled using a branch component with one junction; the junction connects the outlet of this component to the inlet of Component 340, with the "to" volume modeled in crossflow. Details of the pipe configuration are not known at this time, so the length is assumed to be something a little longer than the elevation change between the feedwater pump and the feedwater nozzle on the steam generator. This assumption should have no effect on the calculated plant response, as the feedwater flow rate and steam generator pressure are controlled, so the pressure loss in this piping will be immaterial. The loss coefficients at the junction were calculated assuming the connection is a tee with all of the flow going between the branch and one leg of the tee. The pipe walls are not modeled with heat structures, as heat transfer in the feedwater system is not expected to be important to the steam generator conditions.

Component 340 is the steam generator downcomer. It is modeled as an 11-volume pipe extending from the bottom of the inner shell lap ring to the bottom of the inner shell. The internal junctions are located at the same elevations as those in the boiler region. Heat structures connected to this component represent the steam generator outer shell (Structure 3400) and the inner cylindrical shell (Structure 3500).

Component 345 is the junction between the steam generator downcomer and the boiler region. It is modeled using a single junction component connecting the outlet of Component 340 to the outlet of the first cell in Component 350. The junction area and hydraulic diameter are those of the downcomer. The abrupt area change flag is set to 2, and the loss coefficient is based on a sudden expansion (contraction in reverse flow) into the bottom boiler volume.

Component 350 is the steam generator boiler region. It is modeled as a 13-volume pipe extending from the top of the tube sheet to the top of the inner cone. Node boundaries in the boiler region are placed at the centerlines of the baffle plates and halfway in between them, resulting in 10 cells spanning the straight portion of the tubes. The flow area at the baffle plates is modeled as just the flow around the end of the plate; it is assumed that thermal expansion of the tubes and tie rods will result in a negligible flow area between the tubes and the baffle plate. The volume occupied by the baffle plates is also neglected. Loss coefficients at the baffle plates are estimated as though the area change was through a sharp-edged orifice, and are based on the volume flow area. Cells 11 and 12 are equal-length cells extending from the top baffle plate to the bottom of the inner cone, while cell 13 is the volume inside the inner cone. The Utube bends are contained in cell 11.

Component 355 is the steam dome, the region above the top of the inner cone. It is modeled as a branch with two junctions. The dome includes only part of the rounded portion of the end cap; the rest, together with the cylindrical (straight) portion, is included in Component 360. The first junction is the inlet from Component 350 and is modeled as a smooth area change with no loss coefficients: it is assumed that the entering flow occupies the same area as the top of the inner cone, and that the flow going down into the upper annulus occupies the same area as the annulus. The second junction is the connection to the relief valve inlet piping, Component 390. It is modeled as an abrupt area change with user-input loss coefficients based on the flow area ratios of the pipe and steam dome.

Component 360 is the steam annulus, the region between the upper cone and the outer shell. It is modeled as a downward-oriented branch with two junctions. The volume includes the region between the inner cone and the upper shell, and a small cylindrical section below between the inner shell and the flange. The first junction is the inlet from Component 355, which is modeled as a smooth area change with no loss coefficients. The second junction is the connection to the steam line, which is modeled as being connected to the side of the volume; the steam line area and hydraulic diameter are used for the junction. Momentum flux is turned on, as there should be a radial component to the flow in the facility as it moves around the inner cone to the steam line. The abrupt area change flag is set to 2, with loss coefficients based on an abrupt area change from the crossflow area into the pipe. 
Component 365 is the 4-in. piping in the steam line. It includes pressure control valve (PCV-602), which is located at the end of the pipe section in the model. It is modeled using a single volume component. The check valve in this line (V-601) is not modeled explicitly. The component length is estimated, and will not have any effect on the calculated behavior in the steam generator as the steam dome pressure is controlled during steady state operation, and the steam generator is expected to be isolated during most transients.

Component 370 is the pressure control valve (PCV-602). It is modeled as a servo valve controlled by control variable 370. The flow area is the same as that of the upstream volume (Component 365). No loss coefficients are input because the valve area is being changed (and hence the effective loss coefficient is changing) during steady state calculations to maintain the desired steam dome pressure. The valve area is modeled as changing linearly with the stem position. The valve is expected to be closed during transient calculations; even if it is not, the steam generator tubes will be isolated on the primary system side, so that any residual heat transfer in the steam generator will not affect the plant response of interest.

Component 375 is the pressure boundary volume downstream of the pressure control valve. It is modeled as an air-filled volume at atmospheric pressure.

Component 390 is the pipe from the steam generator dome to the pressure relief valve (PSV-600).

Component 395 is the pressure relief valve (PSV-600).

Component 398 is the pressure boundary volume downstream of the pressure relief valve. It is modeled as an air-filled volume at atmospheric pressure.

\subsection{Potable Water Supply System}

Component 400 is the supply pressure boundary volume for the potable water system. It contains $290 \mathrm{~K}$ water at a pressure of $400 \mathrm{kPa}$ (assumed values pending receipt of actual data).

Component 410 is level control valve LCV-010. It is modeled as a servo valve controlled by control variable 410 . The valve area is modeled as changing linearly with the stem position.

Component 420 is the piping between the level control valve and tank T-010.

Component 450 is the RCCS/coolant day tank, tank T-010. It is modeled as a 6-volume pipe. The mixture level tracking model is turned on where permitted to try to prevent air from entering the feedwater or RCCS lines. The thermal stratification model is turned on where permitted to keep hot water returning from the RCCS panels segregated from the cooler water in the tank, and to segregate the colder supply water being added at the bottom of the tank.

Component 460 is the tank T-010 outlet line, which provides feedwater to both the steam generator and the RCCS. It is modeled as a branch with one junction. The junction connects the bottom of the tank, Component 450, to the inlet of this component. Drawing HTTF-M3.2 shows that the pipe has some bends in it, but there are no details about the pipe configuration. Since the important part of this section of pipe is the elevation change, which provides the head at the pump suction, the pipe is modeled as a straight vertical run. There is no heat structure modeling the pipe wall, as heat transfer in this piping is not expected to be important to either the steam generator or RCCS behavior.

Component 470 is the drain valve in the tank T-010 outlet line. It is modeled as a motor valve connecting the outlet of component 460 to the inlet of Component 475. The opening trip is 1470, and the closing trip is 1472 . The valve stroke time is $2.0 \mathrm{~s}$ (assumed value pending receipt of actual data).

Component 475 is the sink volume for the tank T-010 drain valve, Component 470. It is modeled as a constant time-dependent volume with $290 \mathrm{~K}$ water at a pressure of $100 \mathrm{kPa}$. 
Component 490 is the vent/overflow line on tank T-010. It is modeled as a branch with two junctions. Its length is sufficient to allow the pipe to exit the bottom of the tank; any piping beyond this is neglected. It is connected to the outlet of cell 5 of Component 450.

Component 498 is the pressure boundary volume at the end of the vent/overflow line on tank T-010, Component 490. It is filled with $295 \mathrm{~K}$ air at atmospheric pressure.

\subsection{Alternate Break Piping}

Component 605 is the junction between the upper plenum and the control rod drive break nozzle. It is modeled as a single junction. The abrupt area change model is used with user-defined loss coefficients. The loss coefficients are based on the area change between the top of the plenum and the nozzle interior.

Component 610 is the control rod drive break nozzle from the inlet to the center of the piping offtake. It is modeled as a pipe with 23 volumes; the large number of cells reflects the expectation that molecular diffusion will be the principal phenomenon occurring when this break is included in the model.

Component 615 is the junction between the control rod drive break nozzle and the piping. It is modeled as a single junction. It uses the abrupt area change model with user-input loss coefficients; the loss is approximated as that through the branch of a standard tee.

Component 620 is the piping between the control rod drive break nozzle and valve V-332. It is modeled as a pipe with 45 volumes; the large number of cells reflects the expectation that molecular diffusion will be the principal phenomenon occurring when this break is included in the model.

Component 625 is the control rod drive break valve, V-332. It is modeled as a trip valve, using trip 625.

Component 630 is the piping between valve V-332 and the RCST. It is modeled as a pipe with 99 volumes.

Component 635 is a single junction connecting the outlet of Component 630 to the top of the RCST, Component 280. It uses the abrupt area change model with user-input loss coefficients.

Component 655 is the junction between the pressure vessel inlet region and the vessel bottom break line nozzle stub. It is modeled as a single junction. The abrupt area change model is used with userdefined loss coefficients. The loss coefficients are based on the area change between the inlet region and the stub.

Component 660 is the vessel bottom break line nozzle stub. It is modeled as a pipe with 43 volumes; the large number of cells reflects the expectation that molecular diffusion will be the principal phenomenon occurring when this break is included in the model.

Component 665 is the junction between the bottom break line nozzle stub and the bottom break line piping. It is modeled as a single junction. It used the abrupt area change model with user-input loss coefficients.

Component 670 is the vessel bottom break line piping between the pressure vessel nozzle stub and valve $\mathrm{V}-331$. It is modeled as a pipe with 45 volumes.

Component 675 is the pressure vessel bottom break valve, V-331. It is modeled as a trip valve, using trip 675.

Component 680 is the piping between valve V-331 and the RCST. It is modeled as a pipe with 99 volumes.

Component 685 is a single junction connecting the outlet of Component 680 to the bottom of the RCST, Component 280. It uses the abrupt area change model with user-input loss coefficients. 


\subsection{Reactor Cavity and Reactor Cavity Cooling System}

Component 900 is the reactor cavity between the primary pressure vessel and the RCCS panels. It is modeled as a 20 -volume pipe filled with air. The axial nodalization is consistent with the axial nodalization inside the primary pressure vessel. The only connection to the pipe is at the top, so an unphysical temperature profile will occur in the pipe. An alternate component is included in the input file, in which the cavity volume is modeled as a single volume. This will overestimate the mixing in the cavity by making the air all the same temperature. While this is probably closer to the actual conditions in the cavity than those that will be calculated using the pipe component, there is a code limitation that drives the model to use the pipe: the heat structures take their length from the length of the adjacent fluid volume; if there are volumes on both sides of the structure, the length is taken from the right boundary volume. In this model, that length is used in the axial conduction calculation. Using the single volume cavity, each of the primary pressure vessel structures will have the length of the cavity, which is much too large and will distort the axial conduction calculation. Using the pipe component, each structure will have the correct height.

Component 903 is a single junction connecting the top of the reactor cavity to the pressure boundary volume.

Component 905 is the pressure boundary volume for the reactor cavity. It is a time-dependent volume containing $295 \mathrm{~K}$ air at a constant pressure of $100 \mathrm{kPa}$.

Component 920 is the RCCS pump. It is modeled as a time-dependent junction, with the flow determined by control variable 920 . The pump suction is taken from the water storage tank outlet line, Component 460.

Component 930 is the piping between the RCCS pump outlet and the RCCS panel inlet headers. It also includes the short section of piping upstream of the pump, as well as the volumes in the pump and valves. The valves in this line (V-805 and PCV-807) are not modeled explicitly. This piping is modeled with a single volume component and no heat structures for the pipe walls, as heat transfer in this piping is not expected to be important to the RCCS behavior.

Component 940 represents the RCCS panel inlet headers. It is modeled as a branch with one junction, connecting the outlet of Component 930 to the inlet of this component. The junction is modeled with momentum flux turned off on the header side. There is no heat structure modeling the pipe wall, as heat transfer in this piping is not expected to be important to the RCCS behavior.

Component 945 represents the RCCS panel inlet lines. The valves in the lines are not modeled explicitly. The inlet lines are modeled as a branch with two junctions. The first junction connects the top of Component 940 to the inlet of this component. The second junction connects the outlet of this component to the inlet of the RCCS panels, Component 450. There is no heat structure modeling the pipe wall, as heat transfer in this piping is not expected to be important to the RCCS behavior.

Component 950 represents the RCCS panels. They are modeled with a 19-volume pipe. The axial nodalization is consistent with the axial nodalization inside the primary pressure vessel and in the reactor cavity. Structure 9500, which represents the surface facing the primary pressure vessel, and Structure 9501, which represents the back side of the panels, are connected to this component.

Component 955 represents the RCCS outlet lines leading to the outlet headers. They are modeled with a two-junction branch component. The first junction connects the outlet of the RCCS panels (Component 950) to the inlet of this component, and the second junction connects the outlet of this component to the inlet of Component 960. Since the RCCS flow is being provided by a time-dependent junction, the pressure loss in the piping is not important (the flow rate does not depend on a balance between the pump head and the piping pressure loss), and loss coefficients of 0.0 are entered for the 
junctions for simplicity. There is no heat structure modeling the pipe wall, as heat transfer in this piping is not expected to be important to the RCCS behavior.

Component 960 represents the RCCS outlet headers. The two headers are lumped together into a single branch component with one junction connecting to the middle of the fifth cell in Component 450, the RCCS water storage tank. There is no heat structure modeling the pipe wall, as heat transfer in this piping is not expected to be important to the RCCS behavior. 


\section{Heat Structures}

The thickness of the middle rings of the central and side reflectors will likely need to be adjusted based on system characterization data. The amount of material that is influenced by the coolant channels is just estimated in the original model development effort.

The core region is modeled with two heat structures in each channel. The first structure is centered on a coolant channel, and models the ceramic material. The second structure represents the heater rods, and is modeled as a solid cylinder that radiates heat to the outer surface of the ceramic structure. Both of these structures are have a common boundary volume that represents the gas gap between the heater rods and the ceramic.

2-D conduction is used in vertical structures whenever possible. However, there are several code limitations that results in the axial conduction being approximated through the use of a conduction enclosure instead. One such limitation is that the structure must have a boundary volume attached to it, because the code uses the length of the adjacent cell as the heat structure length (the right side volume if there is one, the left side otherwise); without a boundary volume, the length of the heat structure is not known and therefore the distance to be used for the axial conduction is not known. This limitation comes into play for the three of the four solid regions of the inner and outer reflectors; the outer ring of the side reflector is the exception, as it has a boundary volume on the right side.

The Gnielinski correlation is being used for the core coolant channels. This is implemented by using heat transfer package 160 on the 500/600 series input cards (Word 3).

Dummy values are usually entered for the input on the 800 and 900 series cards related to critical heat flux (CHF) parameters. With a single-phase vapor coolant, CHF will not be a concern.

\subsection{Primary Pressure Vessel}

Structure 1000 is the cylindrical portion of the primary pressure vessel. It has 17 axial structures (cell 1 is at the bottom), is made of 304 stainless steel [Drawing 25835, Sheet 1, Rev. AB, items 2 and 3], and is connected to Component 115 on the left side and Component 900 on the right side. Axial conduction is turned on. The left side is in a radiation enclosure with the core barrel and the jacket shell, and the right side is in a radiation enclosure with the RCCS.

Structure 1001 includes both the primary pressure vessel upper head and the upper plenum shield, since the volume between these two structures is filled with insulation. The upper head is made of 304 stainless steel [Drawing 25835, Sheet 1, Rev. AB, item 1]. The upper plenum shield is made of Haynes 230 [Drawing 25835-1, Sheet 1, Rev. AB, items 90-93], fibrous insulation, and 304 stainless steel. The structure is connected to Component 120 on the left side and Component 900 on the right side. The left side is in a radiation enclosure with the upper reflector top plate and upper plenum internals, and the right side is in a radiation enclosure with the RCCS.

Structure 1050 is the middle distributor plate in the coolant inlet region below the outlet plenum. It is a single, horizontal rectangular structure made of 304 stainless steel [Drawing 25835-1, Sheet 1, Rev. AB, item 103], connected to volume 105-01 on the bottom and volume 105-02 on the top.

Structure 1100 is the jacket shell, the outer plate forming the coolant upcomer between the core barrel and the primary pressure vessel in the lower vessel region. It has 2 axial structures (cell 1 is at the bottom), is made of 304 stainless steel [Drawing 25835-1, Sheet 1, Rev. AB, item 85], and is connected to Component 110 on the left side and Component 115 on the right. Axial conduction is turned on. Both sides of the structure are in a radiation enclosure with the core barrel and primary pressure vessel shell.

Structure 1150 is the core barrel. It has 16 axial structures (cell 1 is at the bottom), is made of 304 stainless steel [Drawing 25835-1, Sheet 1, Rev. AB, item 86], and is connected to Components 105, 166, and 175 on the left side and Components 110 and 115 on the right side. Axial conduction is turned on. 
The left side of the structure is in a radiation enclosure with the PSR, and the right side is in a radiation enclosure with the primary pressure vessel barrel and the jacket shell.

Structure 1200 is the upper plenum cylinder. It has one axial structure, connected to Component 120 on the left side and Component 115, cell 17 on the right side. It is made of Haynes alloy 230 [Drawing 25835-1, Sheet 1, Rev. AB, item 90]. The right side of the structure is in a radiation enclosure with the primary pressure vessel cylinder.

Structure 1201 is the upper plenum floor. It is made of graphite [Drawing 25835-1, Sheet 1, Rev. AB, item 110], and is connected to Component 120 on the right side. The left side is not connected to a fluid volume, but is in a conduction enclosure with the upper reflector portion of each of the core region heat structures; the right side is in a radiation enclosure with the upper plenum shield and the upper plenum internals.

Structure 1202 represents the upper plenum internals. It is made of 304 stainless steel, and is connected to Component 120 on the right side; the left side is adiabatic. The right side is in a radiation enclosure with the upper reflector top plate and the upper plenum shield.

Structure 1300 is the center cylindrical region of the central reflector, which is made of Greencast ceramic. Its 14 axial cells (cell 1 is at the top) extend from the top of the upper reflector to the bottom of the lower reflector. The right side of the structure is in a conduction enclosure with the other two sections of the central reflector, Structures 1320 and 1340. 2-D conduction is not available in this structure because it is not connected to any fluid volumes, and therefore the code does not know the length of the axial structures, so the axial conduction is approximated using the conduction enclosure.

Structure 1320 is the middle ring of the central reflector, which is made of Greencast ceramic. Its 14 axial cells (cell 1 is at the top) extend from the top of the upper reflector to the bottom of the lower reflector. The left side of the structure is connected to Component 132. The right side is in a conduction enclosure with Structures 1300 and 1340. Internal axial conduction is turned on.

Structure 1340 is the outer ring of the central reflector, which is made of Greencast ceramic. Its 14 axial cells (cell 1 is at the top) extend from the top of the upper reflector to the bottom of the lower reflector. The left side of the structure is in a conduction enclosure with Structures 1300 and 1320. The right side is in a conduction enclosure with the three core channels and the inner ring of the outer reflector. Axial conduction is approximated through these enclosures, as the structure is not connected to any coolant volumes, and thus the 2-D conduction model is not available.

Structure 1400 is the upper reflector above the inner core ring. It is made of Greencast ceramic, and has two axial cells. 2-D conduction is turned on. The left side of the structure is connected to Component 140. The left side is in a conduction enclosure with the other core channels, the outer ring of the inner reflector, the inner ring of the outer reflector, and the upper plenum plate.

Structure 1401 is the ceramic in the heated region of the inner core ring. It is made of Greencast ceramic, and has 10 axial cells (cell 1 is at the top) extending over the heated length of the core. 2-D conduction is turned on. The left side of the structure is connected to Component 140, and the right side is connected to Component 141. The left side is in a conduction enclosure with the other core channels, the outer ring of the inner reflector, the inner ring of the outer reflector, and the upper plenum plate; the only axial conduction modeled in the enclosure for this structure is from the ends to the top and bottom reflectors. The right side of the structure is in a radiation enclosure with the heater rod, Structure 1403.

Structure 1402 is the bottom reflector below the inner core ring. It is made of Greencast ceramic, and has two axial cells. 2-D conduction is turned on. The left side of the structure is connected to Component 140. The left side is in a conduction enclosure with the other core channels, the outer ring of the inner reflector, the inner ring of the outer reflector, and the upper plenum plate. The right side is in a radiation enclosure with the other core channels and the outlet plenum bottom plate. 
Structure 1403 represents the heater rods in the inner core ring. It is made of graphite and has 10 axial cells. 2-D conduction is turned on. The right side of the structure is connected to Component 141, and is in a radiation enclosure with Structure 1401.

Structure 1450 is the upper reflector above the middle core ring. It is made of Greencast ceramic, and has two axial cells. 2-D conduction is turned on. The left side of the structure is connected to Component 145. The left side is in a conduction enclosure with the other core channels, the outer ring of the inner reflector, the inner ring of the outer reflector, and the upper plenum plate.

Structure 1451 is the ceramic in the heated region of the middle core ring. It is made of Greencast ceramic, and has 10 axial cells (cell 1 is at the top) extending over the heated length of the core. 2-D conduction is turned on. The left side of the structure is connected to Component 145, and the right side is connected to Component 146. The left side is in a conduction enclosure with the other core channels, the outer ring of the inner reflector, the inner ring of the outer reflector, and the upper plenum plate; the only axial conduction modeled in the enclosure for this structure is from the ends to the top and bottom reflectors. The right side of the structure is in a radiation enclosure with the heater rod, Structure 1453.

Structure 1452 is the bottom reflector below the middle core ring. It is made of Greencast ceramic, and has two axial cells. 2-D conduction is turned on. The left side of the structure is connected to Component 145. The left side is in a conduction enclosure with the other core channels, the outer ring of the inner reflector, the inner ring of the outer reflector, and the upper plenum plate. The right side is in a radiation enclosure with the other core channels and the outlet plenum bottom plate.

Structure 1453 represents the heater rods in the middle core ring. It is made of graphite and has 10 axial cells. 2-D conduction is turned on. The right side of the structure is connected to Component 146, and is in a radiation enclosure with Structure 1451.

Structure 1500 is the upper reflector above the outer core ring. It is made of Greencast ceramic, and has two axial cells. 2-D conduction is turned on. The left side of the structure is connected to Component 150. The left side is in a conduction enclosure with the other core channels, the outer ring of the inner reflector, the inner ring of the outer reflector, and the upper plenum plate.

Structure 1501 is the ceramic in the heated region of the inner core ring. It is made of Greencast ceramic, and has 10 axial cells (cell 1 is at the top) extending over the heated length of the core. 2-D conduction is turned on. The left side of the structure is connected to Component 150, and the right side is connected to Component 151. The left side is in a conduction enclosure with the other core channels, the outer ring of the inner reflector, the inner ring of the outer reflector, and the upper plenum plate; the only axial conduction modeled in the enclosure for this structure is from the ends to the top and bottom reflectors. The right side of the structure is in a radiation enclosure with the heater rod, Structure 1503.

Structure 1502 is the bottom reflector below the outer core ring. It is made of Greencast ceramic, and has two axial cells. 2-D conduction is turned on. The left side of the structure is connected to Component 150. The left side is in a conduction enclosure with the other core channels, the outer ring of the inner reflector, the inner ring of the outer reflector, and the upper plenum plate. The right side is in a radiation enclosure with the other core channels and the outlet plenum bottom plate.

Structure 1503 represents the heater rods in the outer core ring. It is made of graphite and has 10 axial cells. 2-D conduction is turned on. The right side of the structure is connected to Component 151, and is in a radiation enclosure with Structure 1501.

Structure 1600 is the center cylindrical region of the side reflector, which is made of Greencast ceramic. Its 14 axial cells (cell 1 is at the top) extend from the top of the upper reflector to the bottom of the lower reflector. The left side of the structure is in a conduction enclosure with the three core channels and the outer ring of the central reflector. The right side of the structure is in a conduction enclosure with the other two sections of the side reflector, Structures 1620 and 1640. 2-D conduction is not available in 
this structure because it is not connected to any fluid volumes, and therefore the code does not know the length of the axial structures, so the axial conduction is approximated using the conduction enclosure.

Structure 1620 is the middle ring of the side reflector, which is made of Greencast ceramic. Its 14 axial cells (cell 1 is at the top) extend from the top of the upper reflector to the bottom of the lower reflector. The left side of the structure is connected to Component 162. The right side is in a conduction enclosure with structures 1300 and 1340. Internal axial conduction is turned on.

Structure 1640 is the outer ring of the side reflector, which is made of Greencast ceramic. Its 14 axial cells (cell 1 is at the top) extend from the top of the upper reflector to the bottom of the lower reflector. The right side of the structure is connected to Component 164. 2-D conduction is turned on. The left side of the structure is in a conduction enclosure with structures 1600 and 1620 . The right side is in a radiation enclosure with the permanent side reflector, Structure 1660.

Structure 1660 is the permanent side reflector, which is made of Shot-Tech SiC 80 ceramic. Its 14 axial cells (cell 1 is at the top) extend from the top of the upper reflector to the bottom of the lower reflector. 2-D conduction is turned on. The left side of the structure is connected to Component 164, and the right side is connected to Component 166. The left side is in a radiation enclosure with the outer surface of the side reflector, Structure 1640, and the right side is in a radiation enclosure with the core barrel, Structure 110.

Structure 1750 represents the outlet plenum bottom plate, which is a composite horizontal structure that includes the outlet plenum bottom plate on the top, the upper bulkhead plate on the bottom, and insulation in between. The top of the structure is connected to Component 175, and the bottom is connected to Component 105. The top surface is in a radiation enclosure with the bottom reflector structures and a portion of the core barrel connected to the outlet plenum.

Structure 1751 represents the support columns in the outlet plenum, which are made of Greencast ceramic. The right side of this solid cylinder is connected to Component 175.

\subsection{Primary Coolant System}

Structure 2000 is the structure separating the hot and cold ducts. It is connected to Component 200 on the left side and to Component 270 on the right side. It consists of two cylinders of 304 stainless steel with a $3 / 8$ in. layer of alumina silica insulation between them [Drawing PCS-100, Sheet 1, Rev. AB, items 8-13].

Structure 2001 is the section of the hot duct from the end of the cold duct to the outlet of the isolation/break valve. It is a cylindrical structure with 304 stainless steel on the inside and insulation on the outside. It is connected to cells 5 and 6 of Component 200 on the left side, with a natural convection heat transfer coefficient on the right side.

Structure 2100 is the section of hot duct between the isolation/break valve and the RCST. It is a cylindrical structure with 304 stainless steel on the inside, insulation on the outside, and one axial structure.

Structure 2150 is the pipe between the hot duct and the steam generator inlet plenum. The geometry of the structure in this region is complicated, including the check valve body and a gap between the liner and the nozzle. This will be approximated by a single 304 stainless steel [Drawing PCS-100, Sheet 1, Rev. AB, items 5, 6, and 23] cylindrical structure with an inner radius of that of the inner sleeve and an outer steel radius of the steam generator nozzle; a layer of insulation completes the structure.

Structure 2200 is the inlet plenum portion of the steam generator shell. It is modeled as a cylinder whose inner surface area and total volume are equal to those that of the inlet plenum, inlet nozzle stub, and inlet elbow. The left side is connected to Component 220, and the right side has a constant heat transfer coefficient boundary condition applied to the outside of the insulation. The thin $(0.024 \mathrm{in}$.) 
aluminum jacket on the outside of the insulation is not modeled, as it will provide a negligible resistance to heat transfer compared to the low thermal conductivity of the insulating material.

Structure 2201 is the dividing plate ("pass partition") between the inlet and outlet plena of the steam generator. It is modeled as a rectangular structure, connected to Component $220 \mathrm{on}$ the left side and to Component 228 on the right side.

Structure 2250 represents the 188 steam generator tubes. The tubes are made of 304 stainless steel [Drawing 25838, Sheet 1, Rev. AB, item 2]. The left side is connected to Component 225, and the right side is connected to Component 350. The right side uses the rod bundle with crossflow heat transfer package, as the baffle plates should force some flow across the tubes. Axial conduction is turned on in the tubes because large temperature gradients are expected along the tubes.

Structure 2251 represents the tube sheet. It is modeled as a cylindrical structure with two axial nodes: the first models the half of the tube sheet connected to the inlet end of the steam generator tubes, and the second models the half connected to the outlet end of the tubes. The structure is built around a unit cell, the inner radius being the inner radius of the tubes and the outer radius determined by conservation of mass (area). There are 188 of these unit cells in each half of the tube sheet. Heat transfer from the faces of the tube sheet to the boiler region and to the plena is not modeled.

Structure 2280 is the outlet plenum portion of the steam generator shell. It is modeled as a cylinder whose inner surface area and total volume are equal to those that of the outlet plenum, outlet nozzle stub, and outlet elbow. The left side is connected to Component 228, and the right side has a constant heat transfer coefficient boundary condition applied to the outside of the insulation. The thin $(0.024 \mathrm{in}$.) aluminum jacket on the outside of the insulation is not modeled, as it will provide a negligible resistance to heat transfer compared to the low thermal conductivity of the insulating material.

Structure 2300 is the pipe between the steam generator outlet plenum and the compressor. It is a cylindrical structure with 304 stainless steel on the inside, insulation on the outside, and one axial structure. The left side is connected to Component 230, and the right side has a constant heat transfer coefficient boundary condition applied to the outside of the insulation.

Structure 2350 is the compressor body. It is a cylindrical structure with 304 stainless steel on the inside, insulation on the outside, and one axial structure. The left side is connected to Component 235, and the right side has a constant heat transfer coefficient boundary condition applied to the outside of the insulation.

Structure 2400 is the pipe between the compressor outlet and valve V-203. It is a cylindrical structure with 304 stainless steel on the inside, insulation on the outside, and one axial structure. The left side is connected to Component 240, and the right side has a constant heat transfer coefficient boundary condition applied to the outside of the insulation.

Structure 2500 is the pipe between valve V-203 and the cold duct. It is a cylindrical structure with 304 stainless steel on the inside, insulation on the outside, and three axial structures. The left side is connected to Component 250, and the right side has a constant heat transfer coefficient boundary condition applied to the outside of the insulation.

Structure 2580 is the section of cold duct between the isolation/break valve and the RCST. It is a cylindrical structure with 304 stainless steel on the inside, insulation on the outside, and one axial structure. The left side is connected to Component 258, and the right side has a constant heat transfer coefficient boundary condition applied to the outside of the insulation.

Structure 2600 is the crossover line between the cold leg and the cold duct. It is a cylindrical structure with 304 stainless steel on the inside, insulation on the outside, and one axial structure. The left side is connected to Component 260, and the right side has a constant heat transfer coefficient boundary condition applied to the outside of the insulation. 
Structure 2700 is the outer wall of the cold duct. It is a cylindrical structure with 304 stainless steel on the inside, insulation on the outside, and four axial structures. The left side is connected to Component 270 , and the right side has a constant heat transfer coefficient boundary condition applied to the outside of the insulation.

Structure 2800 is the RCST. It is a cylindrical structure with 304 stainless steel on the inside [Drawing 25836, Sheet 1, Rev. AB, items 1 and 2], insulation on the outside, and either one or two axial structures. The mass of the heads is not completely accounted for with this modeling approach. The left side of the structure is connected to Component 280. The right side has a constant heat transfer coefficient boundary condition applied to the outside of the insulation. The thin $(0.024 \mathrm{in}$.) aluminum jacket on the outside of the insulation is not modeled, as it will provide a negligible resistance to heat transfer compared to the low thermal conductivity of the insulating material.

Structure 2820 is the hot duct break spool piece. It is a cylindrical structure with 304 stainless steel on the inside, insulation on the outside, and one axial structure. The left side of the structure is connected to Component 282, and the right side is connected to Component 280.

\subsection{Alternate Break Piping}

Structure 6200 is the section of piping between the pressure vessel control rod drive break nozzle and valve V-332. It is a cylindrical structure with 304 stainless steel on the inside, insulation on the outside, and the same number of axial structures as the attached pipe has volumes. The left side is connected to Component 620, and the right side has a constant heat transfer coefficient boundary condition applied to the outside of the insulation.

Structure 6300 is the section of piping between the valve V-332 and the RCST. It is a cylindrical structure with 304 stainless steel on the inside, insulation on the outside, and the same number of axial structures as the attached pipe has volumes. The left side is connected to Component 630, and the right side has a constant heat transfer coefficient boundary condition applied to the outside of the insulation.

Structure 6700 is the section of piping between the pressure vessel bottom break nozzle stub and valve V-331. It is a cylindrical structure with 304 stainless steel on the inside, insulation on the outside, and the same number of axial structures as the attached pipe has volumes. The left side is connected to Component 670 , and the right side has a constant heat transfer coefficient boundary condition applied to the outside of the insulation.

Structure 6800 is the section of piping between the valve V-331 and the RCST. It is a cylindrical structure with 304 stainless steel on the inside, insulation on the outside, and the same number of axial structures as the attached pipe has volumes. The left side is connected to Component 680, and the right side has a constant heat transfer coefficient boundary condition applied to the outside of the insulation.

\subsection{Secondary Coolant System}

Structure 3400 is the steam generator outer cylindrical shell, modeled with 13 axial structures. The thicker wall just above the tube sheet is ignored. Most of the left side is connected to Component 340, with the bottom node being connected to the first volume in Component 350 and the top node being connected to Component 360, and the right side has a constant heat transfer coefficient boundary condition applied to the outside of the insulation. The thin (0.024 in.) aluminum jacket on the outside of the insulation is not modeled, as it will provide a negligible resistance to heat transfer compared to the low thermal conductivity of the insulating material. The shell is made of 304 stainless steel [Drawing 25838, Sheet 1, Rev. AB, items 4 and 5].

Structure 3500 is the steam generator inner cylindrical shell separating the downcomer from the boiler. The shell is made of 304 stainless steel [Drawing 25838, Sheet 1, Rev. AB, item 11]. It has 11 axial nodes, and is connected to the boiler on the left side and the downcomer on the right side. The 
portion of the cylinder above the top of the downcomer is neglected, as there is expected to be little temperature difference between the top of the boiler and the steam annulus region, and stored energy in the steam generator structures is not expected to be important in the transients to be simulated.

Structure 3550 is the steam generator upper head. The head is made of 304 stainless steel [Drawing 25838, Sheet 1, Rev. AB, item 7]. The left side is connected to Component 355, and the right side has a constant heat transfer coefficient boundary condition applied to the outside of the insulation. The thin (0.024 in.) aluminum jacket on the outside of the insulation is not modeled, as it will provide a negligible resistance to heat transfer compared to the low thermal conductivity of the insulating material.

\subsection{Reactor Cavity Cooling System}

Structure 9500 is the front wall of the RCCS panels. The left side is connected to Component 900, and is in a radiation enclosure with the primary pressure vessel. The right side is connected to Component 950.

Structure 9501 is the back wall of the RCCS panels. The left side is connected to Component 950, and the right side has a constant heat transfer coefficient boundary condition applied to the insulation. The thin (0.024 in.) aluminum jacket on the outside of the insulation is not modeled, as it will provide a negligible resistance to heat transfer compared to the low thermal conductivity of the insulating material. 


\section{Enclosures}

Enclosure 1 (601xxxxx cards) models the conduction in the central reflector. It includes the radial conduction between the three structures $(1300,1320$, and 1340) and well as the axial conduction in the inner and outer rings (Structures 1300 and 1340).

Enclosure 2 (602xxxxx cards) models the conduction in the core (heater rod) region. It includes radial conduction between the ceramic structures in the three core channels, as well from the core to the adjacent central and side reflector structures (1340 and 1600). It models axial conduction in reflector structures 1340 and 1600 and from the core ceramic structures to the top and bottom reflector structures. It also models conduction from the upper reflector structures to the upper plenum plate.

Enclosure 3 (603xxxxx cards) models the conduction in the side reflector. It includes the radial conduction between the three structures $(1600,1620$, and 1640) and the axial conduction in the inner ring (Structure 1600).

Enclosure 11 (611xxxxx cards) models the radiation from the heater rods to the ceramic in the inner core ring.

Enclosure 12 (612xxxxx cards) models the radiation from the heater rods to the ceramic in the middle core ring.

Enclosure 13 (613xxxxx cards) models the radiation from the heater rods to the ceramic in the outer core ring.

Enclosure 14 (614xxxxx cards) models the radiation from the side reflector to the permanent side reflector.

Enclosure 15 (615xxxxx cards) models the radiation from the permanent side reflector to the core barrel.

Enclosure 16 (616xxxxx cards) models the radiation between the upper plenum plate, upper plenum internals, and the upper plenum shield.

Enclosure 18 (618xxxxx cards) models the radiation between the bottom reflector, core barrel, and lower plenum bottom plate.

Enclosure 19 (619xxxxx cards) models the radiation from the core barrel to the primary pressure vessel wall. In the region where the jacket shell is modeled, the core barrel radiates to the inner surface of the jacket shell, and the outer surface of the jacket shell then radiates to the primary pressure vessel wall.

Enclosure 21 (621xxxxx cards) models the radiation from the primary pressure vessel to the RCCS panels. 


\section{Materials}

Material 1 is Greencast-94F Plus ceramic. It is used in the core, central and side reflectors, top and bottom reflectors, and the posts in the outlet plenum. Only four emissivity data points are available, with a maximum temperature of $150^{\circ} \mathrm{C}$, which is well below the normal operating temperature of the facility. Extrapolating these data using a quadratic or cubic fit resulted in negative emissivities near the nominal steady state operating temperatures. A linear fit was therefore used to extrapolate the data to higher temperatures; although the curve fit statistics were not particularly good $\left(\mathrm{R}^{2}\right.$ value of 0.977$)$, the values were positive over the entire expected temperature range. Sensitivity calculations should be performed to address the large uncertainty in the emissivity.

Material 2 is graphite. It is used in the heater rods and the upper plenum floor.

Material 3 is Type 304 stainless steel.

Material 4 is Haynes 230 alloy.

Material 5 is Shot-Tech $\mathrm{SiC} 80$ ceramic. It is used in the permanent side reflector. The only needed property information on the ceramic product data sheet was the density. The value of $2.37 \mathrm{~g} / \mathrm{cm}^{3}$ is used for the constant density. Thermal conductivity and specific heat capacity values are not available. With no other information, these data are taken from measurements of Thor 80 ceramic, which has a similar chemical composition, with somewhat more alumina and less silica than the Shot-Tech. No measurements of the emissivity of Shot-Tech were made; therefore data for Thor 80 will be used. Only four emissivity data points are available, with a maximum temperature of $150^{\circ} \mathrm{C}$, which is well below the normal operating temperature of the facility. As for the Greencast ceramic, a linear fit of the four data points $\left(\mathrm{R}^{2}\right.$ value of 0.979) was used to extrapolate to higher temperatures.

Material 6 is Enerwrap MA 960 insulation. It is used for the permanent insulation on the outside of the large tanks, on the back side of the RCCS panels, and on some of the piping..

Material 7 is Incoloy Alloy 600. It is used in the steam generator tubes.

Material 8 is alumina silica insulation. It is used between the hot and cold ducts.

Material 9 is glass wool insulation. It is the removable insulation used on the outside of most of the piping. 


\section{6. $\quad$ Trips}

Trip 100 is the scram trip. It is set to be always false, and must be changed to initiate a power decrease.

Trip 205 opens the hot duct break valve, Component 205. It is set to be always false, and must be changed to initiate a break.

Trip 206 closes the hot duct break valve, Component 205. It is set to be always false, and must be changed to reclose a break.

Trip 245 opens the loop isolation valve V-303, Component 245. It is set to be always false, and the valve is initialized to be fully open.

Trip 246 closes the loop isolation valve V-303, Component 245. It is set to be always false, and must be changed to close the valve.

Trip 255 opens the cold leg break valve, Component 255. It is set to be always false, and must be changed to initiate a break.

Trip 256 closes the cold leg break valve, Component 255. It is set to be always false, and must be changed to reclose a break.

Trip 294 is the opening (setpoint) pressure for the PCS relief valve, PSV-100, Component 295.

Trip 295 is the closing (reseat) pressure for the PCS relief valve, PSV-100, Component 295.

Trip 296 manually opens the depressurization valve, V-400, Component 296. It is set to be always false, and must be changed to open the valve.

Trip 297 manually closes the depressurization valve, V-400, Component 296. It is set to be always false, and must be changed to close the valve.

Trip 394 is the opening (setpoint) pressure for the steam generator relief valve, PSV-600.

Trip 395 is the closing (reseat) pressure for the steam generator relief valve, PSV-600.

Trip 410 is the low liquid level setpoint on tank T-010 for the water supply control logic.

Trip 411 is the high liquid level setpoint on tank T-010 for the water supply control logic.

Trip 412 is true if the liquid level in tank T-010 is above mid-range (halfway between open and close setpoints)

Trip 470 is the high liquid level setpoint on tank T-010 for the tank drain valve control logic.

Trip 471 is the low liquid level setpoint on tank T-010 for the tank drain valve control logic.

Trip 625 manually opens the control rod drive break valve, V-332, Component 625 . It is set to be always false, and must be changed to open the valve.

Trip 675 manually opens the vessel bottom break valve, V-331, Component 675 . It is set to be always false, and must be changed to open the valve.

Trip 1294 is true if valve Component 295 either should open or is already open.

Trip 1295 opens the PCS relief valve, Component 295.

Trip 1296 opens the depressurization valve, Component 296.

Trip 1394 is true if valve Component 395 either should open or is already open.

Trip 1395 opens the steam generator relief valve, PSV-600, Component 395. 
Trip 1409 is true if the tank T-010 water supply valve, Component 410, either should open or is already open.

Trip 1410 opens the tank T-010 water supply valve, Component 410, or maintains a higher flow until the liquid level is above mid-range.

Trip 1411 is true if the tank T-010 water supply valve, Component 410, either should close or is already closed.

Trip 1412 closes the tank T-010 water supply valve, Component 410, or maintains a lower flow until the liquid level is below mid-range.

Trip 1469 is true if the tank drain valve, Component 470, either should open or is already open.

Trip 1470 opens the tank T-010 drain valve, Component 470.

Trip 1471 is true if the tank T-010 drain valve, Component 470, either should close or is already closed.

Trip 1472 closes the tank T-010 drain valve, Component 470. 


\section{General Tables}

Table 100 is the steady state power. It is set to a constant value of $2.2 \mathrm{MW}$.

Table 900 is the scram power decay curve. It is a relative decay power curve provided by General Atomics. The time has been cut in half to reflect the time scaling in the HTTF, and the power multiplier is the scaled value of $1 / 32$ of $350 \mathrm{MW}$. Power values beyond the end of the data provided by General Atomics were extrapolated using an exponential curve fit to the data.

Table 950 is the building temperature, used as a boundary temperature for the back side of the RCCS panels and for the outside of insulated structures. It is set to $300 \mathrm{~K}$.

Table 951 is the convective heat transfer coefficient boundary condition for the back side of the RCCS panels and for the outside of insulated structures. It is set to a value of $15 \mathrm{~W} / \mathrm{m}^{2}-\mathrm{K}$, which is a representative natural convection value. 


\section{Control Variables}

Control variable 1 calculates the heat input (W) to the coolant in Component_140, the flow path through the core region inner ring.

Control variable 2 calculates the heat input (W) to the coolant in Component_145, the flow path through the core region middle ring.

Control variable 3 calculates the heat input (W) to the coolant in Component 150, the flow path through the core region outer ring.

Control variable 4 calculates the heat input (W) to the coolant in Component_132, the flow path through the central reflector cooling channels.

Control variable 5 calculates the heat input (W) to the coolant in Component_162, the flow path through the side reflector cooling channels.

Control variable 6 calculates the heat input (W) to the coolant in Component_164, the gas gap between the side and permanent side reflectors.

Control variable 7 calculates the heat input (W) to the coolant in Component_166, the gas gap between the permanent side reflector and the core barrel.

Control variable 8 calculates the heat input (W) to the coolant in Component_141, the gas gap around the heater rod in the core region inner ring.

Control variable 9 calculates the heat input (W) to the coolant in Component_146, the gas gap around the heater rod in the core region middle ring.

Control variable 10 calculates the heat input (W) to the coolant in Component_151, the gas gap around the heater rod in the core region outer ring.

Control variable 11 calculates the total heat input $(\mathrm{W})$ to the gas in the core region by adding control variables $1-10$.

Control variable 12 integrates the total heat input $(\mathrm{J})$ to the gas in the core region, control variable 11.

Control variable 13 calculates the total heat input (W) to the gas in the primary pressure vessel by taking the difference between the flow enthalpy leaving the vessel (Junction 175-01) and that entering (Junction 100-01). This will generally only be a valid calculation under forced convection flow conditions.

Control variable 14 calculates the total heat input $(\mathrm{J})$ to the gas in the primary pressure vessel by integrating control variable 13 .

Control variable 16 calculates the heat input (W) to the coolant in Component 115, the gap between the core barrel and the primary pressure vessel.

Control variable 20 mimics the total flow $(\mathrm{kg} / \mathrm{s})$ through the core by taking the mass flow through Junction 175-01. A minimum value of 0.001 is applied to prevent division by zero during subsequent use of this flow rate.

Control variable 21 calculates the flow fraction through the central reflector cooling channel by dividing the flow through the channel outlet, Junction 1700101, by the total flow, control variable 20 .

Control variable 22 calculates the flow fraction through the core inner ring by dividing the flow through the channel outlet, Junction 1700102, by the total flow, control variable 20.

Control variable 23 calculates the flow fraction through the core middle ring by dividing the flow through the channel outlet, Junction 1700103, by the total flow, control variable 20. 
Control variable 24 calculates the flow fraction through the core outer ring by dividing the flow through the channel outlet, Junction 1700104, by the total flow, control variable 20.

Control variable 25 calculates the flow fraction through the side reflector cooling channel by dividing the flow through the channel outlet, Junction 1700105, by the total flow, control variable 20.

Control variable 26 calculates the flow fraction through the gap between the side reflector and the permanent side reflector by dividing the flow through the channel outlet, Junction 1700106, by the total flow, control variable 20 .

Control variable 27 calculates the flow fraction through the gap between the permanent side reflector and the core barrel by dividing the flow through the channel outlet, Junction 1700107, by the total flow, control variable 20 .

Control variable 28 calculates the total core bypass flow fraction through the channels connected to the central and side reflectors.

Control variable 29 calculates the total core bypass flow fraction.

Control variable 31 calculates the total primary-to-secondary heat transfer rate $(\mathrm{W})$ by summing the heat addition to the coolant in the steam generator tubes.

Control variable 32 calculates the total primary-to-secondary heat transfer rate (W) by summing the heat transfer out of the steam generator tube heat structures.

Control variable 33 calculates the total primary-to-secondary heat transfer rate (W) by summing the heat addition to the coolant in the steam generator boiler region.

Control variable 35 calculates the total energy transferred to the steam generator (W) by taking the difference between the flow enthalpy leaving the steam generator (Junction 360-02) and that entering (Junction 330-01).

Control variable 36 integrates control variable 35 to calculate the total net energy transferred to the steam generator secondary coolant (J).

Control variable 45 calculates the heat added by the compressor (MW) by taking the difference between the flow enthalpy downstream (Junction 245) and upstream (Junction 235-01) of the compressor.

Control variable 46 integrates control variable 45 to calculate the total energy (MJ) added to the coolant by the compressor.

Control variable 98 calculates the net heat transfer to the RCCS coolant in the RCCS panels (W) by taking the difference between the flow enthalpy downstream (Junction 955-01) and upstream (Junction 945-02) of the panels.

Control variable 99 integrates control variable 98 to calculate the total net energy deposition in the RCCS coolant (J).

Control variable 100 calculates the maximum volume-average structure temperature $(\mathrm{K})$ for the primary pressure vessel cylinder.

Control variable 101 calculates the peak volume-average structure temperature $(\mathrm{K})$ for the primary pressure vessel cylinder.

Control variable 103 calculates the maximum volume-average structure temperature $(\mathrm{K})$ for the core barrel.

Control variable 104 calculates the peak volume-average structure temperature $(\mathrm{K})$ for the core barrel.

Control variable 120 calculates the maximum volume-average structure temperature $(\mathrm{K})$ for the central reflector inner cylinder over the heated length of the core. 
Control variable 121 calculates the maximum volume-average structure temperature $(\mathrm{K})$ for the central reflector middle ring over the heated length of the core.

Control variable 122 calculates the maximum volume-average structure temperature $(\mathrm{K})$ for the central reflector outer ring over the heated length of the core.

Control variable 123 calculates the maximum volume-average structure temperature $(K)$ for the core inner ring ceramic over the heated length of the core.

Control variable 124 calculates the maximum volume-average structure temperature $(\mathrm{K})$ for the core middle ring ceramic over the heated length of the core.

Control variable 125 calculates the maximum volume-average structure temperature $(\mathrm{K})$ for the core outer ring ceramic over the heated length of the core.

Control variable 126 calculates the maximum volume-average structure temperature $(\mathrm{K})$ for the side reflector inner ring over the heated length of the core.

Control variable 127 calculates the maximum volume-average structure temperature $(\mathrm{K})$ for the side reflector middle ring over the heated length of the core.

Control variable 128 calculates the maximum volume-average structure temperature $(\mathrm{K})$ for the side reflector outer ring over the heated length of the core.

Control variable 129 calculates the maximum volume-average structure temperature $(\mathrm{K})$ for the permanent side reflector over the heated length of the core.

Control variable 130 calculates the peak volume-average structure temperature $(\mathrm{K})$ achieved during the simulation for the central reflector center cylinder over the heated length of the core.

Control variable 131 calculates the peak volume-average structure temperature $(\mathrm{K})$ achieved during the simulation for the central reflector middle ring over the heated length of the core.

Control variable 132 calculates the peak volume-average structure temperature $(\mathrm{K})$ achieved during the simulation for the central reflector outer ring over the heated length of the core.

Control variable 133 calculates the peak volume-average structure temperature $(\mathrm{K})$ achieved during the simulation for the core inner ring ceramic over the heated length of the core.

Control variable 134 calculates the peak volume-average structure temperature $(\mathrm{K})$ achieved during the simulation for the core middle ring ceramic over the heated length of the core.

Control variable 135 calculates the peak volume-average structure temperature $(\mathrm{K})$ achieved during the simulation for the core outer ring ceramic over the heated length of the core.

Control variable 136 calculates the peak volume-average structure temperature $(\mathrm{K})$ achieved during the simulation for the side reflector inner ring over the heated length of the core.

Control variable 137 calculates the peak volume-average structure temperature $(\mathrm{K})$ achieved during the simulation for the side reflector middle ring over the heated length of the core.

Control variable 138 calculates the peak volume-average structure temperature $(\mathrm{K})$ achieved during the simulation for the side reflector outer ring over the heated length of the core.

Control variable 139 calculates the peak volume-average structure temperature $(\mathrm{K})$ achieved during the simulation for the permanent side reflector over the heated length of the core.

Control variable 140 calculates the maximum volume-average structure temperature $(\mathrm{K})$ for the heater rod in the core inner ring. 
Control variable 145 calculates the maximum volume-average structure temperature $(\mathrm{K})$ for the heater rod in the core middle ring.

Control variable 150 calculates the maximum volume-average structure temperature $(\mathrm{K})$ for the heater rod in the core outer ring.

Control variable 156 calculates the maximum volume-average structure temperature $(\mathrm{K})$ for the heater rods.

Control variable 157 calculates the peak volume-average structure temperature $(\mathrm{K})$ for the heater rods during the simulation.

Control variable 161 calculates the axial average structure temperature $(\mathrm{K})$ for the primary pressure vessel cylinder over the core heated length.

Control variable 162 calculates the axial average structure temperature $(\mathrm{K})$ for the core barrel over the core heated length.

Control variable 166 calculates the axial average structure temperature $(\mathrm{K})$ for the central reflector center cylinder over the core heated length.

Control variable 167 calculates the axial average structure temperature $(\mathrm{K})$ for the central reflector middle ring over the core heated length.

Control variable 168 calculates the axial average structure temperature $(\mathrm{K})$ for the central reflector outer ring over the core heated length.

Control variable 169 calculates the axial average structure temperature $(\mathrm{K})$ for the core inner ring ceramic over the core heated length.

Control variable 170 calculates the axial average structure temperature $(\mathrm{K})$ for the core inner ring heater rod over the core heated length.

Control variable 171 calculates the axial average structure temperature $(\mathrm{K})$ for the core middle ring ceramic over the core heated length.

Control variable 172 calculates the axial average structure temperature $(\mathrm{K})$ for the core middle ring heater rod over the core heated length.

Control variable 173 calculates the axial average structure temperature $(\mathrm{K})$ for the core outer ring ceramic over the core heated length.

Control variable 174 calculates the axial average structure temperature $(\mathrm{K})$ for the core outer ring heater rod over the core heated length.

Control variable 175 calculates the axial average structure temperature $(\mathrm{K})$ for the side reflector inner ring over the core heated length.

Control variable 176 calculates the axial average structure temperature $(\mathrm{K})$ for the side reflector outer ring over the core heated length.

Control variable 177 calculates the axial average structure temperature $(\mathrm{K})$ for the side reflector outer ring over the core heated length.

Control variable 178 calculates the axial average structure temperature $(\mathrm{K})$ for the permanent side reflector over the core heated length.

Control variable 183 calculates the axial average structure temperature $(\mathrm{K})$ for the front (primary pressure vessel) side of the RCCS cooling panels. 
Control variable 184 calculates the axial average structure temperature $(\mathrm{K})$ for the back side of the RCCS cooling panels.

Control variable 233 calculates the primary pressure vessel inlet pressure error $(\mathrm{Pa})$, which is the difference between the calculated and desired steady state pressure at the vessel inlet, Component 100.

Control variable 234 integrates control variable 233, processing the pressure error signal. This processed signal is used to change the primary coolant system pressure to achieve the desired steady state conditions.

Control variable 236 calculates the primary pressure vessel outlet temperature error $(\mathrm{K})$, which is the difference between the calculated and desired steady state gas temperature in the outlet plenum, Component 175.

Control variable 237 integrates control variable 236, processing the temperature error signal. This processed signal is used to change the primary coolant system flow rate to achieve the desired steady state conditions.

Control variable 275 calculates the pressure difference $(\mathrm{Pa})$ between the core inlet and outlet plenums.

Control variable 276 calculates the pressure drop $(\mathrm{Pa})$ across the primary pressure vessel.

Control variable 319 calculates the steam generator outlet temperature error $(\mathrm{K})$, which is the difference between the calculated and desired steady state gas temperature in the steam generator primary side outlet plenum, Component 228.

Control variable 320 integrates control variable 319, processing the temperature error signal. This processed signal is used to change the steam generator feedwater flow rate to achieve the desired steady state conditions.

Control variable 321 integrates the feedwater flow rate, the mass flow in Component 320, to calculate the total amount of water flowing into the steam generator secondary side $(\mathrm{kg})$.

Control variable 350 calculates the collapsed liquid level $(\mathrm{m})$ in the steam generator boiler region.

Control variable 369 calculates the steam generator secondary pressure error $(\mathrm{Pa})$, which is the difference between the calculated and desired steady state pressure in the steam dome, Component 355.

Control variable 370 integrates control variable 369 , processing the pressure error signal. This processed signal is used to change the secondary coolant system pressure by modulating valve Component 370 to achieve the desired steady state conditions.

Control variable 403 calculates the flow demand for the feedwater and RCCS systems.

Control variable 404 is a tripunit that has a value of 1.0 if the liquid level in the water storage tank is below the low setpoint.

Control variable 405 is a tripunit that has a value of -1.0 if the liquid level in the water storage tank is above the high setpoint.

Control variable 406 adds control variables 404 and 405, which will provide a non-zero value if the tank liquid level is out-of-range.

Control variable 407 calculates a liquid level out-of-range contribution to the water storage tank flow demand signal. The amount is assumed to be $25 \%$ of the value of control variable 403 .

Control variable 408 calculates the flow demand signal for the water storage tank makeup by adding control variables 403 and 407 .

Control variable 409 calculates the flow error for the water storage tank makeup by subtracting the flow in Component 410 from the demand value in control variable 408. 
Control variable 410 integrates the error signal in control variable 409. This control variable is then used to modulate the valve area in Component 410, a servo valve. Minimum and maximum values of 0.0 and 1.0 are specified, respectively.

Control variable 450 calculates the collapsed liquid level $(\mathrm{m})$ in the water storage day tank (T-010).

Control variable 451 is a constant that provides the water storage tank low level setpoint (m).

Control variable 452 is a constant that provides the water storage tank high level setpoint (m).

Control variable 453 calculates the mid-range of the tank level setpoints by averaging control variables 451 and 452.

Control variable 901 obtains the steady state power (W) from table 100.

Control variable 904 obtains the decay power (W) from table 900.

Control variable 907 establishes the core power (W) by taking the minimum of the steady state and decay powers after reactor scram; the steady state power is used prior to scram.

Control variable 908 converts the core power from control variable 907 into MW.

Control variable 909 calculates the total energy input (MJ) during the simulation by integrating control variable 908 .

Control variable 918 is a constant that provides the desired outlet temperature $(\mathrm{K})$ for the RCCS panels.

Control variable 919 calculates the RCCS panel coolant outlet temperature error (K).

Control variable 920 is a proportional-integral controller that processes the error in control variable 919 to control the flow rate in the RCCS pump (Component 920).

Control variable 1000 calculates the convective heat transfer $(\mathrm{W})$ to the left side of the primary pressure vessel cylinder heat structure.

Control variable 1001 calculates the radiation heat transfer (W) to the left side of the primary pressure vessel cylinder heat structure.

Control variable 1002 calculates the total heat transfer (W) to the left side of the primary pressure vessel cylinder heat structure.

Control variable 1003 calculates the integral energy transfer $(\mathrm{J})$ to the left side of the primary pressure vessel cylinder heat structure.

Control variable 1004 calculates the convective heat transfer (W) to the right side of the primary pressure vessel cylinder heat structure.

Control variable 1005 calculates the radiation heat transfer $(\mathrm{W})$ to the right side of the primary pressure vessel cylinder heat structure.

Control variable 1006 calculates the total heat transfer $(\mathrm{W})$ to the right side of the primary pressure vessel cylinder heat structure.

Control variable 1007 calculates the integral energy transfer $(\mathrm{J})$ to the right side of the primary pressure vessel cylinder heat structure.

Control variable 1008 calculates the net heat transfer (W) to the primary pressure vessel cylinder heat structure.

Control variable 1009 calculates the integral net heat transfer $(\mathrm{J})$ to the primary pressure vessel cylinder heat structure. 
Control variable 1010 calculates the convective heat transfer (W) to the left side of the primary pressure vessel upper head/upper plenum shield heat structure.

Control variable 1011 calculates the radiation heat transfer (W) to the left side of the primary pressure vessel upper head/upper plenum shield heat structure.

Control variable 1012 calculates the total heat transfer $(\mathrm{W})$ to the left side of the primary pressure vessel upper head/upper plenum shield heat structure.

Control variable 1013 calculates the integral energy transfer $(\mathrm{J})$ to the left side of the primary pressure vessel upper head/upper plenum shield heat structure.

Control variable 1014 calculates the convective heat transfer $(\mathrm{W})$ to the right side of the primary pressure vessel upper head/upper plenum shield heat structure.

Control variable 1015 calculates the radiation heat transfer $(\mathrm{W})$ to the right side of the primary pressure vessel upper head/upper plenum shield heat structure.

Control variable 1016 calculates the total heat transfer $(\mathrm{W})$ to the right side of the primary pressure vessel upper head/upper plenum shield heat structure.

Control variable 1017 calculates the integral energy transfer $(\mathrm{J})$ to the right side of the primary pressure vessel upper head/upper plenum shield heat structure.

Control variable 1018 calculates the net heat transfer (W) to the primary pressure vessel upper head/upper plenum shield heat structure.

Control variable 1019 calculates the integral net heat transfer $(\mathrm{J})$ to the primary pressure vessel upper head/upper plenum shield heat structure.

Control variable 1020 calculates the convective heat transfer (W) to the left side of the core barrel heat structure.

Control variable 1021 calculates the radiation heat transfer (W) to the left side of the core barrel heat structure.

Control variable 1022 calculates the total heat transfer (W) to the left side of the core barrel heat structure.

Control variable 1023 calculates the integral energy transfer $(\mathrm{J})$ to the left side of the core barrel heat structure.

Control variable 1024 calculates the convective heat transfer (W) to the right side of the core barrel heat structure.

Control variable 1025 calculates the radiation heat transfer (W) to the right side of the core barrel heat structure.

Control variable 1026 calculates the total heat transfer (W) to the right side of the core barrel heat structure.

Control variable 1027 calculates the integral energy transfer $(\mathrm{J})$ to the right side of the core barrel heat structure.

Control variable 1028 calculates the net heat transfer (W) to the core barrel heat structure.

Control variable 1029 calculates the integral net heat transfer $(\mathrm{J})$ to the core barrel heat structure.

Control variable 1030 calculates the convective heat transfer (W) to the left side of the upper plenum cylinder heat structure. 
Control variable 1031 calculates the radiation heat transfer (W) to the left side of the upper plenum cylinder heat structure. (This control variable is not currently used.)

Control variable 1032 calculates the total heat transfer (W) to the left side of the upper plenum cylinder heat structure.

Control variable 1033 calculates the integral energy transfer $(\mathrm{J})$ to the left side of the upper plenum cylinder heat structure.

Control variable 1034 calculates the convective heat transfer (W) to the right side of the upper plenum cylinder heat structure.

Control variable 1035 calculates the radiation heat transfer (W) to the right side of the upper plenum cylinder heat structure.

Control variable 1036 calculates the total heat transfer (W) to the right side of the upper plenum cylinder heat structure.

Control variable 1037 calculates the integral energy transfer $(\mathrm{J})$ to the right side of the upper plenum cylinder heat structure.

Control variable 1038 calculates the net heat transfer (W) to the upper plenum cylinder heat structure.

Control variable 1039 calculates the integral net heat transfer $(\mathrm{J})$ to the upper plenum cylinder heat structure.

Control variable 1041 calculates the conduction heat transfer (W) to the left side of the upper plenum floor heat structure.

Control variable 1042 calculates the total heat transfer (W) to the left side of the upper plenum floor heat structure.

Control variable 1043 calculates the integral energy transfer $(\mathrm{J})$ to the left side of the upper plenum floor heat structure.

Control variable 1044 calculates the convective heat transfer (W) to the right side of the upper plenum floor heat structure.

Control variable 1045 calculates the radiation heat transfer (W) to the right side of the upper plenum floor heat structure.

Control variable 1046 calculates the total heat transfer (W) to the right side of the upper plenum floor heat structure.

Control variable 1047 calculates the integral energy transfer $(\mathrm{J})$ to the right side of the upper plenum floor heat structure.

Control variable 1048 calculates the net heat transfer (W) to the upper plenum floor heat structure.

Control variable 1049 calculates the integral net heat transfer $(\mathrm{J})$ to the upper plenum floor heat structure.

Control variable 1054 calculates the convective heat transfer (W) to the right side of the upper plenum internals heat structure.

Control variable 1055 calculates the radiation heat transfer (W) to the right side of the upper plenum internals heat structure.

Control variable 1056 calculates the total heat transfer (W) to the right side of the upper plenum internals heat structure. 
Control variable 1057 calculates the integral energy transfer $(\mathrm{J})$ to the right side of the upper plenum internals heat structure.

Control variable 1058 calculates the net heat transfer (W) to the upper plenum internals heat structure.

Control variable 1059 calculates the integral net heat transfer $(\mathrm{J})$ to the upper plenum internals heat structure.

Control variable 1065 calculates the conduction heat transfer (W) to the right side of the central reflector center cylinder heat structure.

Control variable 1066 calculates the total heat transfer $(\mathrm{W})$ to the right side of the central reflector center cylinder heat structure.

Control variable 1067 calculates the integral energy transfer $(\mathrm{J})$ to the right side of the central reflector center cylinder heat structure.

Control variable 1068 calculates the net heat transfer $(\mathrm{W})$ to the central reflector center cylinder heat structure.

Control variable 1069 calculates the integral net heat transfer $(\mathrm{J})$ to the central reflector center cylinder heat structure.

Control variable 1070 calculates the convective heat transfer $(\mathrm{W})$ to the left side of the central reflector middle ring heat structure.

Control variable 1071 calculates the radiation heat transfer (W) to the left side of the central reflector middle ring heat structure.

Control variable 1072 calculates the total heat transfer (W) to the left side of the central reflector middle ring heat structure.

Control variable 1073 calculates the integral energy transfer $(\mathrm{J})$ to the left side of the central reflector middle ring heat structure.

Control variable 1075 calculates the conduction heat transfer (W) to the right side of the central reflector middle ring heat structure.

Control variable 1076 calculates the total heat transfer $(\mathrm{W})$ to the right side of the central reflector middle ring heat structure.

Control variable 1077 calculates the integral energy transfer $(\mathrm{J})$ to the right side of the central reflector middle ring heat structure.

Control variable 1078 calculates the net heat transfer (W) to the central reflector middle ring heat structure.

Control variable 1079 calculates the integral net heat transfer $(\mathrm{J})$ to the central reflector middle ring heat structure.

Control variable 1081 calculates the conduction heat transfer (W) to the left side of the central reflector outer ring heat structure.

Control variable 1082 calculates the total heat transfer (W) to the left side of the central reflector outer ring heat structure.

Control variable 1083 calculates the integral energy transfer $(\mathrm{J})$ to the left side of the central reflector outer ring heat structure.

Control variable 1085 calculates the conduction heat transfer (W) to the right side of the central reflector outer ring heat structure. 
Control variable 1086 calculates the total heat transfer (W) to the right side of the central reflector outer ring heat structure.

Control variable 1087 calculates the integral energy transfer $(\mathrm{J})$ to the right side of the central reflector outer ring heat structure.

Control variable 1088 calculates the net heat transfer $(\mathrm{W})$ to the central reflector outer ring heat structure.

Control variable 1089 calculates the integral net heat transfer $(\mathrm{J})$ to the central reflector outer ring heat structure.

Control variable 1090 calculates the convective heat transfer (W) to the left side of the inner core ring ceramic heat structure.

Control variable 1091 calculates the conduction heat transfer $(\mathrm{W})$ to the left side of the inner core ring ceramic heat structure.

Control variable 1092 calculates the total heat transfer (W) to the left side of the inner core ring ceramic heat structure.

Control variable 1093 calculates the integral energy transfer $(\mathrm{J})$ to the left side of the inner core ring ceramic heat structure.

Control variable 1094 calculates the convective heat transfer (W) to the right side of the inner core ring ceramic heat structure.

Control variable 1095 calculates the radiation heat transfer $(\mathrm{W})$ to the right side of the inner core ring ceramic heat structure.

Control variable 1096 calculates the total heat transfer (W) to the right side of the inner core ring ceramic heat structure.

Control variable 1097 calculates the integral energy transfer $(\mathrm{J})$ to the right side of the inner core ring ceramic heat structure.

Control variable 1098 calculates the net heat transfer (W) to the inner core ring ceramic heat structure.

Control variable 1099 calculates the integral net heat transfer $(\mathrm{J})$ to the inner core ring ceramic heat structure.

Control variable 1100 calculates the convective heat transfer $(\mathrm{W})$ to the left side of the middle core ring ceramic heat structure.

Control variable 1101 calculates the conduction heat transfer $(\mathrm{W})$ to the left side of the middle core ring ceramic heat structure.

Control variable 1102 calculates the total heat transfer (W) to the left side of the middle core ring ceramic heat structure.

Control variable 1103 calculates the integral energy transfer $(\mathrm{J})$ to the left side of the middle core ring ceramic heat structure.

Control variable 1104 calculates the convective heat transfer (W) to the right side of the middle core ring ceramic heat structure.

Control variable 1105 calculates the radiation heat transfer $(\mathrm{W})$ to the right side of the middle core ring ceramic heat structure. 
Control variable 1106 calculates the total heat transfer (W) to the right side of the middle core ring ceramic heat structure.

Control variable 1107 calculates the integral energy transfer $(\mathrm{J})$ to the right side of the middle core ring ceramic heat structure.

Control variable 1108 calculates the net heat transfer (W) to the middle core ring ceramic heat structure.

Control variable 1109 calculates the integral net heat transfer $(\mathrm{J})$ to the middle core ring ceramic heat structure.

Control variable 1110 calculates the convective heat transfer $(\mathrm{W})$ to the left side of the outer core ring ceramic heat structure.

Control variable 1111 calculates the conduction heat transfer $(\mathrm{W})$ to the left side of the outer core ring ceramic heat structure.

Control variable 1112 calculates the total heat transfer (W) to the left side of the outer core ring ceramic heat structure.

Control variable 1113 calculates the integral energy transfer $(\mathrm{J})$ to the left side of the outer core ring ceramic heat structure.

Control variable 1114 calculates the convective heat transfer (W) to the right side of the outer core ring ceramic heat structure.

Control variable 1115 calculates the radiation heat transfer $(\mathrm{W})$ to the right side of the outer core ring ceramic heat structure.

Control variable 1116 calculates the total heat transfer $(\mathrm{W})$ to the right side of the outer core ring ceramic heat structure.

Control variable 1117 calculates the integral energy transfer $(\mathrm{J})$ to the right side of the outer core ring ceramic heat structure.

Control variable 1118 calculates the net heat transfer $(\mathrm{W})$ to the outer core ring ceramic heat structure.

Control variable 1119 calculates the integral net heat transfer $(\mathrm{J})$ to the outer core ring ceramic heat structure.

Control variable 1121 calculates the conduction heat transfer (W) to the left side of the side reflector inner ring heat structure.

Control variable 1122 calculates the total heat transfer (W) to the left side of the side reflector inner ring heat structure.

Control variable 1123 calculates the integral energy transfer $(\mathrm{J})$ to the left side of the side reflector inner ring heat structure.

Control variable 1125 calculates the conduction heat transfer $(\mathrm{W})$ to the right side of the side reflector inner ring heat structure.

Control variable 1126 calculates the total heat transfer (W) to the right side of the side reflector inner ring heat structure.

Control variable 1127 calculates the integral energy transfer $(\mathrm{J})$ to the right side of the side reflector inner ring heat structure. 
Control variable 1128 calculates the net heat transfer (W) to the side reflector inner ring heat structure.

Control variable 1129 calculates the integral net heat transfer $(\mathrm{J})$ to the side reflector inner ring heat structure.

Control variable 1130 calculates the convective heat transfer $(\mathrm{W})$ to the left side of the side reflector middle ring heat structure.

Control variable 1131 calculates the conduction heat transfer $(\mathrm{W})$ to the left side of the side reflector middle ring heat structure.

Control variable 1132 calculates the total heat transfer (W) to the left side of the side reflector middle ring heat structure.

Control variable 1133 calculates the integral energy transfer $(\mathrm{J})$ to the left side of the side reflector middle ring heat structure.

Control variable 1135 calculates the conduction heat transfer $(\mathrm{W})$ to the right side of the side reflector middle ring heat structure.

Control variable 1136 calculates the total heat transfer (W) to the right side of the side reflector middle ring heat structure.

Control variable 1137 calculates the integral energy transfer $(\mathrm{J})$ to the right side of the side reflector middle ring heat structure.

Control variable 1138 calculates the net heat transfer (W) to the side reflector middle ring heat structure.

Control variable 1139 calculates the integral net heat transfer $(\mathrm{J})$ to the side reflector middle ring heat structure.

Control variable 1141 calculates the conduction heat transfer (W) to the left side of the side reflector outer ring heat structure.

Control variable 1142 calculates the total heat transfer (W) to the left side of the side reflector outer ring heat structure.

Control variable 1143 calculates the integral energy transfer $(\mathrm{J})$ to the left side of the side reflector outer ring heat structure.

Control variable 1144 calculates the convective heat transfer (W) to the right side of the side reflector outer ring heat structure.

Control variable 1145 calculates the radiation heat transfer $(\mathrm{W})$ to the right side of the side reflector outer ring heat structure.

Control variable 1146 calculates the total heat transfer (W) to the right side of the side reflector outer ring heat structure.

Control variable 1147 calculates the integral energy transfer $(\mathrm{J})$ to the right side of the side reflector outer ring heat structure.

Control variable 1148 calculates the net heat transfer (W) to the side reflector outer ring heat structure.

Control variable 1149 calculates the integral net heat transfer $(\mathrm{J})$ to the side reflector outer ring heat structure. 
Control variable 1150 calculates the convective heat transfer $(\mathrm{W})$ to the left side of the permanent side reflector heat structure.

Control variable 1151 calculates the radiation heat transfer $(\mathrm{W})$ to the left side of the permanent side reflector heat structure.

Control variable 1152 calculates the total heat transfer (W) to the left side of the permanent side reflector heat structure.

Control variable 1153 calculates the integral energy transfer $(J)$ to the left side of the permanent side reflector heat structure.

Control variable 1154 calculates the convective heat transfer (W) to the right side of the permanent side reflector heat structure.

Control variable 1155 calculates the radiation heat transfer $(\mathrm{W})$ to the right side of the permanent side reflector heat structure.

Control variable 1156 calculates the total heat transfer $(\mathrm{W})$ to the right side of the permanent side reflector heat structure.

Control variable 1157 calculates the integral energy transfer $(\mathrm{J})$ to the right side of the permanent side reflector heat structure.

Control variable 1158 calculates the net heat transfer (W) to the permanent side reflector heat structure.

Control variable 1159 calculates the integral net heat transfer $(\mathrm{J})$ to the permanent side reflector heat structure.

Control variable 1160 calculates the convective heat transfer (W) to the left side of the outlet plenum bottom plate heat structure.

Control variable 1161 calculates the radiation heat transfer $(\mathrm{W})$ to the left side of the outlet plenum bottom plate heat structure.

Control variable 1162 calculates the total heat transfer (W) to the left side of the outlet plenum bottom plate heat structure.

Control variable 1163 calculates the integral energy transfer $(\mathrm{J})$ to the left side of the outlet plenum bottom plate heat structure.

Control variable 1164 calculates the convective heat transfer (W) to the right side of the outlet plenum bottom plate heat structure.

Control variable 1166 calculates the total heat transfer (W) to the right side of the outlet plenum bottom plate heat structure.

Control variable 1167 calculates the integral energy transfer $(\mathrm{J})$ to the right side of the outlet plenum bottom plate heat structure.

Control variable 1168 calculates the net heat transfer (W) to the outlet plenum bottom plate heat structure.

Control variable 1169 calculates the integral net heat transfer $(\mathrm{J})$ to the outlet plenum bottom plate heat structure.

Control variable 1174 calculates the convective heat transfer (W) to the right side of the outlet plenum support columns heat structure. 
Control variable 1176 calculates the total heat transfer (W) to the right side of the outlet plenum support columns heat structure.

Control variable 1177 calculates the integral energy transfer $(\mathrm{J})$ to the right side of the outlet plenum support columns heat structure.

Control variable 1178 calculates the net heat transfer (W) to the outlet plenum support columns heat structure.

Control variable 1179 calculates the integral net heat transfer $(\mathrm{J})$ to the outlet plenum support columns heat structure.

Control variable 1180 calculates the convective heat transfer (W) to the left side of the RCCS panels front (vessel) side heat structure.

Control variable 1181 calculates the radiation heat transfer $(\mathrm{W})$ to the left side of the RCCS panels front (vessel) side heat structure.

Control variable 1182 calculates the total heat transfer (W) to the left side of the RCCS panels front (vessel) side heat structure.

Control variable 1183 calculates the integral energy transfer $(\mathrm{J})$ to the left side of the RCCS panels front (vessel) side heat structure.

Control variable 1184 calculates the convective heat transfer (W) to the right side of the RCCS panels front (vessel) side heat structure.

Control variable 1186 calculates the total heat transfer (W) to the right side of the RCCS panels front (vessel) side heat structure.

Control variable 1187 calculates the integral energy transfer $(\mathrm{J})$ to the right side of the RCCS panels front (vessel) side heat structure.

Control variable 1188 calculates the net heat transfer (W) to the RCCS panels front (vessel) side heat structure.

Control variable 1189 calculates the integral net heat transfer $(\mathrm{J})$ to the RCCS panels front (vessel) side heat structure.

Control variable 1190 calculates the convective heat transfer (W) to the left side of the RCCS panels back side heat structure.

Control variable 1192 calculates the total heat transfer (W) to the left side of the RCCS panels back side heat structure.

Control variable 1193 calculates the integral energy transfer $(\mathrm{J})$ to the left side of the RCCS panels back side heat structure.

Control variable 1194 calculates the convective heat transfer (W) to the right side of the RCCS panels back side heat structure.

Control variable 1196 calculates the total heat transfer (W) to the right side of the RCCS panels back side heat structure.

Control variable 1197 calculates the integral energy transfer $(\mathrm{J})$ to the right side of the RCCS panels back side heat structure.

Control variable 1198 calculates the net heat transfer (W) to the RCCS panels back side heat structure. 
Control variable 1199 calculates the integral net heat transfer $(\mathrm{J})$ to the RCCS panels back side heat structure.

Control variable 1214 calculates the convective heat transfer (W) to the right side of the inner core ring heater rod heat structure.

Control variable 1215 calculates the radiation heat transfer $(\mathrm{W})$ to the right side of the inner core ring heater rod heat structure.

Control variable 1216 calculates the total heat transfer (W) to the right side of the inner core ring heater rod heat structure.

Control variable 1217 calculates the integral energy transfer $(\mathrm{J})$ to the right side of the inner core ring heater rod heat structure.

Control variable 1224 calculates the convective heat transfer $(\mathrm{W})$ to the right side of the middle core ring heater rod heat structure.

Control variable 1225 calculates the radiation heat transfer $(\mathrm{W})$ to the right side of the middle core ring heater rod heat structure.

Control variable 1226 calculates the total heat transfer (W) to the right side of the middle core ring heater rod heat structure.

Control variable 1227 calculates the integral energy transfer $(\mathrm{J})$ to the right side of the middle core ring heater rod heat structure.

Control variable 1234 calculates the convective heat transfer (W) to the right side of the outer core ring heater rod heat structure.

Control variable 1235 calculates the radiation heat transfer $(\mathrm{W})$ to the right side of the outer core ring heater rod heat structure.

Control variable 1236 calculates the total heat transfer $(\mathrm{W})$ to the right side of the outer core ring heater rod heat structure.

Control variable 1237 calculates the integral energy transfer $(\mathrm{J})$ to the right side of the outer core ring heater rod heat structure.

Control variable 1301 calculates the net heat removal (W) from the heater rods.

Control variable 1302 calculates the net heat removal (W) from the ceramic around the heater rods.

Control variable 1303 calculates the net heat removal (W) from the core ceramic blocks.

Control variable 1304 calculates the net heat removal (W) from the core and reflectors.

Control variable 1305 calculates the net heat removal (W) from the core, reflectors, and core barrel.

Control variable 1306 calculates the net heat removal (W) from the primary pressure vessel and its internals.

Control variable 1401 calculates the environmental heat loss (W) from structure 2001.

Control variable 1402 calculates the environmental heat loss (W) from structure 2100.

Control variable 1403 calculates the environmental heat loss (W) from structure 2150.

Control variable 1404 calculates the environmental heat loss (W) from structure 2200.

Control variable 1405 calculates the environmental heat loss (W) from structure 2280.

Control variable 1406 calculates the environmental heat loss (W) from structure 2300. 
Control variable 1407 calculates the environmental heat loss (W) from structure 2350.

Control variable 1408 calculates the environmental heat loss (W) from structure 2400.

Control variable 1409 calculates the environmental heat loss (W) from structure 2500.

Control variable 1410 calculates the environmental heat loss (W) from structure 2580.

Control variable 1411 calculates the environmental heat loss (W) from structure 2600.

Control variable 1412 calculates the environmental heat loss (W) from structure 2700.

Control variable 1413 calculates the environmental heat loss (W) from structure 2800.

Control variable 1414 calculates the environmental heat loss (W) from structure 2820.

Control variable 1415 calculates the environmental heat loss (W) from structure 3400.

Control variable 1416 calculates the environmental heat loss (W) from structure 3550.

Control variable 1417 calculates the environmental heat loss (W) from structures 6100 and 6200.

Control variable 1418 calculates the environmental heat loss (W) from structures 6300 and 6400.

Control variable 1420 calculates the total environmental heat loss (W) from the loop piping.

Control variable 1421 calculates the total environmental heat loss (W) from the steam generator body.

Control variable 1422 calculates the total environmental heat loss (W) from the primary coolant system.

Control variable 1423 calculates the total environmental heat loss (W) from the secondary coolant system.

Control variable 1425 calculates the total environmental heat loss (W).

Control variable 1426 integrates the total environmental heat loss $(\mathrm{J})$.

Control variable 1601 calculates the total fluid mass in Component 140.

Control variable 1602 calculates the total fluid mass in Component 145.

Control variable 1603 calculates the total fluid mass in Component 150.

Control variable 1604 calculates the total fluid mass in Component 132.

Control variable 1605 calculates the total fluid mass in Component 162.

Control variable 1606 calculates the total fluid mass in Component 164.

Control variable 1607 calculates the total fluid mass in Component 166.

Control variable 1608 calculates the total fluid mass in the core region.

Control variable 1609 calculates the total fluid mass in Component 115.

Control variable 1610 calculates the total fluid mass in the remaining components in the primary pressure vessel $(100,105,110,120,175)$.

Control variable 1611 calculates the total fluid mass in the primary pressure vessel.

Control variable 1615 calculates the total fluid mass in the hot leg, Components 200 and 215.

Control variable 1616 calculates the total fluid mass on the primary side of the steam generator, Components 220, 225, and 228. 
Control variable 1617 calculates the total fluid mass in the cold leg, Components 230, 235, 240, 250, 260, 270, and 293.

Control variable 1618 calculates the total fluid mass in the primary coolant system piping.

Control variable 1619 calculates the total fluid mass in the primary coolant system inside of the break valves (does not include the piping between the valves and the RCST or the RCST itself).

Control variable 1621 calculates the total fluid mass in the RCST, Components 210, 258, and 280.

Control variable 1626 calculates the total fluid mass in the secondary side of the steam generator, Components 340, 350, 355, and 360 .

Control variable 1627 calculates the total fluid mass in the secondary coolant system.

Control variable 1631 calculates the total fluid mass in the RCCS cooling panels, Component 950.

Control variable 1632 calculates the total fluid mass in the RCCS.

Control variable 1636 calculates the total fluid mass in the water storage tank, Component 450.

Control variable 1637 calculates the total fluid mass in the potable water system.

Control variable 1640 calculates the total fluid mass in the water systems.

The control variables in the 2000s calculate various scaling parameters that can be used for comparison with the reference plant or other experiment facilities. The parameters below are taken from Scaling Studies and Conceptual Experiment Designs for NGNP CFD Assessment, INEEL/EXT-04-02502.

Non-dimensional heat flux: $\mathrm{q}^{+}=\beta \mathrm{q}_{\text {"wall }} /\left(\mathrm{G} \mathrm{c}_{\mathrm{p}}\right)$

Acceleration parameter: $\quad \mathrm{K}_{\mathrm{v}}=4 \mathrm{q}^{+} / \mathrm{Re}_{\mathrm{D}}$

Buoyancy parameter: $\quad \mathrm{Bo}^{*}=\mathrm{Gr}^{*} /\left(\operatorname{Re}_{\mathrm{Dh}}{ }^{3.425} \operatorname{Pr}^{0.8}\right)$

Some of these scaling parameters require average values over the heated length. These averages are calculated as the simple average of the values of those parameters in the first and last cells over the heated length.

Control variable 2001 calculates the pressure difference $(\mathrm{Pa})$ across the heated length of Component 115.

Control variable 2002 calculates the average pressure $(\mathrm{Pa})$ along the heated length of Component 115.

Control variable 2003 calculates the gas temperature difference $(\mathrm{K})$ across the heated length of Component 115.

Control variable 2004 calculates the average gas temperature $(\mathrm{K})$ along the heated length of Component 115.

Control variable 2005 calculates the average gas density $\left(\mathrm{kg} / \mathrm{m}^{3}\right)$ along the heated length of Component 115.

Control variable 2006 calculates the gas specific heat capacity $(\mathrm{J} / \mathrm{kg}-\mathrm{K})$ at the inlet of the heated length of Component 115.

Control variable 2007 calculates the gas specific heat capacity $(\mathrm{J} / \mathrm{kg}-\mathrm{K})$ at the outlet of the heated length of Component 115.

Control variable 2008 calculates the average gas specific heat capacity $(\mathrm{J} / \mathrm{kg}-\mathrm{K})$ along the heated length of Component 115.

Control variable 2009 calculates the gas viscosity $(\mathrm{kg} / \mathrm{m}-\mathrm{s})$ near the middle of the heated length of Component 115. 
Control variable 2010 calculates the reciprocal gas viscosity $(\mathrm{m}-\mathrm{s} / \mathrm{kg})$ near the middle of the heated length of Component 115.

Control variable 2011 calculates the gas thermal expansion coefficient $\left(\mathrm{kg} / \mathrm{m}^{3}-\mathrm{K}\right)$ near the middle of the heated length of Component 115.

Control variable 2012 calculates the gas specific heat capacity $(\mathrm{J} / \mathrm{kg}-\mathrm{K})$ near the middle of the heated length of Component 115.

Control variable 2013 calculates the gas thermal conductivity $(\mathrm{W} / \mathrm{m}-\mathrm{K})$ near the middle of the heated length of Component 115.

Control variable 2014 calculates the reciprocal gas thermal conductivity $(\mathrm{m}-\mathrm{K} / \mathrm{W})$ near the middle of the heated length of Component 115.

Control variable 2015 calculates the wall-to-gas temperature difference $(\mathrm{K})$ near the middle of the heated length of Component 115.

Control variable 2016 calculates the gas mass flux $\left(\mathrm{kg} / \mathrm{m}^{2}-\mathrm{s}\right)$ near the middle of the heated length of Component 115.

Control variable 2017 calculates the gas Reynolds number near the middle of the heated length of Component 115.

Control variable 2018 calculates the gas Nusselt number near the middle of the heated length of Component 115.

Control variable 2019 calculates the gas Prandtl number near the middle of the heated length of Component 115.

Control variable 2020 calculates the gas Grashof number near the middle of the heated length of Component 115.

Control variable 2021 calculates the gas Froude number near the middle of the heated length of Component 115.

Control variable 2022 calculates the numerator for the non-dimensional heat flux parameter $\mathrm{q}^{+}$.

Control variable 2023 calculates the denominator for the non-dimensional heat flux parameter $\mathrm{q}^{+}$.

Control variable 2024 calculates the non-dimensional heat flux parameter $\mathrm{q}^{+}$near the middle of the heated length of Component 115.

Control variable 2025 calculates the acceleration parameter $\mathrm{K}_{\mathrm{v}}$ near the middle of the heated length of Component 115.

Control variable 2026 calculates the square of the gas Reynolds number near the middle of the heated length of Component 115.

Control variable 2027 calculates the gas Richardson number near the middle of the heated length of Component 115.

Control variable 2028 calculates the gas $\mathrm{Re}^{3.425}$ near the middle of the heated length of Component 115. It does this by raising the square of the gas $\mathrm{Re}$ (control variable 2026) to the 1.7125 $(=3.425 / 2)$ power to protect against trying to raise a negative number to a real power.

Control variable 2029 calculates the gas $\operatorname{Pr}^{0.8}$ near the middle of the heated length of Component 115 .

Control variable 2030 calculates the denominator for the buoyancy parameter $\mathrm{Bo}^{*}$.

Control variable 2031 calculates the buoyancy parameter Bo* near the middle of the heated length of Component 115. 
Control variable 2051 calculates the pressure difference $(\mathrm{Pa})$ across the heated length of Component 132.

Control variable 2052 calculates the average pressure $(\mathrm{Pa})$ along the heated length of Component 132 .

Control variable 2053 calculates the gas temperature difference $(\mathrm{K})$ across the heated length of Component 132.

Control variable 2054 calculates the average gas temperature $(\mathrm{K})$ along the heated length of Component 132.

Control variable 2055 calculates the average gas density $\left(\mathrm{kg} / \mathrm{m}^{3}\right)$ along the heated length of Component 132.

Control variable 2056 calculates the gas specific heat capacity $(\mathrm{J} / \mathrm{kg}-\mathrm{K})$ at the inlet of the heated length of Component 132.

Control variable 2057 calculates the gas specific heat capacity $(\mathrm{J} / \mathrm{kg}-\mathrm{K})$ at the outlet of the heated length of Component 132.

Control variable 2058 calculates the average gas specific heat capacity $(\mathrm{J} / \mathrm{kg}-\mathrm{K})$ along the heated length of Component 132.

Control variable 2059 calculates the gas viscosity $(\mathrm{kg} / \mathrm{m}-\mathrm{s})$ near the middle of the heated length of Component 132.

Control variable 2060 calculates the reciprocal gas viscosity $(\mathrm{m}-\mathrm{s} / \mathrm{kg})$ near the middle of the heated length of Component 132.

Control variable 2061 calculates the gas thermal expansion coefficient $\left(\mathrm{kg} / \mathrm{m}^{3}-\mathrm{K}\right)$ near the middle of the heated length of Component 132.

Control variable 2062 calculates the gas specific heat capacity $(\mathrm{J} / \mathrm{kg}-\mathrm{K})$ near the middle of the heated length of Component 132.

Control variable 2063 calculates the gas thermal conductivity $(\mathrm{W} / \mathrm{m}-\mathrm{K})$ near the middle of the heated length of Component 132.

Control variable 2064 calculates the reciprocal gas thermal conductivity $(\mathrm{m}-\mathrm{K} / \mathrm{W})$ near the middle of the heated length of Component 132.

Control variable 2065 calculates the wall-to-gas temperature difference $(\mathrm{K})$ near the middle of the heated length of Component 132.

Control variable 2066 calculates the gas mass flux $\left(\mathrm{kg} / \mathrm{m}^{2}-\mathrm{s}\right)$ near the middle of the heated length of Component 132.

Control variable 2067 calculates the gas Reynolds number near the middle of the heated length of Component 132.

Control variable 2068 calculates the gas Nusselt number near the middle of the heated length of Component 132.

Control variable 2069 calculates the gas Prandtl number near the middle of the heated length of Component 132.

Control variable 2070 calculates the gas Grashof number near the middle of the heated length of Component 132.

Control variable 2071 calculates the gas Froude number near the middle of the heated length of Component 132. 
Control variable 2072 calculates the numerator for the non-dimensional heat flux parameter $\mathrm{q}^{+}$.

Control variable 2073 calculates the denominator for the non-dimensional heat flux parameter $\mathrm{q}^{+}$.

Control variable 2074 calculates the non-dimensional heat flux parameter $\mathrm{q}^{+}$near the middle of the heated length of Component 132.

Control variable 2075 calculates the acceleration parameter $K_{v}$ near the middle of the heated length of Component 132.

Control variable 2076 calculates the square of the gas Reynolds number near the middle of the heated length of Component 132.

Control variable 2077 calculates the gas Richardson number near the middle of the heated length of Component 132.

Control variable 2078 calculates the gas $\mathrm{Re}^{3.425}$ near the middle of the heated length of Component 132. It does this by raising the square of the gas $R e$ (control variable 2076) to the 1.7125 $(=3.425 / 2)$ power to protect against trying to raise a negative number to a real power.

Control variable 2079 calculates the gas $\operatorname{Pr}^{0.8}$ near the middle of the heated length of Component 132 .

Control variable 2080 calculates the denominator for the buoyancy parameter Bo*.

Control variable 2081 calculates the buoyancy parameter Bo* near the middle of the heated length of Component 132.

Control variable 2101 calculates the pressure difference $(\mathrm{Pa})$ across the heated length of Component 140.

Control variable 2102 calculates the average pressure $(\mathrm{Pa})$ along the heated length of Component 140.

Control variable 2103 calculates the gas temperature difference $(\mathrm{K})$ across the heated length of Component 140.

Control variable 2104 calculates the average gas temperature $(\mathrm{K})$ along the heated length of Component 140.

Control variable 2105 calculates the average gas density $\left(\mathrm{kg} / \mathrm{m}^{3}\right)$ along the heated length of Component 140.

Control variable 2106 calculates the gas specific heat capacity $(\mathrm{J} / \mathrm{kg}-\mathrm{K})$ at the inlet of the heated length of Component 140.

Control variable 2107 calculates the gas specific heat capacity $(\mathrm{J} / \mathrm{kg}-\mathrm{K})$ at the outlet of the heated length of Component 140.

Control variable 2108 calculates the average gas specific heat capacity $(\mathrm{J} / \mathrm{kg}-\mathrm{K})$ along the heated length of Component 140.

Control variable 2109 calculates the gas viscosity $(\mathrm{kg} / \mathrm{m}-\mathrm{s})$ near the middle of the heated length of Component 140.

Control variable 2110 calculates the reciprocal gas viscosity $(\mathrm{m}-\mathrm{s} / \mathrm{kg})$ near the middle of the heated length of Component 140.

Control variable 2111 calculates the gas thermal expansion coefficient $\left(\mathrm{kg} / \mathrm{m}^{3}-\mathrm{K}\right)$ near the middle of the heated length of Component 140.

Control variable 2112 calculates the gas specific heat capacity $(\mathrm{J} / \mathrm{kg}-\mathrm{K})$ near the middle of the heated length of Component 140. 
Control variable 2113 calculates the gas thermal conductivity $(\mathrm{W} / \mathrm{m}-\mathrm{K})$ near the middle of the heated length of Component 140.

Control variable 2114 calculates the reciprocal gas thermal conductivity $(\mathrm{m}-\mathrm{K} / \mathrm{W})$ near the middle of the heated length of Component 140.

Control variable 2115 calculates the wall-to-gas temperature difference $(\mathrm{K})$ near the middle of the heated length of Component 140.

Control variable 2116 calculates the gas mass flux $\left(\mathrm{kg} / \mathrm{m}^{2}-\mathrm{s}\right)$ near the middle of the heated length of Component 140.

Control variable 2117 calculates the gas Reynolds number near the middle of the heated length of Component 140.

Control variable 2118 calculates the gas Nusselt number near the middle of the heated length of Component 140.

Control variable 2119 calculates the gas Prandtl number near the middle of the heated length of Component 140.

Control variable 2120 calculates the gas Grashof number near the middle of the heated length of Component 140.

Control variable 2121 calculates the gas Froude number near the middle of the heated length of Component1140.

Control variable 2122 calculates the numerator for the non-dimensional heat flux parameter $\mathrm{q}^{+}$.

Control variable 2123 calculates the denominator for the non-dimensional heat flux parameter $\mathrm{q}^{+}$.

Control variable 2124 calculates the non-dimensional heat flux parameter $\mathrm{q}^{+}$near the middle of the heated length of Component 140.

Control variable 2125 calculates the acceleration parameter $\mathrm{K}_{\mathrm{v}}$ near the middle of the heated length of Component 140.

Control variable 2126 calculates the square of the gas Reynolds number near the middle of the heated length of Component 140.

Control variable 2127 calculates the gas Richardson number near the middle of the heated length of Component 140.

Control variable 2128 calculates the gas $\mathrm{Re}^{3.425}$ near the middle of the heated length of Component 140. It does this by raising the square of the gas $R e$ (control variable 2126) to the 1.7125 $(=3.425 / 2)$ power to protect against trying to raise a negative number to a real power.

Control variable 2129 calculates the gas $\operatorname{Pr}^{0.8}$ near the middle of the heated length of Component 140 .

Control variable 2130 calculates the denominator for the buoyancy parameter Bo*

Control variable 2131 calculates the buoyancy parameter Bo* near the middle of the heated length of Component 140 .

Control variable 2151 calculates the pressure difference $(\mathrm{Pa})$ across the heated length of Component 145.

Control variable 2152 calculates the average pressure $(\mathrm{Pa})$ along the heated length of Component 145 .

Control variable 2153 calculates the gas temperature difference $(\mathrm{K})$ across the heated length of Component 145. 
Control variable 2154 calculates the average gas temperature $(\mathrm{K})$ along the heated length of Component 145.

Control variable 2155 calculates the average gas density $\left(\mathrm{kg} / \mathrm{m}^{3}\right)$ along the heated length of Component 145.

Control variable 2156 calculates the gas specific heat capacity $(\mathrm{J} / \mathrm{kg}-\mathrm{K})$ at the inlet of the heated length of Component 145.

Control variable 2157 calculates the gas specific heat capacity $(\mathrm{J} / \mathrm{kg}-\mathrm{K})$ at the outlet of the heated length of Component 145.

Control variable 2158 calculates the average gas specific heat capacity $(\mathrm{J} / \mathrm{kg}-\mathrm{K})$ along the heated length of Component 145.

Control variable 2159 calculates the gas viscosity $(\mathrm{kg} / \mathrm{m}-\mathrm{s})$ near the middle of the heated length of Component 145.

Control variable 2160 calculates the reciprocal gas viscosity $(\mathrm{m}-\mathrm{s} / \mathrm{kg})$ near the middle of the heated length of Component 145.

Control variable 2161 calculates the gas thermal expansion coefficient $\left(\mathrm{kg} / \mathrm{m}^{3}-\mathrm{K}\right)$ near the middle of the heated length of Component 145.

Control variable 2162 calculates the gas specific heat capacity $(\mathrm{J} / \mathrm{kg}-\mathrm{K})$ near the middle of the heated length of Component 145.

Control variable 2163 calculates the gas thermal conductivity $(\mathrm{W} / \mathrm{m}-\mathrm{K})$ near the middle of the heated length of Component 145.

Control variable 2164 calculates the reciprocal gas thermal conductivity $(\mathrm{m}-\mathrm{K} / \mathrm{W})$ near the middle of the heated length of Component 145.

Control variable 2165 calculates the wall-to-gas temperature difference $(\mathrm{K})$ near the middle of the heated length of Component 145.

Control variable 2166 calculates the gas mass flux $\left(\mathrm{kg} / \mathrm{m}^{2}-\mathrm{s}\right)$ near the middle of the heated length of Component 145 .

Control variable 2167 calculates the gas Reynolds number near the middle of the heated length of Component 145.

Control variable 2168 calculates the gas Nusselt number near the middle of the heated length of Component 145 .

Control variable 2169 calculates the gas Prandtl number near the middle of the heated length of Component 145 .

Control variable 2170 calculates the gas Grashof number near the middle of the heated length of Component 145.

Control variable 2171 calculates the gas Froude number near the middle of the heated length of Component1132.

Control variable 2172 calculates the numerator for the non-dimensional heat flux parameter $\mathrm{q}^{+}$.

Control variable 2173 calculates the denominator for the non-dimensional heat flux parameter $\mathrm{q}^{+}$.

Control variable 2174 calculates the non-dimensional heat flux parameter $\mathrm{q}^{+}$near the middle of the heated length of Component 145. 
Control variable 2175 calculates the acceleration parameter $\mathrm{K}_{\mathrm{v}}$ near the middle of the heated length of Component 145.

Control variable 2176 calculates the square of the gas Reynolds number near the middle of the heated length of Component 145.

Control variable 2177 calculates the gas Richardson number near the middle of the heated length of Component 145.

Control variable 2178 calculates the gas $\mathrm{Re}^{3.425}$ near the middle of the heated length of Component 145. It does this by raising the square of the gas Re (control variable 2176) to the 1.7125 $(=3.425 / 2)$ power to protect against trying to raise a negative number to a real power.

Control variable 2179 calculates the gas $\operatorname{Pr}^{0.8}$ near the middle of the heated length of Component 145 .

Control variable 2180 calculates the denominator for the buoyancy parameter Bo*

Control variable 2181 calculates the buoyancy parameter Bo* near the middle of the heated length of Component 145.

Control variable 2201 calculates the pressure difference $(\mathrm{Pa})$ across the heated length of Component 150.

Control variable 2202 calculates the average pressure $(\mathrm{Pa})$ along the heated length of Component 150 .

Control variable 2203 calculates the gas temperature difference $(\mathrm{K})$ across the heated length of Component 150.

Control variable 2204 calculates the average gas temperature $(\mathrm{K})$ along the heated length of Component 150.

Control variable 2205 calculates the average gas density $\left(\mathrm{kg} / \mathrm{m}^{3}\right)$ along the heated length of Component 150.

Control variable 2206 calculates the gas specific heat capacity $(\mathrm{J} / \mathrm{kg}-\mathrm{K})$ at the inlet of the heated length of Component 150.

Control variable 2207 calculates the gas specific heat capacity $(\mathrm{J} / \mathrm{kg}-\mathrm{K})$ at the outlet of the heated length of Component 150.

Control variable 2208 calculates the average gas specific heat capacity $(\mathrm{J} / \mathrm{kg}-\mathrm{K})$ along the heated length of Component 150.

Control variable 2209 calculates the gas viscosity $(\mathrm{kg} / \mathrm{m}-\mathrm{s})$ near the middle of the heated length of Component 150.

Control variable 2210 calculates the reciprocal gas viscosity $(\mathrm{m}-\mathrm{s} / \mathrm{kg})$ near the middle of the heated length of Component 150 .

Control variable 2211 calculates the gas thermal expansion coefficient $\left(\mathrm{kg} / \mathrm{m}^{3}-\mathrm{K}\right)$ near the middle of the heated length of Component 150.

Control variable 2212 calculates the gas specific heat capacity $(\mathrm{J} / \mathrm{kg}-\mathrm{K})$ near the middle of the heated length of Component 150.

Control variable 2213 calculates the gas thermal conductivity $(\mathrm{W} / \mathrm{m}-\mathrm{K})$ near the middle of the heated length of Component 150.

Control variable 2214 calculates the reciprocal gas thermal conductivity $(\mathrm{m}-\mathrm{K} / \mathrm{W})$ near the middle of the heated length of Component 150. 
Control variable 2215 calculates the wall-to-gas temperature difference $(\mathrm{K})$ near the middle of the heated length of Component 150.

Control variable 2216 calculates the gas mass flux $\left(\mathrm{kg} / \mathrm{m}^{2}-\mathrm{s}\right)$ near the middle of the heated length of Component 150.

Control variable 2217 calculates the gas Reynolds number near the middle of the heated length of Component 150.

Control variable 2218 calculates the gas Nusselt number near the middle of the heated length of Component 150.

Control variable 2219 calculates the gas Prandtl number near the middle of the heated length of Component 150.

Control variable 2220 calculates the gas Grashof number near the middle of the heated length of Component 150.

Control variable 2221 calculates the gas Froude number near the middle of the heated length of Component1150.

Control variable 2222 calculates the numerator for the non-dimensional heat flux parameter $\mathrm{q}^{+}$.

Control variable 2223 calculates the denominator for the non-dimensional heat flux parameter $\mathrm{q}^{+}$.

Control variable 2224 calculates the non-dimensional heat flux parameter $\mathrm{q}^{+}$near the middle of the heated length of Component 150.

Control variable 2225 calculates the acceleration parameter $\mathrm{K}_{\mathrm{v}}$ near the middle of the heated length of Component 150.

Control variable 2226 calculates the square of the gas Reynolds number near the middle of the heated length of Component 150 .

Control variable 2227 calculates the gas Richardson number near the middle of the heated length of Component 150.

Control variable 2228 calculates the gas $\mathrm{Re}^{3.425}$ near the middle of the heated length of Component 150. It does this by raising the square of the gas $R e$ (control variable 2226) to the 1.7125 $(=3.425 / 2)$ power to protect against trying to raise a negative number to a real power.

Control variable 2229 calculates the gas $\operatorname{Pr}^{0.8}$ near the middle of the heated length of Component 150 .

Control variable 2230 calculates the denominator for the buoyancy parameter Bo*

Control variable 2231 calculates the buoyancy parameter Bo* near the middle of the heated length of Component 150.

Control variable 2251 calculates the pressure difference $(\mathrm{Pa})$ across the heated length of Component 162.

Control variable 2252 calculates the average pressure $(\mathrm{Pa})$ along the heated length of Component 162.

Control variable 2253 calculates the gas temperature difference $(\mathrm{K})$ across the heated length of Component 162.

Control variable 2254 calculates the average gas temperature $(\mathrm{K})$ along the heated length of Component 162.

Control variable 2255 calculates the average gas density $\left(\mathrm{kg} / \mathrm{m}^{3}\right)$ along the heated length of Component 162. 
Control variable 2256 calculates the gas specific heat capacity $(\mathrm{J} / \mathrm{kg}-\mathrm{K})$ at the inlet of the heated length of Component 162.

Control variable 2257 calculates the gas specific heat capacity $(\mathrm{J} / \mathrm{kg}-\mathrm{K})$ at the outlet of the heated length of Component 162.

Control variable 2258 calculates the average gas specific heat capacity $(\mathrm{J} / \mathrm{kg}-\mathrm{K})$ along the heated length of Component 162.

Control variable 2259 calculates the gas viscosity $(\mathrm{kg} / \mathrm{m}-\mathrm{s})$ near the middle of the heated length of Component 162.

Control variable 2260 calculates the reciprocal gas viscosity $(\mathrm{m}-\mathrm{s} / \mathrm{kg})$ near the middle of the heated length of Component 162.

Control variable 2261 calculates the gas thermal expansion coefficient $\left(\mathrm{kg} / \mathrm{m}^{3}-\mathrm{K}\right)$ near the middle of the heated length of Component 162.

Control variable 2262 calculates the gas specific heat capacity $(\mathrm{J} / \mathrm{kg}-\mathrm{K})$ near the middle of the heated length of Component 162.

Control variable 2263 calculates the gas thermal conductivity $(\mathrm{W} / \mathrm{m}-\mathrm{K})$ near the middle of the heated length of Component 162.

Control variable 2264 calculates the reciprocal gas thermal conductivity $(\mathrm{m}-\mathrm{K} / \mathrm{W})$ near the middle of the heated length of Component 162.

Control variable 2265 calculates the wall-to-gas temperature difference $(\mathrm{K})$ near the middle of the heated length of Component 162.

Control variable 2266 calculates the gas mass flux $\left(\mathrm{kg} / \mathrm{m}^{2}-\mathrm{s}\right)$ near the middle of the heated length of Component 162.

Control variable 2267 calculates the gas Reynolds number near the middle of the heated length of Component 162.

Control variable 2268 calculates the gas Nusselt number near the middle of the heated length of Component 162.

Control variable 2269 calculates the gas Prandtl number near the middle of the heated length of Component 162.

Control variable 2270 calculates the gas Grashof number near the middle of the heated length of Component 162.

Control variable 2271 calculates the gas Froude number near the middle of the heated length of Component1132.

Control variable 2272 calculates the numerator for the non-dimensional heat flux parameter $\mathrm{q}^{+}$.

Control variable 2273 calculates the denominator for the non-dimensional heat flux parameter $\mathrm{q}^{+}$.

Control variable 2274 calculates the non-dimensional heat flux parameter $\mathrm{q}^{+}$near the middle of the heated length of Component 162.

Control variable 2275 calculates the acceleration parameter $\mathrm{K}_{\mathrm{v}}$ near the middle of the heated length of Component 162.

Control variable 2276 calculates the square of the gas Reynolds number near the middle of the heated length of Component 162. 
Control variable 2277 calculates the gas Richardson number near the middle of the heated length of Component 162.

Control variable 2278 calculates the gas $\mathrm{Re}^{3.425}$ near the middle of the heated length of Component 162. It does this by raising the square of the gas $R e$ (control variable 2276) to the 1.7125 $(=3.425 / 2)$ power to protect against trying to raise a negative number to a real power.

Control variable 2279 calculates the gas $\operatorname{Pr}^{0.8}$ near the middle of the heated length of Component 162 .

Control variable 2280 calculates the denominator for the buoyancy parameter $\mathrm{Bo}^{*}$.

Control variable 2281 calculates the buoyancy parameter Bo* near the middle of the heated length of Component 162.

Control variable 2301 calculates the pressure difference $(\mathrm{Pa})$ across the heated length of Component 164.

Control variable 2302 calculates the average pressure $(\mathrm{Pa})$ along the heated length of Component 164.

Control variable 2303 calculates the gas temperature difference $(\mathrm{K})$ across the heated length of Component 164.

Control variable 2304 calculates the average gas temperature $(\mathrm{K})$ along the heated length of Component 164.

Control variable 2305 calculates the average gas density $\left(\mathrm{kg} / \mathrm{m}^{3}\right)$ along the heated length of Component 164.

Control variable 2306 calculates the gas specific heat capacity $(\mathrm{J} / \mathrm{kg}-\mathrm{K})$ at the inlet of the heated length of Component 164.

Control variable 2307 calculates the gas specific heat capacity $(\mathrm{J} / \mathrm{kg}-\mathrm{K})$ at the outlet of the heated length of Component 164.

Control variable 2308 calculates the average gas specific heat capacity $(\mathrm{J} / \mathrm{kg}-\mathrm{K})$ along the heated length of Component 164.

Control variable 2309 calculates the gas viscosity $(\mathrm{kg} / \mathrm{m}-\mathrm{s})$ near the middle of the heated length of Component 164.

Control variable 2310 calculates the reciprocal gas viscosity $(\mathrm{m}-\mathrm{s} / \mathrm{kg})$ near the middle of the heated length of Component 164.

Control variable 2311 calculates the gas thermal expansion coefficient $\left(\mathrm{kg} / \mathrm{m}^{3}-\mathrm{K}\right)$ near the middle of the heated length of Component 164.

Control variable 2312 calculates the gas specific heat capacity $(\mathrm{J} / \mathrm{kg}-\mathrm{K})$ near the middle of the heated length of Component 164.

Control variable 2313 calculates the gas thermal conductivity $(\mathrm{W} / \mathrm{m}-\mathrm{K})$ near the middle of the heated length of Component 164.

Control variable 2314 calculates the reciprocal gas thermal conductivity $(\mathrm{m}-\mathrm{K} / \mathrm{W})$ near the middle of the heated length of Component 164.

Control variable 2315 calculates the wall-to-gas temperature difference $(\mathrm{K})$ near the middle of the heated length of Component 164.

Control variable 2316 calculates the gas mass flux $\left(\mathrm{kg} / \mathrm{m}^{2}-\mathrm{s}\right)$ near the middle of the heated length of Component 164. 
Control variable 2317 calculates the gas Reynolds number near the middle of the heated length of Component 164.

Control variable 2318 calculates the gas Nusselt number near the middle of the heated length of Component 164.

Control variable 2319 calculates the gas Prandtl number near the middle of the heated length of Component 164.

Control variable 2320 calculates the gas Grashof number near the middle of the heated length of Component 164.

Control variable 2321 calculates the gas Froude number near the middle of the heated length of Component 1150.

Control variable 2322 calculates the numerator for the non-dimensional heat flux parameter $\mathrm{q}^{+}$.

Control variable 2323 calculates the denominator for the non-dimensional heat flux parameter $\mathrm{q}^{+}$.

Control variable 2324 calculates the non-dimensional heat flux parameter $\mathrm{q}^{+}$near the middle of the heated length of Component 164.

Control variable 2325 calculates the acceleration parameter $\mathrm{K}_{\mathrm{v}}$ near the middle of the heated length of Component 164.

Control variable 2326 calculates the square of the gas Reynolds number near the middle of the heated length of Component 164.

Control variable 2327 calculates the gas Richardson number near the middle of the heated length of Component 164.

Control variable 2328 calculates the gas $\mathrm{Re}^{3.425}$ near the middle of the heated length of Component 164. It does this by raising the square of the gas Re (control variable 2326) to the 1.7125 $(=3.425 / 2)$ power to protect against trying to raise a negative number to a real power.

Control variable 2329 calculates the gas $\operatorname{Pr}^{0.8}$ near the middle of the heated length of Component 164 .

Control variable 2330 calculates the denominator for the buoyancy parameter Bo*

Control variable 2331 calculates the buoyancy parameter Bo* near the middle of the heated length of Component 164.

Control variable 2351 calculates the pressure difference $(\mathrm{Pa})$ across the heated length of Component 166.

Control variable 2352 calculates the average pressure $(\mathrm{Pa})$ along the heated length of Component 166.

Control variable 2353 calculates the gas temperature difference $(\mathrm{K})$ across the heated length of Component 166.

Control variable 2354 calculates the average gas temperature $(\mathrm{K})$ along the heated length of Component 166.

Control variable 2355 calculates the average gas density $\left(\mathrm{kg} / \mathrm{m}^{3}\right)$ along the heated length of Component 166.

Control variable 2356 calculates the gas specific heat capacity $(\mathrm{J} / \mathrm{kg}-\mathrm{K})$ at the inlet of the heated length of Component 166.

Control variable 2357 calculates the gas specific heat capacity $(\mathrm{J} / \mathrm{kg}-\mathrm{K})$ at the outlet of the heated length of Component 166. 
Control variable 2358 calculates the average gas specific heat capacity $(\mathrm{J} / \mathrm{kg}-\mathrm{K})$ along the heated length of Component 166.

Control variable 2359 calculates the gas viscosity $(\mathrm{kg} / \mathrm{m}-\mathrm{s})$ near the middle of the heated length of Component 166.

Control variable 2360 calculates the reciprocal gas viscosity $(\mathrm{m}-\mathrm{s} / \mathrm{kg})$ near the middle of the heated length of Component 166.

Control variable 2361 calculates the gas thermal expansion coefficient $\left(\mathrm{kg} / \mathrm{m}^{3}-\mathrm{K}\right)$ near the middle of the heated length of Component 166.

Control variable 2362 calculates the gas specific heat capacity $(\mathrm{J} / \mathrm{kg}-\mathrm{K})$ near the middle of the heated length of Component 166.

Control variable 2363 calculates the gas thermal conductivity $(\mathrm{W} / \mathrm{m}-\mathrm{K})$ near the middle of the heated length of Component 166.

Control variable 2364 calculates the reciprocal gas thermal conductivity $(\mathrm{m}-\mathrm{K} / \mathrm{W})$ near the middle of the heated length of Component 166.

Control variable 2365 calculates the wall-to-gas temperature difference $(\mathrm{K})$ near the middle of the heated length of Component 166.

Control variable 2366 calculates the gas mass flux $\left(\mathrm{kg} / \mathrm{m}^{2}-\mathrm{s}\right)$ near the middle of the heated length of Component 166.

Control variable 2367 calculates the gas Reynolds number near the middle of the heated length of Component 166.

Control variable 2368 calculates the gas Nusselt number near the middle of the heated length of Component 166.

Control variable 2369 calculates the gas Prandtl number near the middle of the heated length of Component 166.

Control variable 2370 calculates the gas Grashof number near the middle of the heated length of Component 166.

Control variable 2371 calculates the gas Froude number near the middle of the heated length of Component1132.

Control variable 2372 calculates the numerator for the non-dimensional heat flux parameter $\mathrm{q}^{+}$.

Control variable 2373 calculates the denominator for the non-dimensional heat flux parameter $\mathrm{q}^{+}$.

Control variable 2374 calculates the non-dimensional heat flux parameter $\mathrm{q}^{+}$near the middle of the heated length of Component 166.

Control variable 2375 calculates the acceleration parameter $\mathrm{K}_{\mathrm{v}}$ near the middle of the heated length of Component 166.

Control variable 2376 calculates the square of the gas Reynolds number near the middle of the heated length of Component 166.

Control variable 2377 calculates the gas Richardson number near the middle of the heated length of Component 166.

Control variable 2378 calculates the gas $\mathrm{Re}^{3.425}$ near the middle of the heated length of Component 166. It does this by raising the square of the gas $R e$ (control variable 2376) to the 1.7125 $(=3.425 / 2)$ power to protect against trying to raise a negative number to a real power. 
Control variable 2379 calculates the gas $\operatorname{Pr}^{0.8}$ near the middle of the heated length of Component 166 .

Control variable 2380 calculates the denominator for the buoyancy parameter Bo*.

Control variable 2381 calculates the buoyancy parameter Bo* near the middle of the heated length of Component 166.

Control variable 2401 calculates the pressure difference $(\mathrm{Pa})$ across the heated length of Component 950.

Control variable 2402 calculates the average pressure $(\mathrm{Pa})$ along the heated length of Component 950.

Control variable 2403 calculates the gas temperature difference $(K)$ across the heated length of Component 950.

Control variable 2404 calculates the average gas temperature $(\mathrm{K})$ along the heated length of Component 950.

Control variable 2405 calculates the average gas density $\left(\mathrm{kg} / \mathrm{m}^{3}\right)$ along the heated length of Component 950.

Control variable 2406 calculates the gas specific heat capacity $(\mathrm{J} / \mathrm{kg}-\mathrm{K})$ at the inlet of the heated length of Component 950.

Control variable 2407 calculates the gas specific heat capacity $(\mathrm{J} / \mathrm{kg}-\mathrm{K})$ at the outlet of the heated length of Component 950.

Control variable 2408 calculates the average gas specific heat capacity $(\mathrm{J} / \mathrm{kg}-\mathrm{K})$ along the heated length of Component 950.

Control variable 2409 calculates the gas viscosity $(\mathrm{kg} / \mathrm{m}-\mathrm{s})$ near the middle of the heated length of Component 950.

Control variable 2410 calculates the reciprocal gas viscosity $(\mathrm{m}-\mathrm{s} / \mathrm{kg})$ near the middle of the heated length of Component 950.

Control variable 2411 calculates the gas thermal expansion coefficient $\left(\mathrm{kg} / \mathrm{m}^{3}-\mathrm{K}\right)$ near the middle of the heated length of Component 950.

Control variable 2412 calculates the gas specific heat capacity $(\mathrm{J} / \mathrm{kg}-\mathrm{K})$ near the middle of the heated length of Component 950.

Control variable 2413 calculates the gas thermal conductivity $(\mathrm{W} / \mathrm{m}-\mathrm{K})$ near the middle of the heated length of Component 950.

Control variable 2414 calculates the reciprocal gas thermal conductivity $(\mathrm{m}-\mathrm{K} / \mathrm{W})$ near the middle of the heated length of Component 950.

Control variable 2415 calculates the wall-to-gas temperature difference $(\mathrm{K})$ near the middle of the heated length of Component 950.

Control variable 2416 calculates the gas mass flux $\left(\mathrm{kg} / \mathrm{m}^{2}-\mathrm{s}\right)$ near the middle of the heated length of Component 950.

Control variable 2417 calculates the gas Reynolds number near the middle of the heated length of Component 950.

Control variable 2418 calculates the gas Nusselt number near the middle of the heated length of Component 950.

Control variable 2419 calculates the gas Prandtl number near the middle of the heated length of Component 950. 
Control variable 2420 calculates the gas Grashof number near the middle of the heated length of Component 950.

Control variable 2421 calculates the gas Froude number near the middle of the heated length of Component 1150 .

Control variable 2422 calculates the numerator for the non-dimensional heat flux parameter $\mathrm{q}^{+}$.

Control variable 2423 calculates the denominator for the non-dimensional heat flux parameter $\mathrm{q}^{+}$.

Control variable 2424 calculates the non-dimensional heat flux parameter $\mathrm{q}^{+}$near the middle of the heated length of Component 950.

Control variable 2425 calculates the acceleration parameter $\mathrm{K}_{\mathrm{v}}$ near the middle of the heated length of Component 950.

Control variable 2426 calculates the square of the gas Reynolds number near the middle of the heated length of Component 950.

Control variable 2427 calculates the gas Richardson number near the middle of the heated length of Component 950.

Control variable 2428 calculates the gas $\mathrm{Re}^{3.425}$ near the middle of the heated length of Component 950. It does this by raising the square of the gas $R e$ (control variable 2426) to the 1.7125 $(=3.425 / 2)$ power to protect against trying to raise a negative number to a real power.

Control variable 2429 calculates the gas $\operatorname{Pr}^{0.8}$ near the middle of the heated length of Component 950 .

Control variable 2430 calculates the denominator for the buoyancy parameter $\mathrm{Bo}^{*}$.

Control variable 2431 calculates the buoyancy parameter Bo* near the middle of the heated length of Component 950.

The 3000 series control variables are intended to provide an approximation of the stored energy of the system. The volumetric heat capacity is in $\mathrm{MJ} / \mathrm{m}^{3}-\mathrm{K}$ and the stored energy is in MJ.

Control variable 3001 calculates the volumetric heat capacity in Structure 1000, axial node 1.

Control variable 3002 calculates the stored energy in Structure 1000, axial node 1.

Control variable 3003 calculates the volumetric heat capacity in Structure 1000, axial node 2.

Control variable 3004 calculates the stored energy in Structure 1000, axial node 2.

Control variable 3005 calculates the volumetric heat capacity in Structure 1000, axial node 3.

Control variable 3006 calculates the stored energy in Structure 1000, axial node 3.

Control variable 3007 calculates the volumetric heat capacity in Structure 1000, axial node 4.

Control variable 3008 calculates the stored energy in Structure 1000, axial node 4.

Control variable 3009 calculates the volumetric heat capacity in Structure 1000, axial node 5.

Control variable 3010 calculates the stored energy in Structure 1000, axial node 5.

Control variable 3011 calculates the volumetric heat capacity in Structure 1000, axial node 6.

Control variable 3012 calculates the stored energy in Structure 1000, axial node 6.

Control variable 3013 calculates the volumetric heat capacity in Structure 1000, axial node 7.

Control variable 3014 calculates the stored energy in Structure 1000, axial node 7.

Control variable 3015 calculates the volumetric heat capacity in Structure 1000, axial node 8. 
Control variable 3016 calculates the stored energy in Structure 1000, axial node 8.

Control variable 3017 calculates the volumetric heat capacity in Structure 1000, axial node 9.

Control variable 3018 calculates the stored energy in Structure 1000, axial node 9.

Control variable 3019 calculates the volumetric heat capacity in Structure 1000, axial node 10.

Control variable 3020 calculates the stored energy in Structure 1000, axial node 10.

Control variable 3021 calculates the volumetric heat capacity in Structure 1000, axial node 11.

Control variable 3022 calculates the stored energy in Structure 1000, axial node 11.

Control variable 3023 calculates the volumetric heat capacity in Structure 1000, axial node 12.

Control variable 3024 calculates the stored energy in Structure 1000, axial node 12.

Control variable 3025 calculates the volumetric heat capacity in Structure 1000, axial node 13.

Control variable 3026 calculates the stored energy in Structure 1000, axial node 13.

Control variable 3027 calculates the volumetric heat capacity in Structure 1000, axial node 14.

Control variable 3028 calculates the stored energy in Structure 1000, axial node 14.

Control variable 3029 calculates the volumetric heat capacity in Structure 1000, axial node 15.

Control variable 3030 calculates the stored energy in Structure 1000, axial node 15.

Control variable 3031 calculates the volumetric heat capacity in Structure 1000, axial node 16.

Control variable 3032 calculates the stored energy in Structure 1000, axial node 16.

Control variable 3033 calculates the volumetric heat capacity in Structure 1000, axial node 17.

Control variable 3034 calculates the stored energy in Structure 1000, axial node 17.

Control variable 3035 calculates the volumetric heat capacity in Structure 1001, axial node 1.

Control variable 3036 calculates the stored energy in Structure 1001, axial node 1.

Control variable 3038 calculates the stored energy in the pressure vessel cylinder and head, Structures 1000 and 1001.

Control variable 3041 calculates the volumetric heat capacity in Structure 1050, axial node 1.

Control variable 3042 calculates the stored energy in Structure 1050, axial node 1.

Control variable 3043 calculates the volumetric heat capacity in Structure 1100, axial node 1.

Control variable 3044 calculates the stored energy in Structure 1100, axial node 1.

Control variable 3045 calculates the volumetric heat capacity in Structure 1100, axial node 2.

Control variable 3046 calculates the stored energy in Structure 1100, axial node 2.

Control variable 3049 calculates the volumetric heat capacity in Structure 1150, axial node 1.

Control variable 3050 calculates the stored energy in Structure 1150, axial node 1.

Control variable 3051 calculates the volumetric heat capacity in Structure 1150, axial node 2.

Control variable 3052 calculates the stored energy in Structure 1150, axial node 2.

Control variable 3053 calculates the volumetric heat capacity in Structure 1150, axial node 3.

Control variable 3054 calculates the stored energy in Structure 1150, axial node 3. 
Control variable 3055 calculates the volumetric heat capacity in Structure 1150, axial node 4. Control variable 3056 calculates the stored energy in Structure 1150, axial node 4.

Control variable 3057 calculates the volumetric heat capacity in Structure 1150, axial node 5. Control variable 3058 calculates the stored energy in Structure 1150, axial node 5.

Control variable 3059 calculates the volumetric heat capacity in Structure 1150, axial node 6. Control variable 3060 calculates the stored energy in Structure 1150, axial node 6.

Control variable 3061 calculates the volumetric heat capacity in Structure 1150, axial node 7. Control variable 3062 calculates the stored energy in Structure 1150, axial node 7.

Control variable 3063 calculates the volumetric heat capacity in Structure 1150, axial node 8. Control variable 3064 calculates the stored energy in Structure 1150, axial node 8.

Control variable 3065 calculates the volumetric heat capacity in Structure 1150, axial node 9. Control variable 3066 calculates the stored energy in Structure 1150, axial node 9.

Control variable 3067 calculates the volumetric heat capacity in Structure 1150, axial node 10. Control variable 3068 calculates the stored energy in Structure 1150, axial node 10.

Control variable 3069 calculates the volumetric heat capacity in Structure 1150, axial node 11. Control variable 3070 calculates the stored energy in Structure 1150, axial node 11.

Control variable 3071 calculates the volumetric heat capacity in Structure 1150, axial node 12. Control variable 3072 calculates the stored energy in Structure 1150, axial node 12.

Control variable 3073 calculates the volumetric heat capacity in Structure 1150, axial node 13. Control variable 3074 calculates the stored energy in Structure 1150, axial node 13.

Control variable 3075 calculates the volumetric heat capacity in Structure 1150, axial node 14. Control variable 3076 calculates the stored energy in Structure 1150, axial node 14.

Control variable 3077 calculates the volumetric heat capacity in Structure 1150, axial node 15. Control variable 3078 calculates the stored energy in Structure 1150, axial node 15.

Control variable 3079 calculates the volumetric heat capacity in Structure 1150, axial node 16. Control variable 3080 calculates the stored energy in Structure 1150, axial node 16.

Control variable 3081 calculates the stored energy in the core barrel, Structure 1150.

Control variable 3083 calculates the volumetric heat capacity in Structure 1200, axial node 1. Control variable 3084 calculates the stored energy in Structure 1200, axial node 1.

Control variable 3085 calculates the volumetric heat capacity in Structure 1201, axial node 1. Control variable 3086 calculates the stored energy in Structure 1201, axial node 1.

Control variable 3087 calculates the volumetric heat capacity in Structure 1202, axial node 1. Control variable 3088 calculates the stored energy in Structure 1202, axial node 1.

Control variable 3091 calculates the volumetric heat capacity in Structure 1300, axial node 1. Control variable 3092 calculates the stored energy in Structure 1300, axial node 1. 
Control variable 3093 calculates the volumetric heat capacity in Structure 1300, axial node 2. Control variable 3094 calculates the stored energy in Structure 1300, axial node 2.

Control variable 3095 calculates the volumetric heat capacity in Structure 1300, axial node 3. Control variable 3096 calculates the stored energy in Structure 1300, axial node 3.

Control variable 3097 calculates the volumetric heat capacity in Structure 1300, axial node 4. Control variable 3098 calculates the stored energy in Structure 1300, axial node 4.

Control variable 3099 calculates the volumetric heat capacity in Structure 1300, axial node 5. Control variable 3100 calculates the stored energy in Structure 1300, axial node 5.

Control variable 3101 calculates the volumetric heat capacity in Structure 1300, axial node 6. Control variable 3102 calculates the stored energy in Structure 1300, axial node 6.

Control variable 3103 calculates the volumetric heat capacity in Structure 1300, axial node 7. Control variable 3104 calculates the stored energy in Structure 1300, axial node 7.

Control variable 3105 calculates the volumetric heat capacity in Structure 1300, axial node 8. Control variable 3106 calculates the stored energy in Structure 1300, axial node 8.

Control variable 3107 calculates the volumetric heat capacity in Structure 1300, axial node 9.

Control variable 3108 calculates the stored energy in Structure 1300, axial node 9.

Control variable 3109 calculates the volumetric heat capacity in Structure 1300, axial node 10.

Control variable 3110 calculates the stored energy in Structure 1300, axial node 10.

Control variable 3111 calculates the volumetric heat capacity in Structure 1300, axial node 11. Control variable 3112 calculates the stored energy in Structure 1300, axial node 11.

Control variable 3113 calculates the volumetric heat capacity in Structure 1300, axial node 12. Control variable 3114 calculates the stored energy in Structure 1300, axial node 12.

Control variable 3115 calculates the volumetric heat capacity in Structure 1300, axial node 13. Control variable 3116 calculates the stored energy in Structure 1300, axial node 13.

Control variable 3117 calculates the volumetric heat capacity in Structure 1300, axial node 14. Control variable 3118 calculates the stored energy in Structure 1300, axial node 14.

Control variable 3121 calculates the volumetric heat capacity in Structure 1320, axial node 1. Control variable 3122 calculates the stored energy in Structure 1320, axial node 1.

Control variable 3123 calculates the volumetric heat capacity in Structure 1320, axial node 2. Control variable 3124 calculates the stored energy in Structure 1320, axial node 2.

Control variable 3125 calculates the volumetric heat capacity in Structure 1320, axial node 3. Control variable 3126 calculates the stored energy in Structure 1320, axial node 3.

Control variable 3127 calculates the volumetric heat capacity in Structure 1320, axial node 4. Control variable 3128 calculates the stored energy in Structure 1320, axial node 4. Control variable 3129 calculates the volumetric heat capacity in Structure 1320, axial node 5. 
Control variable 3130 calculates the stored energy in Structure 1320, axial node 5.

Control variable 3131 calculates the volumetric heat capacity in Structure 1320, axial node 6.

Control variable 3132 calculates the stored energy in Structure 1320, axial node 6.

Control variable 3133 calculates the volumetric heat capacity in Structure 1320, axial node 7.

Control variable 3134 calculates the stored energy in Structure 1320, axial node 7.

Control variable 3135 calculates the volumetric heat capacity in Structure 1320, axial node 8.

Control variable 3136 calculates the stored energy in Structure 1320, axial node 8.

Control variable 3137 calculates the volumetric heat capacity in Structure 1320, axial node 9.

Control variable 3138 calculates the stored energy in Structure 1320, axial node 9.

Control variable 3139 calculates the volumetric heat capacity in Structure 1320, axial node 10.

Control variable 3140 calculates the stored energy in Structure 1320, axial node 10.

Control variable 3141 calculates the volumetric heat capacity in Structure 1320, axial node 11.

Control variable 3142 calculates the stored energy in Structure 1320, axial node 11.

Control variable 3143 calculates the volumetric heat capacity in Structure 1320, axial node 12.

Control variable 3144 calculates the stored energy in Structure 1320, axial node 12.

Control variable 3145 calculates the volumetric heat capacity in Structure 1320, axial node 13.

Control variable 3146 calculates the stored energy in Structure 1320, axial node 13.

Control variable 3147 calculates the volumetric heat capacity in Structure 1320, axial node 14.

Control variable 3148 calculates the stored energy in Structure 1320, axial node 14.

Control variable 3151 calculates the volumetric heat capacity in Structure 1340, axial node 1.

Control variable 3152 calculates the stored energy in Structure 1340, axial node 1.

Control variable 3153 calculates the volumetric heat capacity in Structure 1340, axial node 2.

Control variable 3154 calculates the stored energy in Structure 1340, axial node 2.

Control variable 3155 calculates the volumetric heat capacity in Structure 1340, axial node 3.

Control variable 3156 calculates the stored energy in Structure 1340, axial node 3.

Control variable 3157 calculates the volumetric heat capacity in Structure 1340, axial node 4.

Control variable 3158 calculates the stored energy in Structure 1340, axial node 4.

Control variable 3159 calculates the volumetric heat capacity in Structure 1340, axial node 5.

Control variable 3160 calculates the stored energy in Structure 1340, axial node 5.

Control variable 3161 calculates the volumetric heat capacity in Structure 1340, axial node 6.

Control variable 3162 calculates the stored energy in Structure 1340, axial node 6.

Control variable 3163 calculates the volumetric heat capacity in Structure 1340, axial node 7.

Control variable 3164 calculates the stored energy in Structure 1340, axial node 7.

Control variable 3165 calculates the volumetric heat capacity in Structure 1340, axial node 8.

Control variable 3166 calculates the stored energy in Structure 1340, axial node 8. 
Control variable 3167 calculates the volumetric heat capacity in Structure 1340, axial node 9. Control variable 3168 calculates the stored energy in Structure 1340, axial node 9.

Control variable 3169 calculates the volumetric heat capacity in Structure 1340, axial node 10. Control variable 3170 calculates the stored energy in Structure 1340, axial node 10.

Control variable 3171 calculates the volumetric heat capacity in Structure 1340, axial node 11. Control variable 3172 calculates the stored energy in Structure 1340, axial node 11.

Control variable 3173 calculates the volumetric heat capacity in Structure 1340, axial node 12. Control variable 3174 calculates the stored energy in Structure 1340, axial node 12.

Control variable 3175 calculates the volumetric heat capacity in Structure 1340, axial node 13. Control variable 3176 calculates the stored energy in Structure 1340, axial node 13.

Control variable 3177 calculates the volumetric heat capacity in Structure 1340, axial node 14.

Control variable 3178 calculates the stored energy in Structure 1340, axial node 14.

Control variable 3179 calculates the stored energy in the central reflector, Structures 1300, 1320, and 1340.

Control variable 3181 calculates the volumetric heat capacity in Structure 1400, axial node 1.

Control variable 3182 calculates the stored energy in Structure 1400, axial node 1.

Control variable 3183 calculates the volumetric heat capacity in Structure 1400, axial node 2.

Control variable 3184 calculates the stored energy in Structure 1400, axial node 2.

Control variable 3185 calculates the volumetric heat capacity in Structure 1401, axial node 1.

Control variable 3186 calculates the stored energy in Structure 1401, axial node 1.

Control variable 3187 calculates the volumetric heat capacity in Structure 1401, axial node 2.

Control variable 3188 calculates the stored energy in Structure 1401, axial node 2.

Control variable 3189 calculates the volumetric heat capacity in Structure 1401, axial node 3.

Control variable 3190 calculates the stored energy in Structure 1401, axial node 3.

Control variable 3191 calculates the volumetric heat capacity in Structure 1401, axial node 4.

Control variable 3192 calculates the stored energy in Structure 1401, axial node 4.

Control variable 3193 calculates the volumetric heat capacity in Structure 1401, axial node 5.

Control variable 3194 calculates the stored energy in Structure 1401, axial node 5.

Control variable 3195 calculates the volumetric heat capacity in Structure 1401, axial node 6.

Control variable 3196 calculates the stored energy in Structure 1401, axial node 6.

Control variable 3197 calculates the volumetric heat capacity in Structure 1401, axial node 7.

Control variable 3198 calculates the stored energy in Structure 1401, axial node 7.

Control variable 3199 calculates the volumetric heat capacity in Structure 1401, axial node 8.

Control variable 3200 calculates the stored energy in Structure 1401, axial node 8.

Control variable 3201 calculates the volumetric heat capacity in Structure 1401, axial node 9. 
Control variable 3202 calculates the stored energy in Structure 1401, axial node 9.

Control variable 3203 calculates the volumetric heat capacity in Structure 1401, axial node 10. Control variable 3204 calculates the stored energy in Structure 1401, axial node 10.

Control variable 3205 calculates the volumetric heat capacity in Structure 1402, axial node 1. Control variable 3206 calculates the stored energy in Structure 1402, axial node 1.

Control variable 3207 calculates the volumetric heat capacity in Structure 1402, axial node 2. Control variable 3208 calculates the stored energy in Structure 1402, axial node 2.

Control variable 3211 calculates the volumetric heat capacity in Structure 1450, axial node 1. Control variable 3212 calculates the stored energy in Structure 1450, axial node 1.

Control variable 3213 calculates the volumetric heat capacity in Structure 1450, axial node 2. Control variable 3214 calculates the stored energy in Structure 1450, axial node 2.

Control variable 3215 calculates the volumetric heat capacity in Structure 1451, axial node 1. Control variable 3216 calculates the stored energy in Structure 1451, axial node 1.

Control variable 3217 calculates the volumetric heat capacity in Structure 1451, axial node 2. Control variable 3218 calculates the stored energy in Structure 1451, axial node 2.

Control variable 3219 calculates the volumetric heat capacity in Structure 1451, axial node 3. Control variable 3220 calculates the stored energy in Structure 1451, axial node 3.

Control variable 3221 calculates the volumetric heat capacity in Structure 1451, axial node 4. Control variable 3222 calculates the stored energy in Structure 1451, axial node 4.

Control variable 3223 calculates the volumetric heat capacity in Structure 1451, axial node 5. Control variable 3224 calculates the stored energy in Structure 1451, axial node 5.

Control variable 3225 calculates the volumetric heat capacity in Structure 1451, axial node 6. Control variable 3226 calculates the stored energy in Structure 1451, axial node 6.

Control variable 3227 calculates the volumetric heat capacity in Structure 1451, axial node 7. Control variable 3228 calculates the stored energy in Structure 1451, axial node 7.

Control variable 3229 calculates the volumetric heat capacity in Structure 1451, axial node 8. Control variable 3230 calculates the stored energy in Structure 1451, axial node 8.

Control variable 3231 calculates the volumetric heat capacity in Structure 1451, axial node 9. Control variable 3232 calculates the stored energy in Structure 1451, axial node 9.

Control variable 3233 calculates the volumetric heat capacity in Structure 1451, axial node 10. Control variable 3234 calculates the stored energy in Structure 1451, axial node 10.

Control variable 3235 calculates the volumetric heat capacity in Structure 1452, axial node 1. Control variable 3236 calculates the stored energy in Structure 1452, axial node 1.

Control variable 3237 calculates the volumetric heat capacity in Structure 1452, axial node 2. Control variable 3238 calculates the stored energy in Structure 1452, axial node 2. 
Control variable 3241 calculates the volumetric heat capacity in Structure 1500, axial node 1. Control variable 3242 calculates the stored energy in Structure 1500, axial node 1.

Control variable 3243 calculates the volumetric heat capacity in Structure 1500, axial node 2. Control variable 3244 calculates the stored energy in Structure 1500, axial node 2.

Control variable 3245 calculates the volumetric heat capacity in Structure 1501, axial node 1. Control variable 3246 calculates the stored energy in Structure 1501, axial node 1.

Control variable 3247 calculates the volumetric heat capacity in Structure 1501, axial node 2. Control variable 3248 calculates the stored energy in Structure 1501, axial node 2.

Control variable 3249 calculates the volumetric heat capacity in Structure 1501, axial node 3. Control variable 3250 calculates the stored energy in Structure 1501, axial node 3.

Control variable 3251 calculates the volumetric heat capacity in Structure 1501, axial node 4. Control variable 3252 calculates the stored energy in Structure 1501, axial node 4.

Control variable 3253 calculates the volumetric heat capacity in Structure 1501, axial node 5. Control variable 3254 calculates the stored energy in Structure 1501, axial node 5.

Control variable 3255 calculates the volumetric heat capacity in Structure 1501, axial node 6. Control variable 3256 calculates the stored energy in Structure 1501, axial node 6.

Control variable 3257 calculates the volumetric heat capacity in Structure 1501, axial node 7. Control variable 3258 calculates the stored energy in Structure 1501, axial node 7.

Control variable 3259 calculates the volumetric heat capacity in Structure 1501, axial node 8. Control variable 3260 calculates the stored energy in Structure 1501, axial node 8.

Control variable 3261 calculates the volumetric heat capacity in Structure 1501, axial node 9. Control variable 3262 calculates the stored energy in Structure 1501, axial node 9.

Control variable 3263 calculates the volumetric heat capacity in Structure 1501, axial node 10. Control variable 3264 calculates the stored energy in Structure 1501, axial node 10.

Control variable 3265 calculates the volumetric heat capacity in Structure 1502, axial node 1. Control variable 3266 calculates the stored energy in Structure 1502, axial node 1.

Control variable 3267 calculates the volumetric heat capacity in Structure 1502, axial node 2. Control variable 3268 calculates the stored energy in Structure 1502, axial node 2.

Control variable 3269 calculates the stored energy in the core ceramic, Structures 1400, 1401, 1402, 1450, 1451, 1452, 1500, 1501, and 1502 .

Control variable 3271 calculates the volumetric heat capacity in Structure 1403, axial node 1. Control variable 3272 calculates the stored energy in Structure 1403, axial node 1.

Control variable 3273 calculates the volumetric heat capacity in Structure 1403, axial node 2. Control variable 3274 calculates the stored energy in Structure 1403, axial node 2.

Control variable 3275 calculates the volumetric heat capacity in Structure 1403, axial node 3. 
Control variable 3276 calculates the stored energy in Structure 1403, axial node 3.

Control variable 3277 calculates the volumetric heat capacity in Structure 1403, axial node 4.

Control variable 3278 calculates the stored energy in Structure 1403, axial node 4.

Control variable 3279 calculates the volumetric heat capacity in Structure 1403, axial node 5.

Control variable 3280 calculates the stored energy in Structure 1403, axial node 5.

Control variable 3281 calculates the volumetric heat capacity in Structure 1403, axial node 6.

Control variable 3282 calculates the stored energy in Structure 1403, axial node 6.

Control variable 3283 calculates the volumetric heat capacity in Structure 1403, axial node 7.

Control variable 3284 calculates the stored energy in Structure 1403, axial node 7.

Control variable 3285 calculates the volumetric heat capacity in Structure 1403, axial node 8.

Control variable 3286 calculates the stored energy in Structure 1403, axial node 8.

Control variable 3287 calculates the volumetric heat capacity in Structure 1403, axial node 9.

Control variable 3288 calculates the stored energy in Structure 1403, axial node 9.

Control variable 3289 calculates the volumetric heat capacity in Structure 1403, axial node 10.

Control variable 3290 calculates the stored energy in Structure 1403, axial node 10.

Control variable 3291 calculates the volumetric heat capacity in Structure 1453, axial node 1.

Control variable 3292 calculates the stored energy in Structure 1453, axial node 1.

Control variable 3293 calculates the volumetric heat capacity in Structure 1453, axial node 2.

Control variable 3294 calculates the stored energy in Structure 1453, axial node 2.

Control variable 3295 calculates the volumetric heat capacity in Structure 1453, axial node 3.

Control variable 3296 calculates the stored energy in Structure 1453, axial node 3.

Control variable 3297 calculates the volumetric heat capacity in Structure 1453, axial node 4.

Control variable 3298 calculates the stored energy in Structure 1453, axial node 4.

Control variable 3299 calculates the volumetric heat capacity in Structure 1453, axial node 5.

Control variable 3300 calculates the stored energy in Structure 1453, axial node 5.

Control variable 3301 calculates the volumetric heat capacity in Structure 1453, axial node 6.

Control variable 3302 calculates the stored energy in Structure 1453, axial node 6.

Control variable 3303 calculates the volumetric heat capacity in Structure 1453, axial node 7.

Control variable 3304 calculates the stored energy in Structure 1453, axial node 7.

Control variable 3305 calculates the volumetric heat capacity in Structure 1453, axial node 8.

Control variable 3306 calculates the stored energy in Structure 1453, axial node 8.

Control variable 3307 calculates the volumetric heat capacity in Structure 1453, axial node 9.

Control variable 3308 calculates the stored energy in Structure 1453, axial node 9.

Control variable 3309 calculates the volumetric heat capacity in Structure 1453, axial node 10.

Control variable 3310 calculates the stored energy in Structure 1453, axial node 10. 
Control variable 3311 calculates the volumetric heat capacity in Structure 1503, axial node 1. Control variable 3312 calculates the stored energy in Structure 1503, axial node 1.

Control variable 3313 calculates the volumetric heat capacity in Structure 1503, axial node 2. Control variable 3314 calculates the stored energy in Structure 1503, axial node 2.

Control variable 3315 calculates the volumetric heat capacity in Structure 1503, axial node 3. Control variable 3316 calculates the stored energy in Structure 1503, axial node 3.

Control variable 3317 calculates the volumetric heat capacity in Structure 1503, axial node 4. Control variable 3318 calculates the stored energy in Structure 1503, axial node 4.

Control variable 3319 calculates the volumetric heat capacity in Structure 1503, axial node 5. Control variable 3320 calculates the stored energy in Structure 1503, axial node 5.

Control variable 3321 calculates the volumetric heat capacity in Structure 1503, axial node 6. Control variable 3322 calculates the stored energy in Structure 1503, axial node 6.

Control variable 3323 calculates the volumetric heat capacity in Structure 1503, axial node 7. Control variable 3324 calculates the stored energy in Structure 1503, axial node 7.

Control variable 3325 calculates the volumetric heat capacity in Structure 1503, axial node 8. Control variable 3326 calculates the stored energy in Structure 1503, axial node 8.

Control variable 3327 calculates the volumetric heat capacity in Structure 1503, axial node 9. Control variable 3328 calculates the stored energy in Structure 1503, axial node 9.

Control variable 3329 calculates the volumetric heat capacity in Structure 1503, axial node 10. Control variable 3330 calculates the stored energy in Structure 1503, axial node 10.

Control variable 3331 calculates the stored energy in the heater rods, Structures 1403, 1453, and 1503.

Control variable 3341 calculates the volumetric heat capacity in Structure 1600, axial node 1. Control variable 3342 calculates the stored energy in Structure 1600, axial node 1.

Control variable 3343 calculates the volumetric heat capacity in Structure 1600, axial node 2. Control variable 3344 calculates the stored energy in Structure 1600, axial node 2.

Control variable 3345 calculates the volumetric heat capacity in Structure 1600, axial node 3. Control variable 3346 calculates the stored energy in Structure 1600, axial node 3.

Control variable 3347 calculates the volumetric heat capacity in Structure 1600, axial node 4. Control variable 3348 calculates the stored energy in Structure 1600, axial node 4.

Control variable 3349 calculates the volumetric heat capacity in Structure 1600, axial node 5. Control variable 3350 calculates the stored energy in Structure 1600, axial node 5.

Control variable 3351 calculates the volumetric heat capacity in Structure 1600, axial node 6. Control variable 3352 calculates the stored energy in Structure 1600, axial node 6.

Control variable 3353 calculates the volumetric heat capacity in Structure 1600, axial node 7. 
Control variable 3354 calculates the stored energy in Structure 1600, axial node 7.

Control variable 3355 calculates the volumetric heat capacity in Structure 1600, axial node 8.

Control variable 3356 calculates the stored energy in Structure 1600, axial node 8.

Control variable 3357 calculates the volumetric heat capacity in Structure 1600, axial node 9.

Control variable 3358 calculates the stored energy in Structure 1600, axial node 9.

Control variable 3359 calculates the volumetric heat capacity in Structure 1600, axial node 10.

Control variable 3360 calculates the stored energy in Structure 1600, axial node 10.

Control variable 3361 calculates the volumetric heat capacity in Structure 1600, axial node 11.

Control variable 3362 calculates the stored energy in Structure 1600, axial node 11.

Control variable 3363 calculates the volumetric heat capacity in Structure 1600, axial node 12.

Control variable 3364 calculates the stored energy in Structure 1600, axial node 12.

Control variable 3365 calculates the volumetric heat capacity in Structure 1600, axial node 13.

Control variable 3366 calculates the stored energy in Structure 1600, axial node 13.

Control variable 3367 calculates the volumetric heat capacity in Structure 1600, axial node 14.

Control variable 3368 calculates the stored energy in Structure 1600, axial node 14.

Control variable 3371 calculates the volumetric heat capacity in Structure 1620, axial node 1.

Control variable 3372 calculates the stored energy in Structure 1620, axial node 1.

Control variable 3373 calculates the volumetric heat capacity in Structure 1620, axial node 2.

Control variable 3374 calculates the stored energy in Structure 1620, axial node 2.

Control variable 3375 calculates the volumetric heat capacity in Structure 1620, axial node 3.

Control variable 3376 calculates the stored energy in Structure 1620, axial node 3.

Control variable 3377 calculates the volumetric heat capacity in Structure 1620, axial node 4.

Control variable 3378 calculates the stored energy in Structure 1620, axial node 4.

Control variable 3379 calculates the volumetric heat capacity in Structure 1620, axial node 5.

Control variable 3380 calculates the stored energy in Structure 1620, axial node 5.

Control variable 3381 calculates the volumetric heat capacity in Structure 1620, axial node 6.

Control variable 3382 calculates the stored energy in Structure 1620, axial node 6.

Control variable 3383 calculates the volumetric heat capacity in Structure 1620, axial node 7.

Control variable 3384 calculates the stored energy in Structure 1620, axial node 7.

Control variable 3385 calculates the volumetric heat capacity in Structure 1620, axial node 8.

Control variable 3386 calculates the stored energy in Structure 1620, axial node 8.

Control variable 3387 calculates the volumetric heat capacity in Structure 1620, axial node 9.

Control variable 3388 calculates the stored energy in Structure 1620, axial node 9.

Control variable 3389 calculates the volumetric heat capacity in Structure 1620, axial node 10.

Control variable 3390 calculates the stored energy in Structure 1620, axial node 10. 
Control variable 3391 calculates the volumetric heat capacity in Structure 1620, axial node 11. Control variable 3392 calculates the stored energy in Structure 1620, axial node 11.

Control variable 3393 calculates the volumetric heat capacity in Structure 1620, axial node 12. Control variable 3394 calculates the stored energy in Structure 1620, axial node 12.

Control variable 3395 calculates the volumetric heat capacity in Structure 1620, axial node 13. Control variable 3396 calculates the stored energy in Structure 1620, axial node 13.

Control variable 3397 calculates the volumetric heat capacity in Structure 1620, axial node 14. Control variable 3398 calculates the stored energy in Structure 1620, axial node 14.

Control variable 3401 calculates the volumetric heat capacity in Structure 1640, axial node 1. Control variable 3402 calculates the stored energy in Structure 1640, axial node 1.

Control variable 3403 calculates the volumetric heat capacity in Structure 1640, axial node 2. Control variable 3404 calculates the stored energy in Structure 1640, axial node 2.

Control variable 3405 calculates the volumetric heat capacity in Structure 1640, axial node 3. Control variable 3406 calculates the stored energy in Structure 1640, axial node 3.

Control variable 3407 calculates the volumetric heat capacity in Structure 1640, axial node 4. Control variable 3408 calculates the stored energy in Structure 1640, axial node 4.

Control variable 3409 calculates the volumetric heat capacity in Structure 1640, axial node 5. Control variable 3410 calculates the stored energy in Structure 1640, axial node 5.

Control variable 3411 calculates the volumetric heat capacity in Structure 1640, axial node 6. Control variable 3412 calculates the stored energy in Structure 1640, axial node 6.

Control variable 3413 calculates the volumetric heat capacity in Structure 1640, axial node 7. Control variable 3414 calculates the stored energy in Structure 1640, axial node 7.

Control variable 3415 calculates the volumetric heat capacity in Structure 1640, axial node 8. Control variable 3416 calculates the stored energy in Structure 1640, axial node 8.

Control variable 3417 calculates the volumetric heat capacity in Structure 1640, axial node 9. Control variable 3418 calculates the stored energy in Structure 1640, axial node 9.

Control variable 3419 calculates the volumetric heat capacity in Structure 1640, axial node 10. Control variable 3420 calculates the stored energy in Structure 1640, axial node 10.

Control variable 3421 calculates the volumetric heat capacity in Structure 1640, axial node 11. Control variable 3422 calculates the stored energy in Structure 1640, axial node 11.

Control variable 3423 calculates the volumetric heat capacity in Structure 1640, axial node 12. Control variable 3424 calculates the stored energy in Structure 1640, axial node 12.

Control variable 3425 calculates the volumetric heat capacity in Structure 1640, axial node 13. Control variable 3426 calculates the stored energy in Structure 1640, axial node 13. Control variable 3427 calculates the volumetric heat capacity in Structure 1640, axial node 14. 
Control variable 3428 calculates the stored energy in Structure 1640, axial node 14.

Control variable 3429 calculates the stored energy in the side reflector, Structures 1600, 1620, and 1640 .

Control variable 3431 calculates the volumetric heat capacity in Structure 1660, axial node 1.

Control variable 3432 calculates the stored energy in Structure 1660, axial node 1.

Control variable 3433 calculates the volumetric heat capacity in Structure 1660, axial node 2.

Control variable 3434 calculates the stored energy in Structure 1660, axial node 2.

Control variable 3435 calculates the volumetric heat capacity in Structure 1660, axial node 3.

Control variable 3436 calculates the stored energy in Structure 1660, axial node 3.

Control variable 3437 calculates the volumetric heat capacity in Structure 1660, axial node 4.

Control variable 3438 calculates the stored energy in Structure 1660, axial node 4.

Control variable 3439 calculates the volumetric heat capacity in Structure 1660, axial node 5.

Control variable 3440 calculates the stored energy in Structure 1660, axial node 5.

Control variable 3441 calculates the volumetric heat capacity in Structure 1660, axial node 6.

Control variable 3442 calculates the stored energy in Structure 1660, axial node 6.

Control variable 3443 calculates the volumetric heat capacity in Structure 1660, axial node 7.

Control variable 3444 calculates the stored energy in Structure 1660, axial node 7.

Control variable 3445 calculates the volumetric heat capacity in Structure 1660, axial node 8.

Control variable 3446 calculates the stored energy in Structure 1660, axial node 8.

Control variable 3447 calculates the volumetric heat capacity in Structure 1660, axial node 9.

Control variable 3448 calculates the stored energy in Structure 1660, axial node 9.

Control variable 3449 calculates the volumetric heat capacity in Structure 1660, axial node 10.

Control variable 3450 calculates the stored energy in Structure 1660, axial node 10.

Control variable 3451 calculates the volumetric heat capacity in Structure 1660, axial node 11.

Control variable 3452 calculates the stored energy in Structure 1660, axial node 11.

Control variable 3453 calculates the volumetric heat capacity in Structure 1660, axial node 12.

Control variable 3454 calculates the stored energy in Structure 1660, axial node 12.

Control variable 3455 calculates the volumetric heat capacity in Structure 1660, axial node 13.

Control variable 3456 calculates the stored energy in Structure 1660, axial node 13.

Control variable 3457 calculates the volumetric heat capacity in Structure 1660, axial node 14.

Control variable 3458 calculates the stored energy in Structure 1660, axial node 14.

Control variable 3459 calculates the stored energy in the PSR, Structure 1660.

Control variable 3461 calculates the volumetric heat capacity in Structure 1750, axial node 1.

Control variable 3462 calculates the stored energy in Structure 1750, axial node 1.

Control variable 3463 calculates the volumetric heat capacity in Structure 1751, axial node 1. 
Control variable 3464 calculates the stored energy in Structure 1751, axial node 1.

Control variable 3466 calculates the stored energy in the core region inside the core barrel.

Control variable 3468 calculates the stored energy in the primary pressure vessel.

Control variable 3471 calculates the volumetric heat capacity in Structure 2000, axial node 1.

Control variable 3472 calculates the stored energy in Structure 2000, axial node 1.

Control variable 3473 calculates the volumetric heat capacity in Structure 2000, axial node 2.

Control variable 3474 calculates the stored energy in Structure 2000, axial node 2.

Control variable 3475 calculates the volumetric heat capacity in Structure 2000, axial node 3.

Control variable 3476 calculates the stored energy in Structure 2000, axial node 3.

Control variable 3477 calculates the volumetric heat capacity in Structure 2000, axial node 4.

Control variable 3478 calculates the stored energy in Structure 2000, axial node 4.

Control variable 3479 calculates the volumetric heat capacity in Structure 2001, axial node 1.

Control variable 3480 calculates the stored energy in Structure 2001, axial node 1.

Control variable 3481 calculates the volumetric heat capacity in Structure 2001, axial node 2.

Control variable 3482 calculates the stored energy in Structure 2001, axial node 2.

Control variable 3483 calculates the volumetric heat capacity in Structure 2100, axial node 1.

Control variable 3484 calculates the stored energy in Structure 2100, axial node 1.

Control variable 3485 calculates the volumetric heat capacity in Structure 2150, axial node 1.

Control variable 3486 calculates the stored energy in Structure 2150, axial node 1.

Control variable 3487 calculates the volumetric heat capacity in Structure 2200, axial node 1.

Control variable 3488 calculates the stored energy in Structure 2200, axial node 1.

Control variable 3489 calculates the volumetric heat capacity in Structure 2201, axial node 1.

Control variable 3490 calculates the stored energy in Structure 2201, axial node 1.

Control variable 3501 calculates the volumetric heat capacity in Structure 2250, axial node 1.

Control variable 3502 calculates the stored energy in Structure 2250, axial node 1.

Control variable 3503 calculates the volumetric heat capacity in Structure 2250, axial node 2.

Control variable 3504 calculates the stored energy in Structure 2250, axial node 2.

Control variable 3505 calculates the volumetric heat capacity in Structure 2250, axial node 3.

Control variable 3506 calculates the stored energy in Structure 2250, axial node 3.

Control variable 3507 calculates the volumetric heat capacity in Structure 2250, axial node 4.

Control variable 3508 calculates the stored energy in Structure 2250, axial node 4.

Control variable 3509 calculates the volumetric heat capacity in Structure 2250, axial node 5.

Control variable 3510 calculates the stored energy in Structure 2250, axial node 5.

Control variable 3511 calculates the volumetric heat capacity in Structure 2250, axial node 6.

Control variable 3512 calculates the stored energy in Structure 2250, axial node 6. 
Control variable 3513 calculates the volumetric heat capacity in Structure 2250, axial node 7. Control variable 3514 calculates the stored energy in Structure 2250, axial node 7.

Control variable 3515 calculates the volumetric heat capacity in Structure 2250, axial node 8. Control variable 3516 calculates the stored energy in Structure 2250, axial node 8.

Control variable 3517 calculates the volumetric heat capacity in Structure 2250, axial node 9. Control variable 3518 calculates the stored energy in Structure 2250, axial node 9.

Control variable 3519 calculates the volumetric heat capacity in Structure 2250, axial node 10. Control variable 3520 calculates the stored energy in Structure 2250, axial node 10.

Control variable 3521 calculates the volumetric heat capacity in Structure 2250, axial node 11. Control variable 3522 calculates the stored energy in Structure 2250, axial node 11.

Control variable 3523 calculates the volumetric heat capacity in Structure 2250, axial node 12. Control variable 3524 calculates the stored energy in Structure 2250, axial node 12.

Control variable 3525 calculates the volumetric heat capacity in Structure 2250, axial node 13. Control variable 3526 calculates the stored energy in Structure 2250, axial node 13.

Control variable 3527 calculates the volumetric heat capacity in Structure 2250, axial node 14. Control variable 3528 calculates the stored energy in Structure 2250, axial node 14.

Control variable 3529 calculates the volumetric heat capacity in Structure 2250, axial node 15. Control variable 3530 calculates the stored energy in Structure 2250, axial node 15.

Control variable 3531 calculates the volumetric heat capacity in Structure 2250, axial node 16. Control variable 3532 calculates the stored energy in Structure 2250, axial node 16.

Control variable 3533 calculates the volumetric heat capacity in Structure 2250, axial node 17. Control variable 3534 calculates the stored energy in Structure 2250, axial node 17.

Control variable 3535 calculates the volumetric heat capacity in Structure 2250, axial node 18. Control variable 3536 calculates the stored energy in Structure 2250, axial node 18.

Control variable 3537 calculates the volumetric heat capacity in Structure 2250, axial node 19. Control variable 3538 calculates the stored energy in Structure 2250, axial node 19.

Control variable 3539 calculates the volumetric heat capacity in Structure 2250, axial node 20. Control variable 3540 calculates the stored energy in Structure 2250, axial node 20.

Control variable 3541 calculates the volumetric heat capacity in Structure 2250, axial node 21. Control variable 3542 calculates the stored energy in Structure 2250, axial node 21.

Control variable 3543 calculates the volumetric heat capacity in Structure 2250, axial node 22. Control variable 3544 calculates the stored energy in Structure 2250, axial node 22.

Control variable 3546 calculates the stored energy in the steam generator tubes, Structure 2250 . Control variable 3547 calculates the volumetric heat capacity in Structure 2251, axial node 1. Control variable 3548 calculates the stored energy in Structure 2251, axial node 1. 
Control variable 3549 calculates the volumetric heat capacity in Structure 2251, axial node 2. Control variable 3550 calculates the stored energy in Structure 2251, axial node 2.

Control variable 3551 calculates the volumetric heat capacity in Structure 2280, axial node 1. Control variable 3552 calculates the stored energy in Structure 2280, axial node 1.

Control variable 3553 calculates the volumetric heat capacity in Structure 2300, axial node 1. Control variable 3554 calculates the stored energy in Structure 2300, axial node 1.

Control variable 3555 calculates the volumetric heat capacity in Structure 2350, axial node 1. Control variable 3556 calculates the stored energy in Structure 2350, axial node 1.

Control variable 3557 calculates the volumetric heat capacity in Structure 2400, axial node 1. Control variable 3558 calculates the stored energy in Structure 2400, axial node 1.

Control variable 3559 calculates the volumetric heat capacity in Structure 2500, axial node 1. Control variable 3560 calculates the stored energy in Structure 2500, axial node 1.

Control variable 3561 calculates the volumetric heat capacity in Structure 2500, axial node 2. Control variable 3562 calculates the stored energy in Structure 2500, axial node 2.

Control variable 3563 calculates the volumetric heat capacity in Structure 2500, axial node 3. Control variable 3564 calculates the stored energy in Structure 2500, axial node 3.

Control variable 3565 calculates the volumetric heat capacity in Structure 2580, axial node 1. Control variable 3566 calculates the stored energy in Structure 2580, axial node 1.

Control variable 3567 calculates the volumetric heat capacity in Structure 2600, axial node 1. Control variable 3568 calculates the stored energy in Structure 2600, axial node 1.

Control variable 3569 calculates the volumetric heat capacity in Structure 2700, axial node 1. Control variable 3570 calculates the stored energy in Structure 2700, axial node 1.

Control variable 3571 calculates the volumetric heat capacity in Structure 2700, axial node 2. Control variable 3572 calculates the stored energy in Structure 2700, axial node 2.

Control variable 3573 calculates the volumetric heat capacity in Structure 2700, axial node 3. Control variable 3574 calculates the stored energy in Structure 2700, axial node 3.

Control variable 3575 calculates the volumetric heat capacity in Structure 2700, axial node 4.

Control variable 3576 calculates the stored energy in Structure 2700, axial node 4.

Control variable 3577 calculates the stored energy in the primary coolant system piping.

Control variable 3578 calculates the stored energy in the primary coolant system.

\section{Split Hot Duct Model}

An alternate model of the hot duct, outlet plenum, and RCST was developed for use in the doubleended hot duct break simulations. The phenomenon of interest is this scenario is single-phase countercurrent flow in the hot duct, with hot (or lighter) gas flowing from the pressure vessel outlet plenum to the RCST along the top of the pipe, with colder (or denser) gas returning from the RCST to the 
outlet plenum along the bottom of the pipe. Since the code cannot simulate this directly, the nodalization must be changed. Figure 5 shows the revised nodalization.

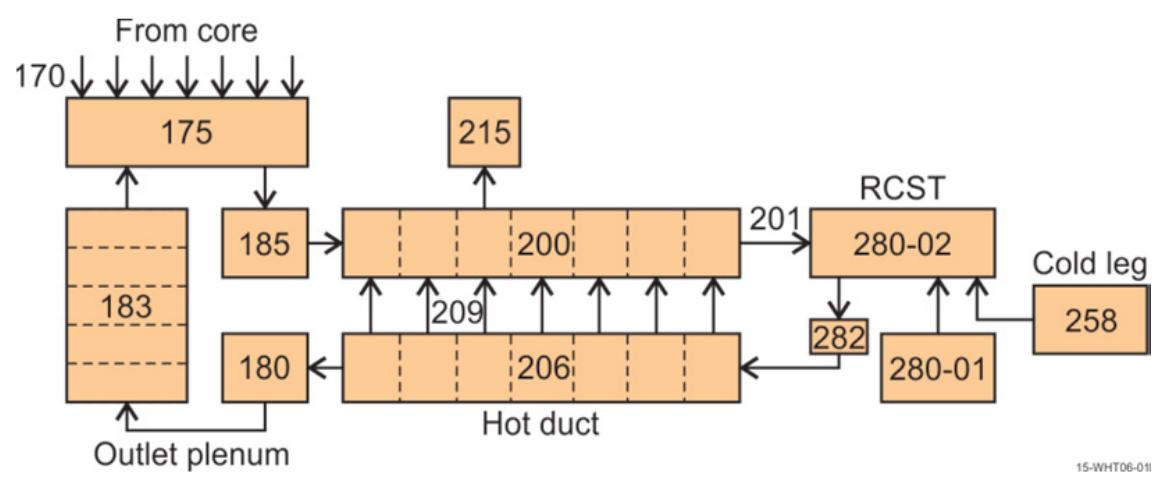

Figure 5. Revised nodalization for the split hot duct input model.

The basic approach is to split the hot duct into top and bottom halves (Components 200 and 206). The break valve (Component 205) is removed from the model, and the piping between the valve and the RCST (Component 210) is now included in the pipe. Each of the cells in the two pipes are connected by crossflow junctions (Component 209) to allow the pressure to equalize along the pipe. The pipe heat structures are also split into top and bottom halves.

The outlet plenum is changed from one component to four, with the objective to allow the plenum to fill with the returning gas before it interacts with the hotter gas in the core. The existing volume (Component 175) is reduced in length, so that no changes in the core channel connections are needed. Component 185 represents a small portion of the outlet plenum volume, and connects Component 175 to the top of the hot duct. Component 180 represents a small portion of the outlet plenum volume, and is connected to the bottom half of the hot duct. There is no direct connection between Components 180 and 185. Component 183 represents most of the outlet plenum volume. It is connected to Component 180 at the inlet and Component 175 at the outlet. Only one heat structure, the plenum bottom plate, is changed. Other structures were not changed in that their response was not expected to be significant enough to warrant the effort of splitting them into a number of axial cells corresponding to the nodalization of pipe Component 183.

The second volume in the RCST is modified so that it connects to the top of the hot duct while maintaining the connection to the cold leg side of the break (which is not renodalized). A small volume (Component 282) is added to make the connection from this second volume to the bottom half of the hot duct. The intent of the original model was for the second volume in the RCST to include all of the tank volume involved in the fluid mixing. This nodalization maintains that. By making the added component very small, its conditions should be very close to those in the mixing volume. No changes are needed for the heat structures.

A number of control variables were changed or added as a result of the renodalization.

Brief descriptions of the altered components are provided below.

Component 175 represents the top $2 \mathrm{~cm}$ of the pressure vessel outlet plenum. It is modeled as a branch with two junctions, both connected to the outlet. The first connects to the inlet of Component 185, and the second connects to the outlet of Component 183. This component is also connected to all of the core channels by Component 170.

Component 180 represents a portion of the outlet plenum near the bottom half of the hot duct. It is modeled as a branch component with two junctions. It is connected in crossflow to the bottom half of the hot duct, and the outlet of the component is connected to the inlet of Component 183. 
Component 183 is a pipe representing the bulk of the outlet plenum. The number of pipe cells can be altered to try to reduce the effect of numerical diffusion in the calculations.

Component 185 represents a portion of the outlet plenum near the top half of the hot duct. It is modeled as a branch with one junction, connecting this volume in crossflow to the top of the hot duct.

Component 200 is a pipe representing the top half of the hot duct connecting the pressure vessel outlet plenum to the RCST. It has seven internal volumes, the third of which is connected to the hot leg piping leading to the steam generator. The flow area is half that of the full pipe, the hydraulic diameter is the same as that of the full pipe, and the z-direction length is half the pipe diameter.

Component 201 connects the outlet of Component 200 to the middle of Component 280-02 in crossflow. It is modeled as a single junction. The smooth area change model is used, with forward and reverse loss coefficients of 1.0 and 0.5 , respectively.

Component 206 is a pipe representing the bottom half of the hot duct. It has seven internal volumes, and is oriented so that positive flow is from the RCST to the outlet plenum. The flow area is half that of the full pipe, and the hydraulic diameter is the same as that of the full pipe. The z-direction length is less than half the pipe diameter, so that elevation closure is maintained with the connection to the outlet plenum.

Component 209 is a multiple junction component connecting the two halves of the hot duct. The seven junctions are oriented from the top of the volumes in Component 206 to the bottom of the volumes in Component 200. The junction area is set to the product of the pipe cell length and the diameter. Small loss coefficients of 0.1 are included to provide some resistance to unphysical recirculating flows that the code has had a tendency to predict in some previous calculations with similar geometry.

Component 280 is the RCST. The second volume has been compressed with this renodalization; it has the same volume as before, but is now $0.14898 \mathrm{~m}$ high instead of $4.0831 \mathrm{~m}$. This allows the top of the hot duct to connect to the middle of the volume while the cold leg break connects to the bottom of the volume. All other input for the component is unchanged.

Component 282 is a small portion of the RCST between the inlet to volume 280-02 and the inlet to the bottom half of the hot duct. It is modeled as a branch with two junctions: the inlet is connected to the inlet of Component 280-02, and the outlet is connected to the inlet of Component 206. The area of this component is arbitrarily set to a small value, so that its fluid conditions should be nearly the same as those in Component 280-02, the mixed volume of the RCST, but not so small that its Courant limit affects the time step during the transient. Forward and reverse loss coefficients of 0.5 and 1.0 , respectively, are used at the connection to the hot duct. No heat structures are associated with this component.

Structure 1750 represents the outlet plenum lower plate. The only change from the original structure is that the left boundary volume is changed to 183010000 (from 175010000).

Structure 2000 represents a portion of the top half of the hot duct. It is identical to the original structure, except that the area factor is cut in half.

Structure 2001 represents a portion of the top half of the hot duct. It is identical to the original structure, except that the area factor is cut in half.

Structure 2002 represents the portion of the top half of the hot duct between the break valve and the RCST. It is identical to Structure 2100, except that the area factor is cut in half.

Structure 2060 represents the portion of the bottom half of the hot duct between the break valve and the RCST. It is identical to Structure 2100, except that the area factor is cut in half.

Structure 2061 represents a portion of the bottom half of the hot duct. It is identical to Structure 2001, except for the left boundary volumes. 
Structure 2062 represents a portion of the bottom half of the hot duct. It is identical to Structure 2000, except for the left boundary volumes.

Control variable 1401 calculates the environmental heat loss (W) from structures 2001 and 2061.

Control variable 1402 calculates the environmental heat loss (W) from structures 2002 and 2060.

Control variable 1615 calculates the total fluid mass in the hot leg, Components 200 and 206.

Control variable 1621 calculates the total fluid mass in the RCST, Components 258, 280, and 282.

Control variable 3472 calculates the stored energy in Structure 2000, axial node 1.

Control variable 3474 calculates the stored energy in Structure 2000, axial node 2.

Control variable 3476 calculates the stored energy in Structure 2000, axial node 3.

Control variable 3478 calculates the stored energy in Structure 2000, axial node 4.

Control variable 3480 calculates the stored energy in Structure 2001, axial node 1.

Control variable 3482 calculates the stored energy in Structure 2001, axial node 2.

Control variable 3483 calculates the volumetric heat capacity in Structure 2002, axial node 1.

Control variable 3484 calculates the stored energy in Structure 2002, axial node 1.

Control variable 3577 calculates the stored energy in the primary coolant system piping.

Control variable 3581 calculates the volumetric heat capacity in Structure 2060, axial node 1.

Control variable 3582 calculates the stored energy in Structure 2060, axial node 1.

Control variable 3583 calculates the volumetric heat capacity in Structure 2061, axial node 1.

Control variable 3584 calculates the stored energy in Structure 2061, axial node 1.

Control variable 3585 calculates the volumetric heat capacity in Structure 2061, axial node 2.

Control variable 3586 calculates the stored energy in Structure 2061, axial node 2.

Control variable 3587 calculates the volumetric heat capacity in Structure 2062, axial node 1.

Control variable 3588 calculates the stored energy in Structure 2062, axial node 1.

Control variable 3589 calculates the volumetric heat capacity in Structure 2062, axial node 2.

Control variable 3590 calculates the stored energy in Structure 2062, axial node 2.

Control variable 3591 calculates the volumetric heat capacity in Structure 2062, axial node 3.

Control variable 3592 calculates the stored energy in Structure 2062, axial node 3.

Control variable 3593 calculates the volumetric heat capacity in Structure 2062, axial node 4.

Control variable 3594 calculates the stored energy in Structure 2062, axial node 4. 


\section{Steady State Testing}

All of the calculations have been performed at full power (2.2 MW) with helium as the primary coolant.

The steam generator was originally nodalized with 12 volumes in the tubes, six up and six down, with the bend in the tubes in cells 6 and 7. The boiler and downcomer regions of the secondary side of the steam generator were modeled with node boundaries at the same elevations. A sensitivity calculation was performed in which the number of cells in the tubes was increased to 22, by doubling the number of nodes in the straight sections and leaving the bend alone; this region of the tubes was in single-phase vapor convection heat transfer on the secondary side anyway, so doubling the nodes here would provide no benefit, but would further reduce the Courant limit. The boiler and downcomer nodalizations were also increased to match the node boundaries on the primary side. For the first and last cells in the tubes, rather than dividing the tube cell length in two, the cell boundary was located at an elevation that divided the first cell in the boiler into equal length cells. This makes the first cell in the tubes longer than the second, because the first cell includes the length of tube in the tube sheet, and results in the system Courant limit being located in the second tube cell.

With the steam generator modeled, the Courant limit is a little above $0.002 \mathrm{~s}$, determined by the second volume in the tubes. Without the steam generator, the Courant limit is about $0.0047 \mathrm{~s}$. 


\section{References}

Baumeister, T., E.A. Avallone, and T. Baumeister III, eds., Marks' Standard Handbook for Mechanical Engineers, Eighth Edition, New York: McGraw-Hill, 1978.

Crane Co., Flow of Fluids through Valves, Fittings, and Pipe, Technical Paper No. 410, 1988.

Hertel, M., Insulation Info for HTTF, e-mail to B. Woods, December 12, 2014.

Hertel, M., e-mail to P. Bayless, January 6, 2015.

Idelchik, I.E., Handbook of Hydraulic Resistance, $3^{\text {rd }}$ Edition, Boca Raton: CRC Press, 1994.

Larsen, R., Normal Emissivity of Two Samples - A Report to Oregon State University, TPRL 4813, Thermophysical Properties Research Laboratory, Inc., January 2012.

Lewco Specialty Products, Inc., High Temperature Insulation Textiles \& Accessories for Industry, undated.

McEligot, D.M. and G.E. McCreery, Scaling Studies and Conceptual Experiment Designs for NGNP CFD Assessment, INEEL/EXT-04-02502, November 2004.

Mueller Temp-Plate purchase order, Quote \# T17039-3.1, April 25, 2011.

Paul Mueller Co., All About Temp-Plate ${ }^{\circledR}$, TP-108-15, 2011.

Roxul Inc., Enerwrap ${ }^{\circledR}$ MA 960 Product Data Sheet, June 5, 2014.

www.EngineeringToolBox.com, Solids - Specific Heats, December 15, 2014.

Table 1. HTTF Drawings used in developing the input model.

\begin{tabular}{|l|c|c|l|}
\hline Drawing Number & Sheet & Revision & Date \\
\hline HTTF-M2 & 1 & $\mathrm{AB}$ & $1 / 8 / 2014$ \\
\hline HTTF-M3 & 1 & $\mathrm{AB}$ & $1 / 8 / 2014$ \\
\hline HTTF-M3.2 & 1 & $\mathrm{AB}$ & $1 / 8 / 2014$ \\
\hline HTTF-M4 & 1 & $\mathrm{AB}$ & $1 / 8 / 2014$ \\
\hline HTTF-PID & 1 & $\mathrm{AB}$ & $1 / 10 / 2014$ \\
\hline HTTF-PCC-201 & 1 & 0 & $10 / 17 / 2012$ \\
\hline HTTF-PCC-202 & 1 & 0 & $10 / 9 / 2012$ \\
\hline PCS-100 & 1 & $\mathrm{AB}$ & $12 / 12 / 2013$ \\
\hline 25832 & 1 & 4 & $12 / 6 / 2013$ \\
\hline 25835 & 1 & $\mathrm{AB}$ & $12 / 12 / 2013$ \\
\hline 25835 & 3 & $\mathrm{AB}$ & $12 / 12 / 2013$ \\
\hline 25835 & 5 & $\mathrm{AB}$ & $12 / 12 / 2013$ \\
\hline $25835-1$ & 1 & $\mathrm{AB}$ & $12 / 12 / 2013$ \\
\hline $25835-1$ & 2 & $\mathrm{AB}$ & $12 / 12 / 2013$ \\
\hline
\end{tabular}




\begin{tabular}{|c|c|c|c|}
\hline Drawing Number & Sheet & Revision & Date \\
\hline $25835-1$ & 3 & $\mathrm{AB}$ & $12 / 12 / 2013$ \\
\hline $25835-1$ & 4 & $\mathrm{AB}$ & $12 / 12 / 2013$ \\
\hline 25836 & 1 & $\mathrm{AB}$ & $6 / 27 / 2013$ \\
\hline 25837 & 1 & $\mathrm{AB}$ & $1 / 6 / 2012$ \\
\hline 25838 & 1 & $\mathrm{AB}$ & $10 / 25 / 2012$ \\
\hline 25838 & 2 & $\mathrm{AB}$ & $10 / 25 / 2012$ \\
\hline 25838 & 3 & $\mathrm{AB}$ & $1 / 6 / 2012$ \\
\hline $26100-S 2$ & 1 & $\mathrm{AB}$ & $1 / 6 / 2015$ \\
\hline $26100-S 2$ & 2 & $\mathrm{AB}$ & $1 / 6 / 2015$ \\
\hline 412001 & 1 & B & $6 / 1 / 2010$ \\
\hline 414001 & 2 & $\mathrm{D}$ & $2 / 10 / 2012$ \\
\hline 414022 & 1 & $\mathrm{D}$ & $2 / 10 / 2012$ \\
\hline 414030 & 1 & $\mathrm{C}$ & $2 / 10 / 2012$ \\
\hline 414031 & 1 & $\mathrm{D}$ & $2 / 10 / 2012$ \\
\hline 414031 & 2 & $\mathrm{D}$ & $2 / 10 / 2012$ \\
\hline 414032 & 1 & $\mathrm{D}$ & $2 / 10 / 2012$ \\
\hline 414032 & 4 & $\mathrm{D}$ & $2 / 10 / 2012$ \\
\hline 414033 & 1 & $\mathrm{D}$ & $2 / 10 / 2012$ \\
\hline 415101 & 1 & $\mathrm{D}$ & $2 / 10 / 2012$ \\
\hline 415102 & 1 & $\mathrm{D}$ & $2 / 10 / 2012$ \\
\hline 415103 & 1 & $\mathrm{D}$ & $2 / 10 / 2012$ \\
\hline 415104 & 1 & $\mathrm{D}$ & $2 / 10 / 2012$ \\
\hline 415105 & 1 & $\mathrm{D}$ & $2 / 10 / 2012$ \\
\hline 415106 & 1 & $\mathrm{D}$ & $2 / 10 / 2012$ \\
\hline 415106 & 2 & $\mathrm{D}$ & $2 / 10 / 2012$ \\
\hline 415106 & 3 & D & $2 / 10 / 2012$ \\
\hline 415107 & 1 & $\mathrm{D}$ & $2 / 10 / 2012$ \\
\hline 415109 & 1 & $\mathrm{D}$ & $2 / 10 / 2012$ \\
\hline 415201 & 1 & $\mathrm{~F}$ & $2 / 10 / 2012$ \\
\hline 415201 & 2 & $\mathrm{~F}$ & $2 / 10 / 2012$ \\
\hline 415201 & 3 & $\mathrm{~F}$ & $2 / 10 / 2012$ \\
\hline 415201 & 4 & $\mathrm{~F}$ & $2 / 10 / 2012$ \\
\hline
\end{tabular}




\begin{tabular}{|l|c|c|l|}
\hline Drawing Number & Sheet & Revision & Date \\
\hline 415202 & 1 & F & $2 / 10 / 2012$ \\
\hline 417001 & 2 & B & $6 / 1 / 2010$ \\
\hline 417010 & 1 & B & $5 / 20 / 2010$ \\
\hline 417023 & 1 & B & $5 / 20 / 2010$ \\
\hline
\end{tabular}

